Florida International University FIU Digital Commons

$11-2-2016$

\title{
Microbial Functional Diversity and the Associated Biogeochemical Interactions Across Miami-Dade County, Florida Soils
}

Priyanka Kushwaha

pkush003@fiu.edu

DOI: $10.25148 /$ etd.FIDC001222

Follow this and additional works at: https:// digitalcommons.fiu.edu/etd

Part of the Biochemistry Commons, Biodiversity Commons, Environmental Microbiology and Microbial Ecology Commons, and the Molecular Biology Commons

\section{Recommended Citation}

Kushwaha, Priyanka, "Microbial Functional Diversity and the Associated Biogeochemical Interactions Across Miami-Dade County, Florida Soils" (2016). FIU Electronic Theses and Dissertations. 3000.

https://digitalcommons.fiu.edu/etd/3000 
FLORIDA INTERNATIONAL UNIVERSITY

Miami, Florida

MICROBIAL FUNCTIONAL DIVERSITY AND THE ASSOCIATED

BIOGEOCHEMICAL INTERACTIONS ACROSS MIAMI-DADE COUNTY, FLORIDA SOILS

A dissertation submitted in partial fulfillment of the

requirements for the degree of

DOCTOR OF PHILOSOPHY

in

BIOCHEMISTRY

by

Priyanka Kushwaha

2016 
To: Dean Michael R. Heithaus

College of Arts, Sciences and Education

This dissertation, written by Priyanka Kushwaha, and entitled Microbial Functional

Diversity and the Associated Biogeochemical Interactions across Miami-Dade County, Florida Soils having been approved in respect to style and intellectual content, is referred to you for judgment.

We have read this dissertation and recommend that it be approved.

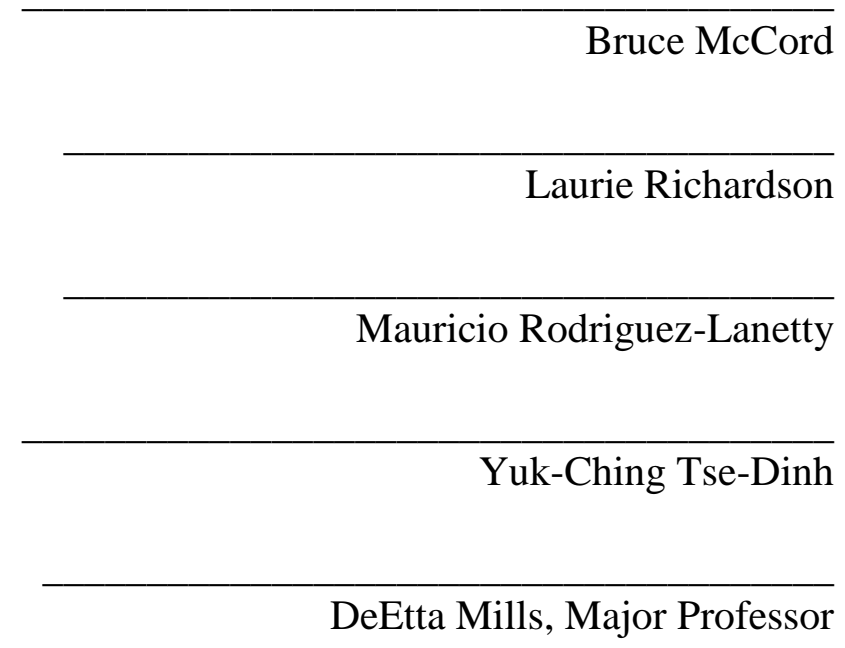

Date of Defense: November 2, 2016

The dissertation of Priyanka Kushwaha is approved.

Dean Michael R. Heithaus College of Arts, Sciences and Education

Andrés G. Gil

Vice President for Research and Economic Development and Dean of the University Graduate School

Florida International University, 2016 
(C) Copyright 2016 by Priyanka Kushwaha

All right reserved. 


\section{DEDICATION}

I dedicate this dissertation to my parents Mr. Satish Kushwaha and Mrs. Rekha Kushwaha. Thank you for your love and support. I also dedicate this dissertation to my brother Dr. Manish Kushwaha. You have been a great inspiration and if it was not for you I would not have discovered the scientist in me. 


\section{ACKNOWLEDGMENTS}

My sincere thanks goes to my PhD advisor Dr. DeEtta Mills for her constant support, guidance, and encouragement throughout the $\mathrm{PhD}$. It has been my immense pleasure to be a part of her lab as she allows you to be an independent researcher and trains you for various academic responsibilities. I would also like to thank my advisory committee members Dr. McCord, Dr. Richardson, Dr. Rodriguez-Lanetty, and Dr. Tse-Dinh for their suggestions for my research and helping me in developing a critical thought process. I am grateful to Dr. John Kominoski and Dr. Krishnaswamy Jayachandran for instrument support. I would also like to acknowledge Dr. Kim, Graduate Program Director, for his constant guidance and reassurance throughout the $\mathrm{PhD}$ program. In addition, I would like to thank the Department of Chemistry and Biochemistry for the Teaching Assistantship.

It is very important to have colleagues with whom you can be friends. I thank Dr. Natalie Damaso, Ivy Cheung, Beatrice Kallifatidis, Christina Burns, Lauren Martin, and Julian Mendel for their assistance and advice with data analyses and manuscript writing. An important role is also played by friends and roommates when you are away from family. I would like to thank Dr. Mansi Sharma for being my friend, philosopher, guide, and constant pillar of support. This dissertation would not have been complete without help from Dr. Ketaki Deshpande. Thank you for giving me feedback, proofing my chapters, and constant motivation during rough times of graduate school. I would also like to thank Madhukar Bommala for being my friend since I started my $\mathrm{PhD}$ at FIU and all my FIU friends for fun get-togethers. In addition, I would like to thank Supurna Dhar for being a wonderful roommate. 
These acknowledgements would not be complete without thanking Mansi Bhandari, Rupa Banerjee, Poorti Kathpalia, and Saurabh Tandon for their selfless friendship of a decade. Finally, my heartiest thanks goes to my parents and brother for believing in me and encouraging me throughout my life. Without the support of all of you, this accomplishment would have not been possible.

Finally, I would like to acknowledge the editors of Taylor and Francis Group LLC Books to allow me to reprint the book chapter that was originally published in the book entitled "Microbiology of the Everglades System" as Chapter 3 of this dissertation. 


\begin{abstract}
OF THE DISSERTATION
MICROBIAL FUNCTIONAL DIVERSITY AND THE ASSOCIATED

BIOGEOCHEMICAL INTERACTIONS ACROSS MIAMI-DADE COUNTY, FLORIDA SOILS

by
\end{abstract}

Priyanka Kushwaha

Florida International University, 2016

Miami, Florida

Professor DeEtta Mills, Major Professor

Decomposition of soil organic matter by microbial processes results in carbon sequestration within soils and/or carbon loss via atmospheric emission of carbon dioxide and methane. Natural as well as anthropogenic factors have been documented to impact soil microbial diversity and the associated biogeochemical functions. The soil microbial communities co-inhabiting Miami-Dade County soils, Florida are under threat because of the ongoing restoration efforts in the adjoining Florida Everglades Parks, predicted climatic changes such as sea-level rise and high rainfall, as well as urbanization. Therefore, an improved understanding of the current microbial functional communities is essential to better assess the impact of soil communities when anthropogenic or climatic disturbances occur. The objectives of the current study were to characterize the biodiversity and distribution of: a) cellulose degrading microbial community, and b) methanogenic guilds responsible for producing the gas methane, across four different Miami-Dade County, Florida soil types using the high throughput technique of GeoChip 5.0 functional microarray. In addition, the influence of vegetation cover, organic content, soil moisture 
content, $\mathrm{pH}$, and soil texture in shaping the soil functional microbial community was also investigated. The function of cellulose degradation was distributed across wide range of taxonomic lineages with the majority belonging to the bacterial groups of Actinobacteria, Firmicutes, Alphaproteobacteria, and Gammaproteobacteria, whereas Ascomycota and Basidiomycota were the only detected fungal phyla. The cellulolytic bacterial community correlated more with the vegetation cover while fungal groups showed influence of moisture and organic content as well as percent silt. Six out of the seven methanogenic orders, with the greatest numbers found in the Methanomicrobiales, Methanosarcinales, and Methanomassiliicoccales, were identified across all four soil types of Miami-Dade. The abundance of the $m c r A$ gene sequences was significantly greater with respect to soil moisture content. Additionally, the recently classified order Methanomassiliicoccales was identified across all four soils, including soils with lower moisture content not thought to provide ideal redox conditions to support methanogens. The greater number of correlation network interactions amongst the methanogenic guilds in the Florida Everglades wetlands versus the urbanized Miami-Dade County soils depicted the impact of the historical drainage of the Florida Everglades on the methanogenic community. Overall, the current study characterized the biodiversity of cellulolytic and methanogenic organisms across dry and saturated soils of Miami-Dade County and demonstrated that microbial guilds were functionally redundant and were influenced to some extent by the soil abiotic factors. Also, results from network analyses provide a platform to assess the future impacts of disturbances on the microbial community. 


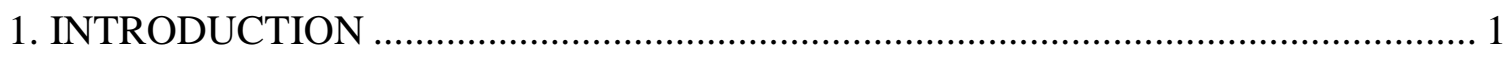

1.1. Natural and anthropogenic disturbances, and the importance of characterizing the microbial composition in Miami-Dade County, Florida soils 1

1.2. Overarching hypotheses: biodiversity, ecosystem function, and impact of disturbance 3

1.3. High throughput metagenomics techniques ....................................................... 5

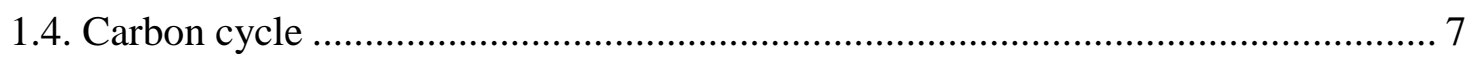

1.5. Rationale of the study, objectives, and hypotheses.............................................. 9

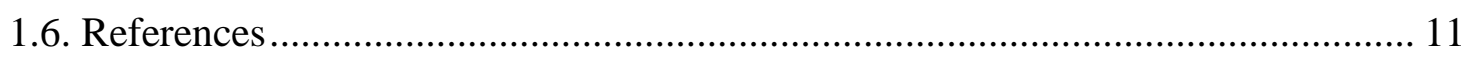

2. BIODIVERSITY AND DISTRIBUTION OF CELLULOLYTIC MICROBIAL COMMUNITY IN MIAMI-DADE COUNTY SOILS, FLORIDA ………………….... 17

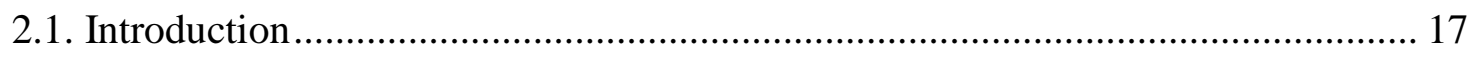

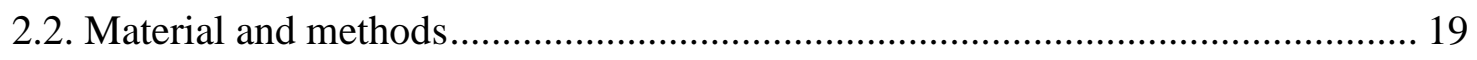

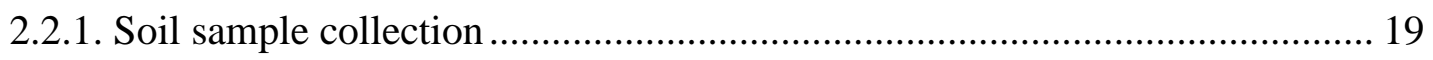

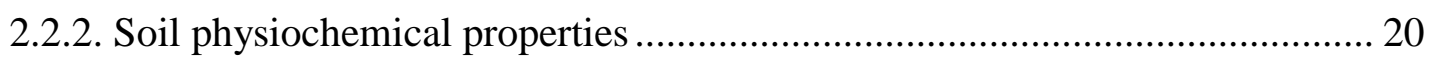

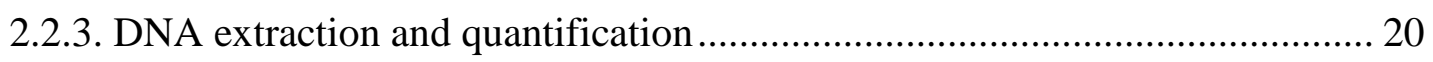

2.2.4. GeoChip 5.0 functional gene microrrays .................................................... 20

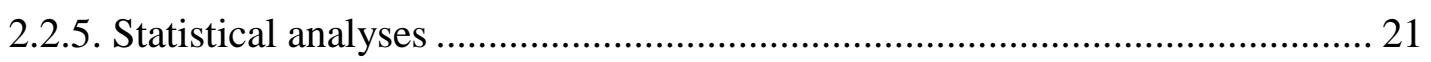

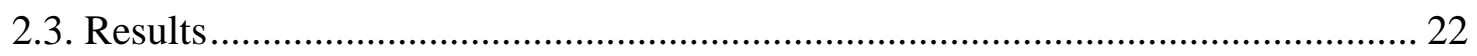

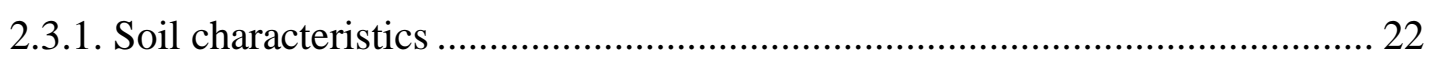

2.3.2. Cellulolytic microorganisms richness as detected by GeoChip microarray ... 23

2.3.3. Cellulolytic assemblages and their associations with abiotic factors ............. 25

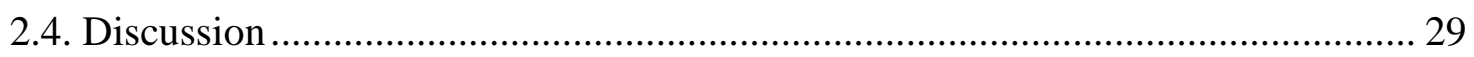

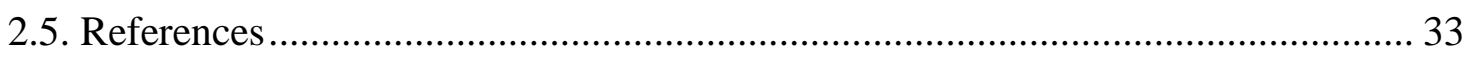

\section{METHANOGENS WITHIN THE SAWGRASS COMMUNITIES OF THE} EVERGLADES AND BISCAYNE BAY WATERSHEDS ………………………...... 38

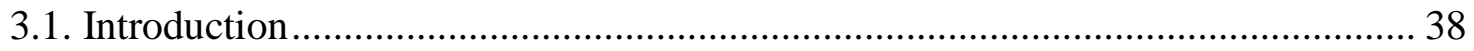

3.2. Function versus structural biodiversity of microbial communities......................... 38

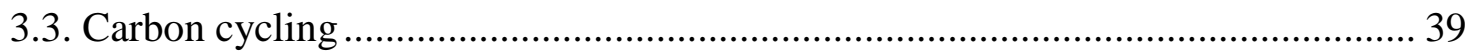

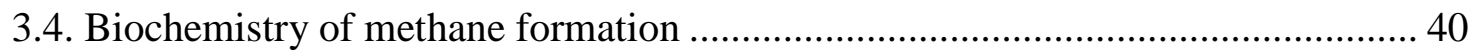


3.5. The Everglades and Biscayne Bay Watersheds ………………………............. 42

3.6. Effects of phosphorus on methanogenesis …………........................................ 43

3.7. Effects of cellulose degradation on methanogenesis ............................................. 44

3.8. Restoration effects on methanogen communities ................................................... 45

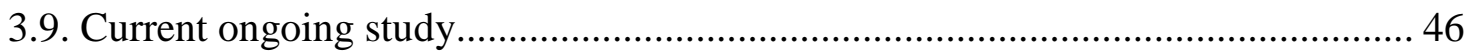

3.9.1. Dominance of unknown $m c r A$ sequences in the Florida Everglades soils ..... 48

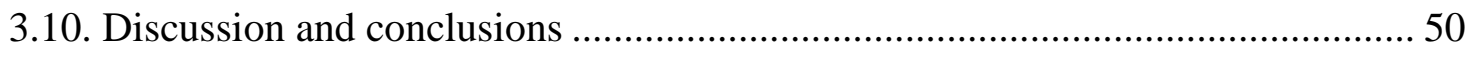

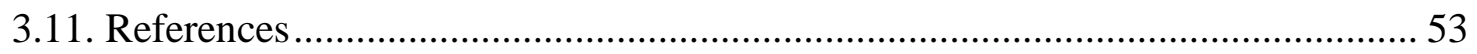

4. INFLUENCE OF ABIOTIC FACTORS ON THE METHANOGENIC $m c r A$ GENE ACROSS OXIC AND ANOXIC MIAMI-DADE COUNTY, FLORIDA SOILS........... 57

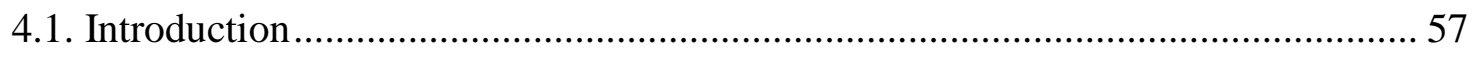

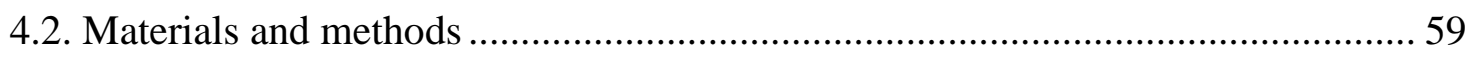

4.2.1. Soil sample collection, soil physicochemical properties, and DNA

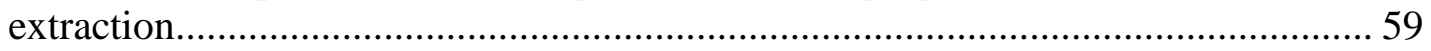

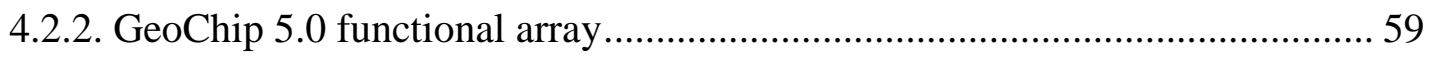

4.2.3. Community comparisons and statistical analyses ............................................. 60

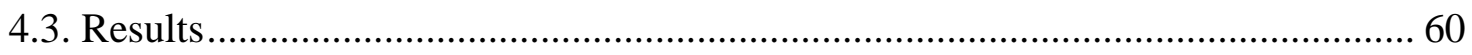

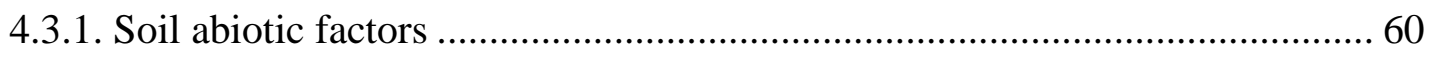

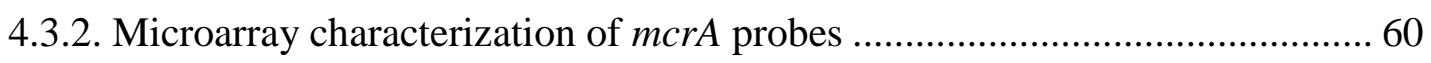

4.3.3. Methanogenic assemblages and the associations with abiotic factors............. 66

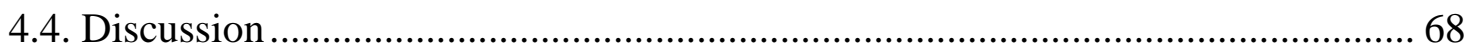

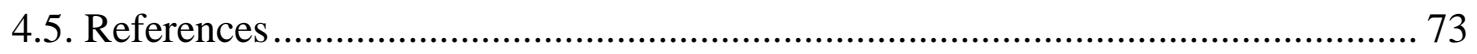

5. NETWORK ANALYSES TO DETERMINE CO-OCCURRENCE PATTERNS OF METHANOGENIC-RELATED GUILDS IN SOILS ............................................... 78

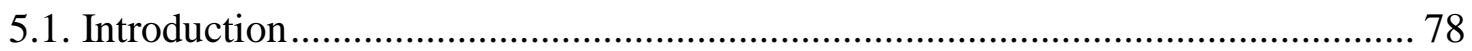

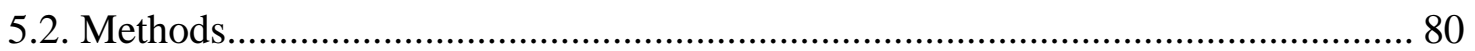

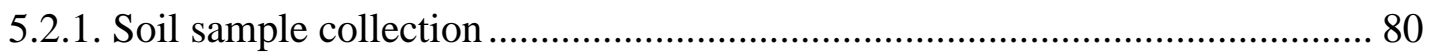

5.2.2. GeoChip 5.0 microarray analyses and correlation network analyses ............. 81

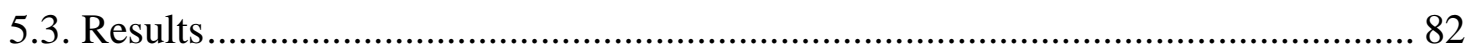

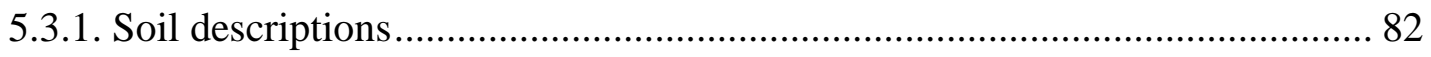

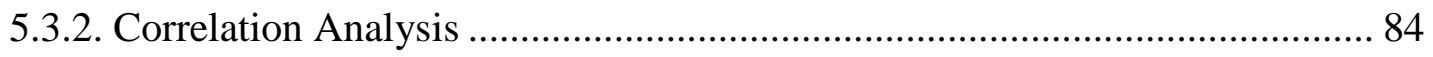

5.3.3. Acetoclastic (AC) pathway genes ................................................................ 90

5.3.4. Hydrogenotrophic (HM) pathway genes ...................................................... 92 
5.3.5. Methylotrophic (MT) pathway genes

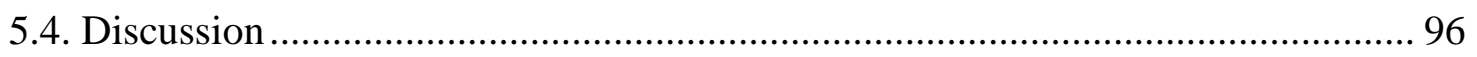

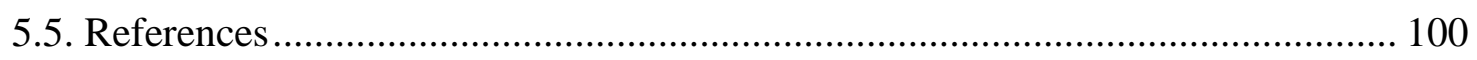

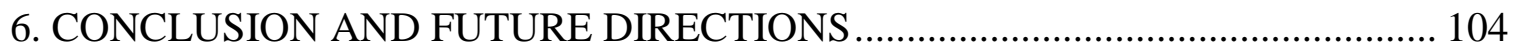

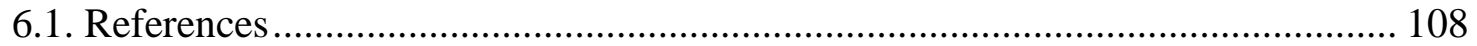

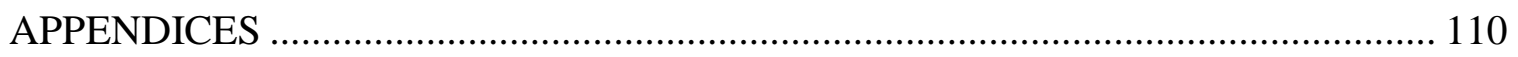

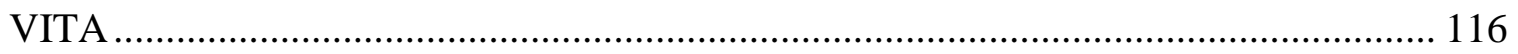




\section{LIST OF TABLES}

TABLE

PAGE

Table 1: Methods used to characterize microbial communities in the Florida Everglades. 2

Table 2: Measured soil physiochemical properties for Miami-Dade County soil samples 22

Table 3: The total number of positive OTUs detected in GeoChip functional microarray for cellulolytic functional genes across the four soil types are shown.

Table 4: PERMANOVA results for the abundance of cellulolytic assemblages............. 27

Table 5: Mantel's test correlation for the abundance of cellulolytic organisms.............. 27

Table 6: Representation of the mcrA OTUs (protein sequences) with archived, known

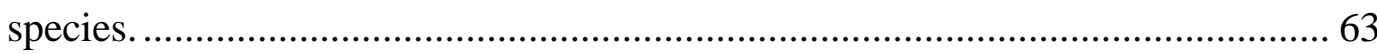

Table 7: Number of gene probes associated with methanogenesis detected across the Miami-Dade County soils.

Table 8: PERMANOVA (adonis) and Mantel's test comparison of methanogenic assemblages and abiotic factors.

Table 9: Site descriptions for Miami-Dade County and Everglades soils. 83

Table 10: Major topological properties of the correlation network of methanogenic related genes in Miami-Dade (MD) and Everglades (EG).

Table 11: Major topological properties of the correlation network of methanogenic pathway genes in Miami-Dade (MD) and Everglades (EG).

Table 12: Methanogenic pathways genes with the highest connectivity in Miami-Dade (MD) and Everglades (EG) soils. 


\section{LIST OF FIGURES}

FIGURE

PAGE

Figure 1: A schematic representation depicting the impact of disturbance on the microbial composition and the ecosystem services provided by them (Allison and Martiny 2008). 4

Figure 2: Microbial degradation of soil organic material (from Madigan et al. 2010)...... 8

Figure 3: NMDS analysis for all cellulolytic OTUs across Miami-Dade County soils.... 26

Figure 4: CCA for cellulolytic community gene abundance across Miami-Dade

County sampling sites using soil factors.................................................... 29

Figure 5: A schematic map of the two soil types in Miami-Dade, County, Florida....... 48

Figure 6: BLAST analyses and subsequent sequence alignment and phylogenetic tree construction were derived from mcrA DNA sequences and were then aligned with MUSCLE.

Figure 7: Maximum-likelihood tree of the $m c r A$ protein sequences detected on

GeoChip functional microarray for the Miami-Dade County soils.

Figure 8: Non-metric multidimensional scaling (NMDS) of $m c r A$ OTUs relative abundance across Miami-Dade County soils. 66

Figure 9: CCA for mcrA gene across Miami-Dade County sampling sites using the soil factors soil moisture, organic content, and percent silt.

Figure 10: Distributions of major functional genes in the network under the Miami-Dade (MD) and the Everglades soils (EG). 84

Figure 11: Correlation networks for a) Miami-Dade (MD) and b) Everglades (EG) samples 85

Figure 12: Subnetworks of AC pathway genes in a) MD and b) EG soils.................... 91

Figure 13: Subnetworks of HG pathway genes in a) MD and b) EG soils..................... 93

Figure 14: Subnetworks of MT pathway genes in a) MD and b) EG soils..................... 95 


\section{LIST OF ABREVIATIONS AND ACRONYMS}

AC.

Acetoclastic

ANOVA

.One-way analysis of variance

AOI Area of interest

IEG Institute of Environmental Genomics

CCA. ..Canonical correspondence analyses

$\mathrm{CH}_{4}$ Methane

$\mathrm{CO}_{2}$ Carbon dioxide

EG. Everglades

$\mathrm{HM}$ Hydrogenotrophic MCR ..Methyl CoM Reductase MD. Miami-Dade ML Maximum Likelihood MT Methylotrophic NMDS Non-metric Multidimensional Scaling OTU Operational Taxonomic Unit PCR Polymerase Chain Reaction PERMANOVA..............Non-parametric Permutational Multivariate Analysis of Variance SE. Standard Error SNR Signal-to-noise Ratio SS1 Urban Land-Udorthents

SS2. Lauderhill Dania-Pahokee SS3. Rock Outcrop-Biscayne-Chekika SS4. Perrine-Biscayne-Pennsuco 
USDA.............................................................United States Department of Agriculture WCA-2A......................................................................Water Conservation Area 2A 


\section{CHAPTER 1}

\section{INTRODUCTION}

\subsection{Natural and anthropogenic disturbances, and the importance of characterizing the microbial composition in Miami-Dade County, Florida soils}

Miami-Dade County Florida watershed is located between the Everglades and Biscayne National parks and the existence of this watershed is expected to be impacted by extensive urbanization by 2050 (South Miami-Dade watershed study and planning report; www.miamidade.gov). Furthermore, studies are being conducted to plan for restoration of the Florida Everglades to improve water quality and control soil organic matter decomposition (Ogram et al. 2011). Such restoration efforts in the Florida Everglades will no doubt result in hydrological changes affecting the adjoining areas in the Miami-Dade County watershed. As a result, microbial communities inhabiting Miami-Dade soils will have to respond rapidly to the changing environmental conditions and restoration activities. If they cannot, the microbial community and the associated ecosystem services provided by them within the watershed could be severely disrupted (Reddy et al. 2002).

Microbial research in South Florida has primarily been conducted in the Florida Everglades, and have focused on the impact of carbon inputs and nutrient loadings (20002015) from the adjoining agricultural areas, and the future salinity effects as a result of sea level rise on microbial composition (Table 1). Until now microbial studies have not been conducted in the Miami-Dade County soils and since these soils will also be impacted as a result of external perturbations in the near future, it is essential to determine the current 
microbial community composition and their putative ecosystem functions in order to better predict effects of the anticipated disturbances.

Table 1: Methods used to characterize microbial communities in the Florida Everglades.

\begin{tabular}{|l|c|c|}
\hline \multicolumn{1}{|c|}{ Methods } & Study description & References \\
\hline Functional genetics & $\begin{array}{c}\text { Analyzed sulfate-reducing prokaryotes in } \\
\text { eutrophic and pristine areas }\end{array}$ & Castro et al. 2002 \\
\hline Community genetics & $\begin{array}{c}\text { Determined association between syntrophs and } \\
\text { methanogens along nutrient gradient }\end{array}$ & $\begin{array}{c}\text { Chauhan et al. } \\
\text { 2004 }\end{array}$ \\
\hline Functional genetics & $\begin{array}{c}\text { Characterized methanogenic assemblages in } \\
\text { eutrophic and oligotrophic areas }\end{array}$ & Castro et al. 2004 \\
\hline Functional genetics & $\begin{array}{c}\text { Sulfate-reducing prokaryotic and } \\
\text { hydrogenotrophic methanogenic interactions in } \\
\text { nutrient-impacted areas }\end{array}$ & Castro et al. 2005 \\
\hline Community genetics & $\begin{array}{c}\text { Syntrophic-archaeal associations in a nutrient- } \\
\text { impacted freshwater marsh }\end{array}$ & Chauhan et al. \\
2006
\end{tabular}




\subsection{Overarching hypotheses: biodiversity, ecosystem function, and impact of}

disturbance

Currently, two overarching hypotheses exist regarding biodiversity and ecosystem function: 1) ecological equivalence, and 2) functional dissimilarity. The "ecological equivalence" hypothesis states that microbial communities in similar environments are functionally redundant, i.e. diverse microbial species perform the same functions. Accordingly, the ecological equivalence hypothesis implies that soil type (i.e., physical, elemental, and chemical composition) selects for function as it assumes that function is attributed to the environmental conditions (Strickland et al. 2009). Furthermore, the ecological hypothesis has also been related to the "biological insurance hypothesis" that states with higher biodiversity in an ecosystem, function is insured during stressful events (Yachi and Loreau 1999). Conversely, the "functional dissimilarity" hypothesis proposes that ecosystem function is not fixed by environmental conditions but is related to the overall microbial community diversity in a given ecosystem (Strickland et al. 2009).

During stress or external perturbations, the ecosystem function can respond in several ways (Allison and Martiny 2008; Figure 1): (a) if resistant, it is expected to remain unchanged; (b) if it is resilient, the perturbation alters the community composition but over time it recovers to the original composition; (c) the microbial community is functionally redundant if the composition is changed under new environmental parameters but it still has functionally redundant taxa that can perform the same ecosystem function; or (d) under the worst case scenario, there could be the complete loss of ecosystem functions because the altered microbial community composition cannot adapt to the perturbation and the community services are lost (Allison and Martiny 2008). 


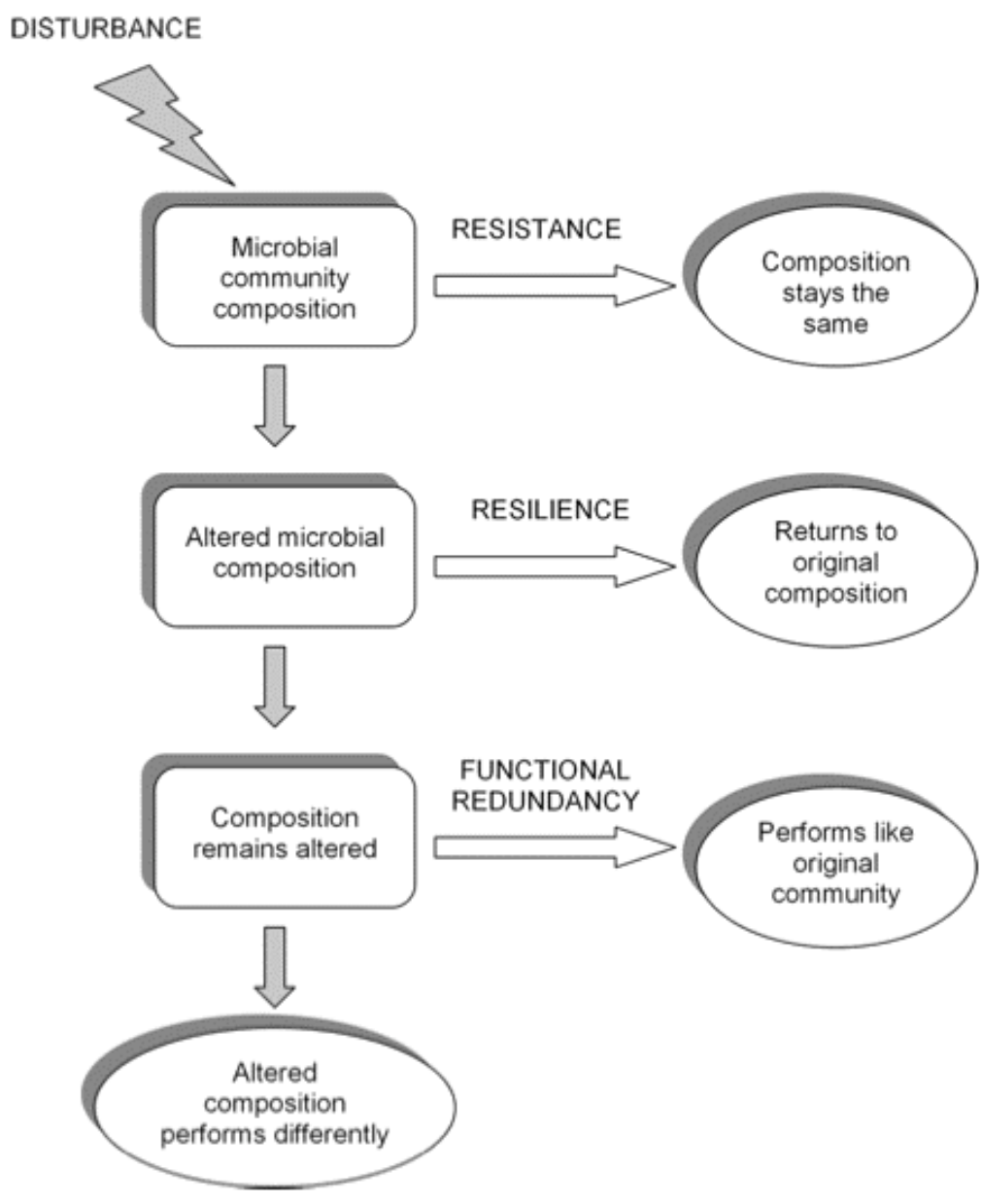

Figure 1: A schematic representation depicting the impact of disturbance on the microbial composition and the ecosystem services provided by them (Allison and Martiny 2008).

Although ecological hypotheses relating microbial diversity, ecosystem function, and impact of disturbances exist, the characterization of microbial communities in environmental samples can be challenging. The determination of the microbial biodiversity and associated ecosystem functions is difficult (Fuhrman et al. 2009) because of the high microbial diversity, their "uncultivated status", and their complex interactions with other organisms (Quince et al. 2008). With the advancement in molecular technology, 
high throughput techniques can now elucidate the composition and subsequent biochemical functions of soil microorganisms (Metzker 2010; Logares et al. 2012), although it remains computationally complex.

\subsection{High throughput metagenomics techniques}

High throughput methods include "open" and "closed" formats. The open format of high-throughput metagenomic sequencing does not require prior knowledge of the organisms present in any sample, and thereby is ideal for characterization of novel organisms, genes, and pathways (Vieites et al. 2009; Roh et al. 2010). On the other hand, high density microarrays are closed formats that represent the known taxonomic and gene functional diversity as identified by the hybridized probes on the microarray chip (He et al. 2007).

Several high-throughput sequencing platforms have been developed and are extensively being applied in microbial ecology studies by targeting the phylogenetic 16S rRNA gene marker (Sogin et al. 2006; Caporaso et al. 2012). However, 16S rRNA sequencing provides limited information about species functions and community interactions in the environment (Zhou et al. 2015). As a result, function is inferred when an environmental 16S rRNA sequence is highly similar in sequence to a characterized species in the archived database (Stackebrandt and Ebers 2006). For example, Robinson et al. (2010) reported that Escherichia coli strains identified from different environments were taxonomically identical when characterized using 16S rRNA (99\% similarity) but performed different functions ranging from being pathogenic to commensal. To resolve this problem, targeted functional gene sequencing can also be performed (Gubry-Rangin et al. 2011; Pester et al. 2012). The disadvantages of using this methodology are difficult 
primer design as functional genes are not always conserved across homologs, poor amplification rates owing to the complexity of the ecosystem, variations in extracted DNA quality, and low target gene abundance (Zhou et al. 2015).

The use of shotgun metagenomics sequencing is employed to counteract the amplification-related problems. While shotgun metagenomics has been successfully administered across various environmental samples (Hess et al. 2011; Castelle et al. 2013), only a few studies have accomplished shotgun sequencing in soils (Tringe et al. 2005; Mackelprang et al. 2011; Delmont et al. 2012; Fierer et al. 2012). Although targeted and shotgun sequencing technologies are promising to investigate the microbial community composition, data analyses can be extremely challenging, especially in case of whole metagenome sequencing. The assembling of high-quality libraries can be cumbersome and high performance computer arrays are often required (Hess et al. 2011; Nagarajan and Pop 2013). In most cases, majority of the genomes cannot be assembled as high number of short reads are detected (Gevers et al. 2012).

On the other hand, microarrays have certain advantages over high throughput sequencing technology. First, the microarray is designed to identify and quantify most known functional genes associated with different biogeochemical pathways simultaneously across different environmental samples, thereby providing information on functional guilds that are critical for ecosystem and microbial ecology studies (Hillebrand and Matthiessen 2009). They also provide taxonomic information on bacteria, Archaea, eukaryotes (including fungi, algae and protists) as well as viruses and are therefore, not limited to which targeted taxonomic primers may be used (Zhou et al. 2013). Second, microarrays have the capacity to yield clear taxonomic composition as functional gene 
markers are often more diverse than phylogenetic markers (Tiquia et al. 2004). Third, functional gene microarrays are not dominated by the polymerase chain reaction (PCR) amplification bias of genes/microbial population as the technology is probe-specific and even low-abundance of microbial community can be detected if the minimal signal is above the set threshold (Wang et al. 2009). Fourth, data obtained from the microarrays are also less susceptible to DNA contaminants as only targeted oligonucleotides will produce signals (Lemon et al. 2010).

Despite the microarray's ability to provide higher taxonomic resolution (e.g., species level), functional diversity detected on a microarray is limited to the probes on the microchip derived from a set of known genes/sequences and may not represent the total diversity of the microbial communities. As a result, rapid advancement of molecular technology, microarrays are not always able to reflect the newest, un-described taxa within an ecosystem as the probes are not represented on the microarrays (Zhou et al. 2015). Nonetheless, microarrays offer a rapid platform to acquire baseline data associated with the putative function of microbial community across environmental samples. Hence, DNA GeoChip functional microarrays were employed in the current study to evaluate soil microbial community composition using functional genes associated with carbon cycle.

\subsection{Carbon cycle}

Microbial decomposition of plant material is a primary step involved in the soil carbon cycle. The complete or partial degradation of plant material results in either mineralization to carbon dioxide $\left(\mathrm{CO}_{2}\right)$ and/or methane $\left(\mathrm{CH}_{4}\right)$ or sequestration of carbon within soils (Figure 2; Cebrian 1999). The initial steps of plant material breakdown such as cellulose hydrolysis can occur in oxic as well as anoxic environments (Lynd et al. 2002). 
The metabolites that are generated from the breakdown of carbohydrates, proteins or lipids in anoxic habitats are utilized by a bacterial consortia of acidogens, fermenters, and acetogens (Figure 2).

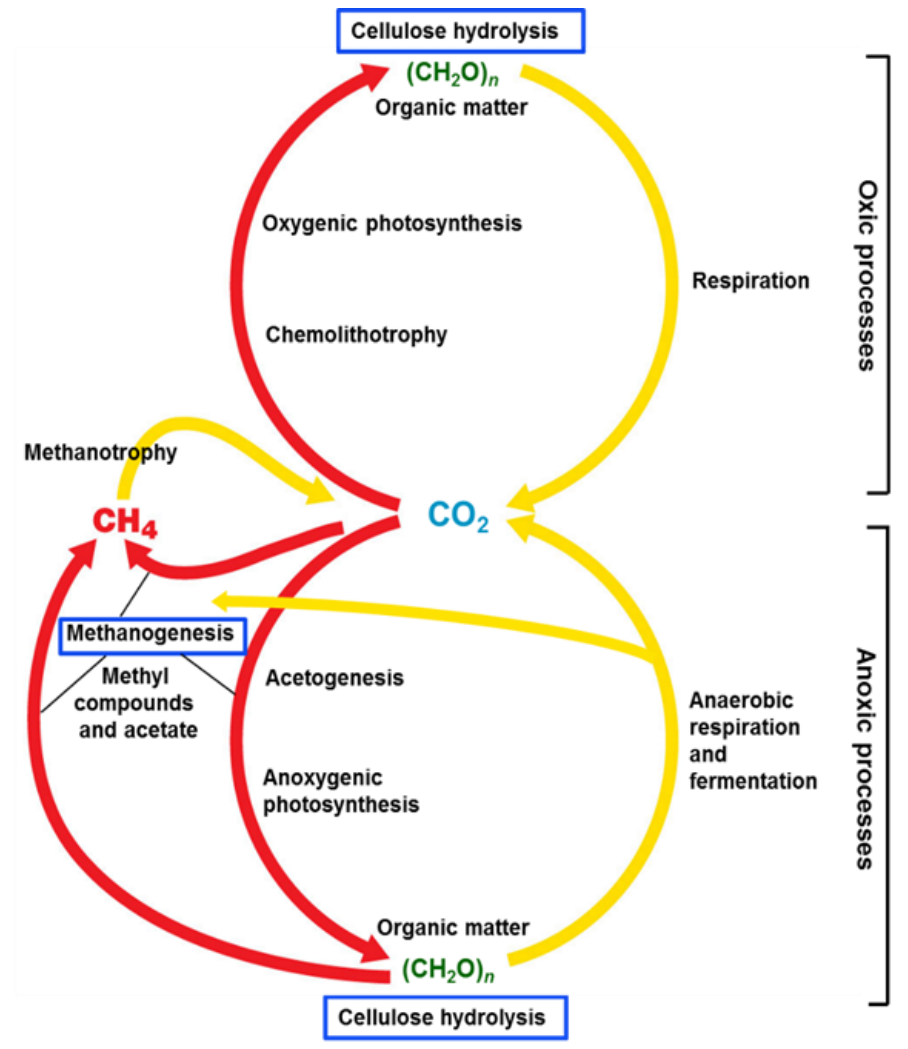

Figure 2: Microbial degradation of soil organic material (from Madigan et al. 2010). A schematic representation of the step-wise breakdown of organic matter in oxic and anoxic environments. The mineralization of plant material containing cellulose is the primary step in the carbon cycle and is catalyzed by the microbial cellulases resulting in $\mathrm{CO}_{2}$ production. In anoxic conditions, the products released as a result of cellulose hydrolysis are fed into the processes of fermentation, acetogenesis, and methanogenesis. Methanogenesis is the last step of the carbon cycle resulting in $\mathrm{CH}_{4}$ production.

Furthermore, specialized Archaea called methanogens, catalyze the last step of the carbon cycle and rely upon the substrates synthesized via the processes of hydrolysis, acidogenesis, acetogenesis, fermentation or a combination of those pathways (Cicerone and Oremland 1988). Accordingly, changes in the activity of cellulolytic and/or 
fermentative bacteria indirectly affect the process of methanogenesis that produces $\mathrm{CH}_{4}$ as its end product (Uz and Ogram 2006). Since processes of cellulose degradation and methanogenesis are critical in catalyzing the first and last step of carbon cycle, respectively, it of utmost importance to determine the baseline functional capacities of microbial communities associated with carbon cycle in Miami-Dade County soils—soils that are threatened to be greatly impacted by the disturbances resulting from climate change, restoration efforts in the Florida Everglades, as well as agricultural and urbanization expansion.

\subsection{Rationale of the study, objectives, and hypotheses}

The capability to perform cellulose degradation has been identified in a wide range of fungi and bacteria and these cellulolytic microorganisms produce extracellular, hydrolytic enzymes—collectively termed as cellulases—-to breakdown cellulose molecules into simpler monomers (Lynd et al. 2002; Wilson 2011). Although, studies related to cellulolytic microorganisms have been conducted in the Florida Everglades, they were limited to use of $16 \mathrm{~S}$ rRNA phylogenetic marker specific to Clostridium sp. (Uz and Ogram 2006; Uz et al. 2007). By targeting only Clostridium related species, the biodiversity of other taxonomic groups were not identified in the Florida Everglades. On the other hand, methanogenic Archaea diversity in the Florida Everglades has been explored using a combination of phylogenetic as well as functional guild markers (Chauhan et al. 2004; Castro et al. 2004; Castro et al. 2005; Bae et al. 2015). However, most of the methanogens are yet uncharacterized as they are strict anaerobes and require fastidious growth conditions. Furthermore, methanogens have been recently described as global autochthonous members of aerated soils that become active under saturated conditions 
(Angel et al. 2012; Hofmann et al. 2016). No studies in Florida have reported the diversity of methanogens in dry, oxic soils. Thus, there is a knowledge gap in the biodiversity of cellulolytic community and the uncharacterized methanogens within dry and saturated soils of Miami-Dade County.

Subsequently, this dissertation focuses on elucidating the current biodiversity of the cellulolytic and methanogenic community using cellulase family genes and the methanogenic genetic marker $m c r A$ gene, in dry as well as saturated soils from MiamiDade County. Additionally, the models of how disturbance may impact microbial community and their associated ecosystem functions as proposed by Allison and Martiny (2008) were utilized to predict the effect of future external disturbances on microbial composition within Miami-Dade County soils. To explore the microbial composition associated with the carbon cycle across Miami-Dade County soil types, a high throughput technique of GeoChip 5.0 microarray was employed.

This dissertation is divided into the four following chapters.

Chapter 2 tests the hypothesis that the taxa associated with cellulase family genes will be functionally redundant and the diversity and abundance of cellulase guilds in forest soil habitats will be greater because of the complex composition of woody plant tissue requiring diverse enzymatic capacity. Functional gene microarrays were employed to compare the functional diversity of cellulase family genes across four soil types of MiamiDade County supporting different plant communities and evaluated the differences in cellulolytic bacterial and fungal composition in relation to the soil abiotic factors.

Chapter 3 is a reprint of a published book chapter and tests the hypothesis that as soil type structures the microbial community, does it also select for functional guild 
diversity in physically dissimilar soil types or is the genetic potential functionally redundant. To address the hypothesis, DNA clone libraries of the methanogenic marker mcrA gene and phylogenetic studies were utilized to determine if similar aboveground habitats influence the belowground methanogenic guilds.

Chapter 4 tests the hypothesis that the methanogenic assemblages will be functionally redundant regardless of habitat and the methanogenic diversity across dry and saturated soils will not differ. The methanogenic guilds in Miami-Dade County soils were phylogenetically characterized using the $m c r A$ gene protein subunit as identified on the functional microarrays. Additionally, the influence of abiotic factors on these guilds was evaluated using ordination and statistical methodologies.

In chapter 5, the methanogenic guilds' gene interactions were investigated under the hypothesis that functional gene networks will be tightly correlated within the "pristine" Everglades wetlands versus the urbanized Miami-Dade County soils and the network graphs can serve as models to infer impact of disturbances on the microbial communities. This chapter examines the methanogenic correlation networks by utilizing all the methanogenesis pathways genes that were detected on the functional microarrays.

\subsection{References}

Allison, S. D., \& Martiny, J. B. (2008). Resistance, resilience, and redundancy in microbial communities. Proceedings of the National Academy of Sciences, 105 (Supplement 1), 11512-11519.

Angel, R., Claus, P., \& Conrad, R. (2012). Methanogenic archaea are globally ubiquitous in aerated soils and become active under wet anoxic conditions. The ISME Journal, 6(4), 847-862.

Bae, H. S., Dierberg, F. E., \& Ogram, A. (2014). Syntrophs dominate sequences associated with the mercury methylation-related gene $h g c A$ in the water conservation areas of 
the Florida Everglades. Applied and Environmental Microbiology, 80(20), 65176526.

Bae, H. S., Holmes, M. E., Chanton, J. P., Reddy, K. R., \& Ogram, A. (2015). Distribution, activities, and interactions of methanogens and sulfate-reducing prokaryotes in the Florida Everglades. Applied and Environmental Microbiology, 81(21), 7431-7442.

Caporaso, J. G., Lauber, C. L., Walters, W. A., Berg-Lyons, D., Huntley, J., Fierer, N., Owens, S.M., Betley, J., Fraser, L., Bauer, M. \& Gormley, N. (2012). Ultra-highthroughput microbial community analysis on the Illumina HiSeq and MiSeq platforms. The ISME Journal, 6(8), 1621-1624.

Castelle, C. J., Hug, L. A., Wrighton, K. C., Thomas, B. C., Williams, K. H., Wu, D., Tringe, S.G., Singer, S.W., Eisen, J.A., \& Banfield, J. F. (2013). Extraordinary phylogenetic diversity and metabolic versatility in aquifer sediment. Nature Communications, 4.

Castro, H., Reddy, K. R., \& Ogram, A. (2002). Composition and function of sulfatereducing prokaryotes in eutrophic and pristine areas of the Florida Everglades. Applied and Environmental Microbiology, 68(12), 6129-6137.

Castro, H., Ogram, A., \& Reddy, K. R. (2004). Phylogenetic characterization of methanogenic assemblages in eutrophic and oligotrophic areas of the Florida Everglades. Applied and Environmental Microbiology, 70(11), 6559-6568.

Castro, H., Newman, S., Reddy, K. R., \& Ogram, A. (2005). Distribution and stability of sulfate-reducing prokaryotic and hydrogenotrophic methanogenic assemblages in nutrient-impacted regions of the Florida Everglades. Applied and Environmental Microbiology, 71(5), 2695-2704.

Cebrian, J. (1999). Patterns in the fate of production in plant communities. The American Naturalist, 154(4), 449-468.

Chauhan, A., Ogram, A., \& Reddy, K. R. (2004). Syntrophic-methanogenic associations along a nutrient gradient in the Florida Everglades. Applied and Environmental Microbiology, 70(6), 3475-3484.

Chauhan, A., Reddy, K. R., \& Ogram, A. V. (2006). Syntrophic-archaeal associations in a nutrient-impacted freshwater marsh. Journal of Applied Microbiology, 100(1), 7384.

Chauhan, A., \& Ogram, A. (2006a). Fatty acid-oxidizing consortia along a nutrient gradient in the Florida Everglades. Applied and Environmental Microbiology, 72(4), 24002406. 
Chauhan, A., \& Ogram, A. (2006b). Phylogeny of acetate-utilizing microorganisms in soils along a nutrient gradient in the Florida Everglades. Applied and Environmental Microbiology, 72(10), 6837-6840.

Chauhan, A., Pathak, A., \& Ogram, A. (2012). Composition of methane-oxidizing bacterial communities as a function of nutrient loading in the Florida everglades. Microbial Ecology, 64(3), 750-759.

Cicerone, R. J., \& Oremland, R. S. (1988). Biogeochemical aspects of atmospheric methane. Global Biogeochemical Cycles, 2(4), 299-327.

Delmont, T. O., Prestat, E., Keegan, K. P., Faubladier, M., Robe, P., Clark, I. M., Pelletier, E., Hirsch, P.R., Meyer, F., Gilbert, J.A., \& Le Paslier, D. (2012). Structure, fluctuation and magnitude of a natural grassland soil metagenome. The ISME Journal, 6(9), 1677-1687.

Fierer, N., Leff, J. W., Adams, B. J., Nielsen, U. N., Bates, S. T., Lauber, C. L., Owens, S., Gilbert, J.A., Wall, D.H., \& Caporaso, J. G. (2012). Cross-biome metagenomic analyses of soil microbial communities and their functional attributes. Proceedings of the National Academy of Sciences, 109(52), 21390-21395.

Fuhrman, J. A. (2009). Microbial community structure and its functional implications. Nature, 459(7244), 193-199.

Gevers, D., Pop, M., Schloss, P. D., \& Huttenhower, C. (2012). Bioinformatics for the human microbiome project. PLoS Computational Biology, 8(11), e1002779.

Gubry-Rangin, C., Hai, B., Quince, C., Engel, M., Thomson, B. C., James, P., Schloter, M., Griffiths, R.I., Prosser, J.I., \& Nicol, G. W. (2011). Niche specialization of terrestrial archaeal ammonia oxidizers. Proceedings of the National Academy of Sciences, 108(52), 21206-21211.

Hartman, W. H., Richardson, C. J., Vilgalys, R., \& Bruland, G. L. (2008). Environmental and anthropogenic controls over bacterial communities in wetland soils. Proceedings of the National Academy of Sciences, 105(46), 17842-17847.

He, Z., Gentry, T. J., Schadt, C. W., Wu, L., Liebich, J., Chong, S. C., Huang, Z., Wu, W., Gu, B., Jardine, P. \& Criddle, C. (2007). GeoChip: a comprehensive microarray for investigating biogeochemical, ecological and environmental processes. The ISME Journal, 1(1), 67-77.

Hess, M., Sczyrba, A., Egan, R., Kim, T. W., Chokhawala, H., Schroth, G., Luo, S., Clark, D.S., Chen, F., Zhang, T. \& Mackie, R. I. (2011). Metagenomic discovery of biomass-degrading genes and genomes from cow rumen. Science, 331(6016), 463467. 
Hillebrand, H., \& Matthiessen, B. (2009). Biodiversity in a complex world: consolidation and progress in functional biodiversity research. Ecology letters, 12(12), 14051419.

Hofmann, K., Praeg, N., Mutschlechner, M., Wagner, A. O., \& Illmer, P. (2016). Abundance and potential metabolic activity of methanogens in well-aerated forest and grassland soils of an alpine region. FEMS Microbiology Ecology, 92(2), fiv171.

Ikenaga, M., Guevara, R., Dean, A. L., Pisani, C., \& Boyer, J. N. (2010). Changes in community structure of sediment bacteria along the Florida coastal Everglades marsh-mangrove-seagrass salinity gradient. Microbial Ecology, 59(2), 284-295.

Inglett, K. S., Inglett, P. W., \& Ramesh Reddy, K. (2011). Soil microbial community composition in a restored calcareous subtropical wetland. Soil Science Society of America Journal, 75(5), 1731-1740.

Lemon, K. P., Klepac-Ceraj, V., Schiffer, H. K., Brodie, E. L., Lynch, S. V., \& Kolter, R. (2010). Comparative analyses of the bacterial microbiota of the human nostril and oropharynx. mBio, 1(3), e00129-10.

Logares, R., Haverkamp, T. H., Kumar, S., Lanzén, A., Nederbragt, A. J., Quince, C., \& Kauserud, H. (2012). Environmental microbiology through the lens of highthroughput DNA sequencing: synopsis of current platforms and bioinformatics approaches. Journal of Microbiological Methods, 91(1), 106-113.

Lynd, L. R., Weimer, P. J., van Zyl, W. H., \& Pretorius, I. S. (2002). Microbial cellulose utilization: Fundamentals and biotechnology. Microbiology and Molecular Biology Reviews, 66(3), 506-77.

Mackelprang, R., Waldrop, M. P., DeAngelis, K. M., David, M. M., Chavarria, K. L., Blazewicz, S. J., Rubin, E.M. , \& Jansson, J. K. (2011). Metagenomic analysis of a permafrost microbial community reveals a rapid response to thaw. Nature, 480(7377), 368-371.

Madigan, M. T., Clark, D. P., Stahl, D., \& Martinko, J. M. (2010). Brock Biology of Microorganisms 13th edition. Benjamin Cummings.

Metzker, M. L. (2010). Sequencing technologies - the next generation. Nature Reviews Genetics, 11(1), 31-46.

Nagarajan, N., \& Pop, M. (2013). Sequence assembly demystified. Nature Reviews Genetics, 14(3), 157-167.

Ogram, A., Chauhan, A., Inglett, K. S., Jayachandran, K., \& Newman, S. (2011). Microbial ecology and Everglades restoration. Critical Reviews in Environmental Science and Technology, 41(S1), 289-308. 
Pester, M., Rattei, T., Flechl, S., Gröngröft, A., Richter, A., Overmann, J., Reinhold-Hurek, B., Loy, A. \& Wagner, M. (2012). amoA-based consensus phylogeny of ammoniaoxidizing Archaea and deep sequencing of amoA genes from soils of four different geographic regions. Environmental Microbiology, 14(2), 525-539.

Quince, C., Curtis, T. P., \& Sloan, W. T. (2008). The rational exploration of microbial diversity. The ISME Journal, 2(10), 997-1006.

Reddy, K. R., Wright, A., Ogram, A., Debusk, W. F., \& Newman, S. (2002). Microbial processes regulating carbon cycling in subtropical wetlands. In Paper 982 Proceedings of the 17th World Congress of Soil Science, Bankok, Thailand.

Robinson, C. J., Bohannan, B. J., \& Young, V. B. (2010). From structure to function: the ecology of host-associated microbial communities. Microbiology and Molecular Biology Reviews, 74(3), 453-476.

Roh, S. W., Abell, G. C., Kim, K. H., Nam, Y. D., \& Bae, J. W. (2010). Comparing microarrays and next-generation sequencing technologies for microbial ecology research. Trends in Biotechnology, 28(6), 291-299.

Smith, J. M., Castro, H., \& Ogram, A. (2007). Structure and function of methanogens along a short-term restoration chronosequence in the Florida Everglades. Applied and Environmental Microbiology, 73(13), 4135-4141.

Sogin, M. L., Morrison, H. G., Huber, J. A., Welch, D. M., Huse, S. M., Neal, P. R., Arrieta, J.M., \& Herndl, G. J. (2006). Microbial diversity in the deep sea and the underexplored "rare biosphere". Proceedings of the National Academy of Sciences, 103(32), 12115-12120.

Stackebrandt, E., \& Ebers, J. (2006). Taxonomic parameters revisited: tarnished gold standards. Microbiology Today, 33(4), 152.

Strickland, M. S., Lauber, C., Fierer, N., \& Bradford, M. A. (2009). Testing the functional significance of microbial community composition. Ecology, 90(2), 441-451.

Tiquia, S. M., Wu, L., Chong, S. C., Passovets, S., Xu, D., Xu, Y., \& Zhou, J. (2004). Evaluation of 50-mer oligonucleotide arrays for detecting microbial populations in environmental samples. Biotechniques, 36(4), 664-675.

Tringe, S. G., Von Mering, C., Kobayashi, A., Salamov, A. A., Chen, K., Chang, H. W., Podar, M., Short, J.M., Mathur, E.J., Detter, J.C., \& Bork, P. (2005). Comparative metagenomics of microbial communities. Science, 308(5721), 554-557.

Uz, I., \& Ogram, A. V. (2006). Cellulolytic and fermentative guilds in eutrophic soils of the Florida Everglades. FEMS Microbiology Ecology, 57(3), 396-408. 
Uz, I., Chauhan, A., \& Ogram, A. V. (2007). Cellulolytic, fermentative, and methanogenic guilds in benthic periphyton mats from the Florida Everglades. FEMS Microbiology Ecology, 61(2), 337-347.

Vieites, J. M., Guazzaroni, M. E., Beloqui, A., Golyshin, P. N., \& Ferrer, M. (2009). Metagenomics approaches in systems microbiology. FEMS Microbiology Reviews, 33(1), 236-255.

Wang, F., Zhou, H., Meng, J., Peng, X., Jiang, L., Sun, P., Zhang, C., Van Nostrand, J.D., Deng, Y., He, Z., \& Wu, L. (2009). GeoChip-based analysis of metabolic diversity of microbial communities at the Juan de Fuca Ridge hydrothermal vent. Proceedings of the National Academy of Sciences, 106(12), 4840-4845.

Wilson, D. B. (2011). Microbial diversity of cellulose hydrolysis. Current Opinion in Microbiology, 14(3), 259-263.

Yachi, S., \& Loreau, M. (1999). Biodiversity and ecosystem productivity in a fluctuating environment: the insurance hypothesis. Proceedings of the National Academy of Sciences, 96(4), 1463-1468.

Zhou, J., Tu, Q., Wu, L., He, Z., Deng, Y., \& Van Nostrand, J. D. (2013, December). Metagenomic Insights of Microbial Feedbacks to Elevated $\mathrm{CO}_{2}$. In AGU Fall Meeting Abstracts (Vol. 1, p. 1099).

Zhou, J., He, Z., Yang, Y., Deng, Y., Tringe, S. G., \& Alvarez-Cohen, L. (2015). Highthroughput metagenomic technologies for complex microbial community analysis: open and closed formats. mBio, 6(1), e02288-14. 


\section{CHAPTER 2}

\section{BIODIVERSITY AND DISTRIBUTION OF CELLULOLYTIC MICROBIAL COMMUNITY IN MIAMI-DADE COUNTY SOILS, FLORIDA}

\subsection{Introduction}

Carbon sequestration in any ecosystem occurs when carbon assimilation through photosynthesis exceeds the carbon loss through plant and heterotrophic respiration (Schulze 2006). In terrestrial ecosystems, two-thirds of the carbon is stored in soils (Jobbágy and Jackson 2000; Amundson 2001). The majority of the soil carbon originates from the aboveground and belowground plant biomass along with contributions from root exudates (Bardgett et al. 2005). Thus, plant polymer degradation is the primary step in carbon cycle that incorporates plant litter into microbial biomass and in the process is either mineralized to $\mathrm{CO}_{2}$ or integrated into the soil carbon pool (Cebrian 1999).

The quality of plant litter varies between plant species as a result of the structural differences in plant tissues. The major components of the plant cell wall are cellulose, hemicellulose, and lignin (Melillo et al. 1982; Aerts 1997; Cornwell et al. 2008) and the percent of these compounds vary across the plant tissues as well as the plant species. Parenchymatic tissue is present in leaves and cortex of young twigs and fine roots and is mostly composed of cellulose. Woody tissues are comprised of three cell wall layers with varying concentration of cellulose (60\% in secondary and tertiary wall), hemicellulose, and lignin (59\% in middle lamella) (Fengel and Wegener 1983; Kögel-Knabner 2002).

Considering cellulose is the most abundant polymer of the plant cell wall, cellulose hydrolysis is the first step in plant litter decomposition. The majority of the cellulose degradation (90-95\%) is achieved by aerobic bacteria and fungi, whereas anaerobic 
bacteria contribute to the remaining 5-10\% of cellulose degradation (Magan 2007; Joergensen and Wichern 2008). Microbial cellulose degradation is performed by production of extracellular cellulase enzymes. Cellulases are comprised of three different type of enzymes: endoglucanases, exoglucanases, and $\beta$-glucosidases. Endoglucanases breakdown the cellulose polymers to produce cellulose fragments consisting of oligosaccharides where as exoglucanases digest organic matter to release either glucose or cellobiose. Lastly, $\beta$-glucosidases hydrolyze soluble cellobiose into glucose (Sun and Cheng 2002; Lynd et al. 2002).

Although research has been carried out in determining the diversity of cellulolytic community (Štursová et al. 2012; Allison et al. 2013; Berlemont and Martiny 2013; Berlemont et al. 2014), no studies have characterized the biodiversity of the cellulolytic community in South Florida, especially in Miami-Dade County soils, that are under threat because of the restoration efforts being carried out in the adjoining Florida Everglades, climate change as well as rapid urbanization. One of the major effects of these disturbances would be changes in hydrology of the soils resulting in a shift of microbial composition. Previous studies in arid and semi-arid grasslands have reported a decline in plant litter decomposition rates, bacterial abundance, and cellulolytic potential with reduced water availability (Allison et al. 2013; Berlemont et al. 2014). Therefore, it is critical to characterize the current cellulolytic community in order to assess the impact of future disturbances.

The objective of this study was to investigate the diversity and distribution of cellulolytic microbes within Miami-Dade County soils with different vegetation cover as well as physical and chemical properties. The plant communities of the selected four soil 
types ranged from forest/woody plants, marsh grasses primarily sawgrass, herbaceous grasses, and marsh grasses. Since plant material composition is more complex in woody plant tissues than grasses, it was hypothesized that there would be greater diversity of cellulase family guilds in the site with woody plants in order to more efficiently prime the carbohydrate hydrolysis of the mixed woody substrates. Additionally, it was hypothesized that the cellulolytic diversity within each soil type will be functionally redundant as cellulase genes are distributed across a variety of taxonomic lineages. In this study, GeoChip functional microarrays were used to estimate diversity of fungal and bacterial cellulase family genes across four different soils types of Miami-Dade County soils. Additionally, correlation of soil physicochemical properties with cellulolytic microbial composition was determined.

\subsection{Material and methods}

\subsubsection{Soil sample collection}

Soils were collected from four distinct soil types: Urban Land-Udorthents (SS1), Lauderhill Dania-Pahokee (SS2), Rock Outcrop-Biscayne-Chekika (SS3), and PerrineBiscayne-Pennsuco (SS4) in Miami-Dade County, Florida during the wet season (JulyOctober) in 2014. Soil types were chosen on the basis of the differences in vegetation cover and soil properties (Table S1) as classified by the United States Department of Agriculture (USDA). Sites were largely undisturbed and at least $100 \mathrm{~m}$ from anthropogenic effects (e.g. roads or construction). For each soil type, samples were collected from six $1.5 \mathrm{~m}^{2}$ subplots that were at least $15 \mathrm{~m}$ apart. Three samples were collected from each subplot, for a total of 18 soil samples per soil site. The top $5-10 \mathrm{~cm}$ of topsoil was sampled with a $5 \mathrm{~cm}$ diameter soil corer. 


\subsubsection{Soil physiochemical properties}

Samples were transported to the laboratory on ice and sieved using a 14 mesh (1.41 $\mathrm{mm}$ ) screen to remove large particulates. Subsequently, $\mathrm{pH}$, moisture content, and organic content were measured. The $\mathrm{pH}$ was measured by making a slurry of 2 parts water per 1 part of soil and analyzed using a Lamotte $\mathrm{pH}$ meter. Moisture content was recorded using the gravimetric method ( $\mathrm{n}=6$ per soil type) and organic content was measured by the gravimetric method in an ash oven at $550^{\circ} \mathrm{C}(\mathrm{n}=6$ per soil type). Soil texture was measured using a hydrometer for a pooled sample from each soil type. To determine significant differences in soil physiochemical properties between soil types, one-way analysis of variance (ANOVA) with Tukey's multiple comparison tests was performed. Furthermore, archived physical and chemical data for the study sites were retrieved by USDA web soil survey area of interest (AOI) queries (Noble et al. 1996; http://websoilsurvey.nrcs.usda.gov/).

\subsubsection{DNA extraction and quantification}

Five hundred milligrams of soil for each subplot was extracted with the Fast DNA Spin Kit for Soil® (MP Biomedical, Solon, $\mathrm{OH}$ ) with minor modifications per Mills et al. (2003) using the FastPrep®-24 System homogenizer. Total DNA was quantified using Qubit® Assay kit on the Qubit 2.0 Fluorometer (Invitrogen, Carlsbad, CA). The extracted DNA from each subplot from a single soil type was pooled together to have one representative DNA sample per soil type for the microarray analyses.

\subsubsection{GeoChip 5.0 functional gene microrrays}

For the GeoChip 5.0 analyses, extracted DNA from the four soil samples was precipitated with $100 \%$ ethanol and $3 \mathrm{M}$ sodium acetate. The quantity and purity of DNA 
$\left(\mathrm{A}_{260 / 280}\right.$ 1.8 and $\left.\mathrm{A}_{260 / 230}>1.7\right)$ was assessed using UV absorbance. The DNA was dried in a vacufuge before it was shipped to Institute of Environmental Genomics (IEG), University of Oklahoma, (Norman, OK) for microarray processing. Whole genome amplification was performed using $20 \mathrm{ng}$ of DNA as template and labeled with fluorescent dyes as described previously (Wu et al. 2006; Xiong et al. 2010). The labeled DNA was then hybridized to the GeoChip at $67^{\circ} \mathrm{C}$ for $24 \mathrm{~h}$ and washed before being scanned using a NimbleGen MS200 Microarray Scanner (Roche NimbleGen, Inc., Madison, WI, USA; Zhang et al. 2015). The spots with the signal-to-noise ratio (SNR) $<2$ or the signal $<200$ or $<1.3$ times the background were removed and the intensities of all positive probes for each sample were obtained from IEG. The relative abundance of positive probes was calculated in each sample for all the taxonomic species associated with the cellulose degradation probes (all of the glycoside hydrolase family genes) and then multiplied by the mean value for the sums of signal intensity in all of the samples (Wang et al. 2015). Finally, the relative abundances were transformed using the natural logarithm plus 1.

\subsubsection{Statistical analyses}

The cellulolytic microbial composition was ordinated using the non-metric multidimensional scaling (NMDS) that used the Bray-Curtis similarity matrix in PRIMERE, ver 7 (Clarke and Gorley 2015). A hierarchical cluster analysis was performed using complete linkage and percentage similarity was used as an overlay on NMDS plots to observe differences in gene abundances and diversity across soils. A non-parametric permutational multivariate analysis of variance (PERMANOVA) using the adonis function (Anderson 2011) and Mantel's tests (Mantel 1967) were used to assess any correlation of soil physiochemical properties to the abundance of cellulolytic community. Furthermore, 
canonical correspondence analyses (CCA) were performed to relate the microbial community structure and soil abiotic factors. The analyses PERMANOVA (adonis) and CCA were performed using vegan package (v.2.3-5) whereas Mantel's test was performed using ade4 package (v. 3.2.5) in R 3.2.5.

\subsection{Results}

\subsubsection{Soil characteristics}

Soil $\mathrm{pH}$ across the sites ranged from $\mathrm{pH}$ 7.4-7.9. Significant differences between moisture content of SS1 and SS3 from soils SS2 and SS4 were observed. Organic content was significantly different only between soil SS1 and SS4 (Table 2). Soil texture of SS1 and SS3 was sandy loamy, whereas SS2 and SS4 had a loamy texture. According to USDA soil survey, Miami-Dade SS2, SS3, and SS4 had high cation-exchange capacity (159.0$161.2 \mathrm{meq} / \mathrm{g})$ compared to SS1 (26.5 meq/g). Electrical conductivity of SS2 and SS3 (6.0 $\mathrm{mmho} / \mathrm{cm})$ was greater than SS1 $(0.1 \mathrm{mmho} / \mathrm{cm})$ and SS4 $(2.0 \mathrm{mmho} / \mathrm{cm})$. The sample SS1 was classified as the most poorly drained soil sample and had the greatest depth to water table (Table S1).

\section{Table 2: Measured soil physiochemical properties for Miami-Dade County soil} samples.

Data are shown as mean \pm SE. Lower-case letters represent the samples with significant differences $(p<0.05)$ using Tukey's HSD test. For example, the moisture content of SS2 was significantly different from SS1 and SS3 and is represented by letter c and d, respectively. Samples with higher standard errors had more heterogenous above ground communities.

\begin{tabular}{|c|c|c|c|c|c|}
\hline \multirow{2}{*}{ Soil sample } & \multirow{2}{*}{$\begin{array}{c}\% \text { Moisture } \pm \\
\text { SE }\end{array}$} & \multirow{2}{*}{$\begin{array}{c}\% \text { Organic } \\
\text { content } \pm \text { SE }\end{array}$} & \multicolumn{3}{|c|}{ Soil texture } \\
\hline & & & $\%$ Sand & \% Clay & $\%$ Silt \\
\hline SS1 & $23.67 \pm 4.38^{\mathrm{ac}}$ & $12.34 \pm 4.80^{\mathrm{a}}$ & 81.28 & 18.10 & 0.62 \\
\hline SS2 & $74.61 \pm 4.44^{\mathrm{cd}}$ & $24.4 \pm 2.66$ & 41.28 & 24.36 & 34.36 \\
\hline SS3 & $29.53 \pm 1.78^{\text {bd }}$ & $13.38 \pm 0.82$ & 76.26 & 16.24 & 7.50 \\
\hline SS4 & $79.55 \pm 2.51^{\mathrm{ab}}$ & $41.04 \pm 8.94^{\mathrm{a}}$ & 46.29 & 21.86 & 31.85 \\
\hline
\end{tabular}

$\neq \mathrm{pH}$ of the soil samples collected in Miami-Dade County ranged from 7.4-7.9. 


\subsubsection{Cellulolytic microorganisms richness as detected by GeoChip microarray}

There were 1446 gene probes associated with four classes of cellulose degradation enzymes (acetyl xylan esterases, endoglucanase, exogluacanase, and $\beta$ - glucanases) and these probes were specific to 752 different fungal and bacterial taxonomic assemblages. Some operational taxonomic units (OTUs) or species were represented by more than one gene probe and these multiple gene probes correspond to different regions of the same gene. An example is the cellulose degradation gene associated with species Acidothermus cellulolyticus $11 B$ was represented by GenBank IDs: 117647806, 117648288, 117648641, and 117649371. In addition, other functional genes associated with Acidothermus cellulolyticus $11 B$ were present on the GeoChip supporting the presence of Acidothermus cellulolyticus $11 B$ in the sample sets.

Cellulose degradation genes analyses detected 278 OTUs including bacteria and fungi in the four sampled soils. The numbers of unique OTUs for cellulose degradation detected for each phylum/class are represented in Table 3. Actinobacteria, Firmicutes, Alphaproteobacteria, Gammaproteobacteria, and fungi were the major taxonomic groups represented in the soil samples. The relative abundance of Actinobacteria (18\%) and fungi (26\%) was the highest in SS2 and SS4, respectively (Table 3). Flavobacteriales (Bacteroidetes), Herpetosiphonales (Chloroflexi), and Lactobacillales (Firmicutes) were the unique orders detected in SS2 while Vibrionales (Gammaproteobacteria) was the only unique order detected in SS4. The SS1 and SS3 samples did not have any unique groups represented in those soils. 
Table 3: The total number of positive OTUs detected in GeoChip functional microarray for cellulolytic functional genes across the four soil types are shown.

Functional genes represented on the microarray have an associated taxonomic OTU affiliation (shown in the first column). The total number of probes represented by an OTU (specific to cellulose degradation) on the microarray present on the GeoChip 5.0 is shown in "\#GeoChip" column. The number of positive probes identified for each soil sample are represented in the columns SS1, SS2, SS3, and SS4 associated to the representative OTU.

\begin{tabular}{|c|c|c|c|c|c|}
\hline & & SS1 & SS2 & SS3 & SS4 \\
\hline & Vegetation & Mixed \& woody & Marsh grasses & Grasses & Marsh grasses \\
\hline & Habitat & Dry & Freshwater \& saturated & Dry & Brackish \& saturated \\
\hline Associated Taxa & \#GeoChip & SS1 & SS2 & SS3 & SS4 \\
\hline Thermobaculum & 1 & 0 & 1 & 1 & 1 \\
\hline Acidobacteria & 3 & 2 & 3 & 3 & 2 \\
\hline Actinobacteria & 80 & 33 & 51 & 48 & 51 \\
\hline Bacteroidetes & 14 & 3 & 8 & 2 & 5 \\
\hline Chloroflexi & 8 & 3 & 4 & 4 & 4 \\
\hline Cyanobacteria & 8 & 1 & 4 & 2 & 2 \\
\hline Deinococcus-Thermus & 4 & 2 & 3 & 3 & 3 \\
\hline Firmicutes & 125 & 14 & 24 & 18 & 21 \\
\hline Lentisphaerae & 2 & 1 & 1 & 1 & 1 \\
\hline Planctomycetes & 2 & 2 & 2 & 2 & 2 \\
\hline Alphaproteobacteria & 50 & 20 & 30 & 28 & 28 \\
\hline Betaproteobacteria & 22 & 7 & 12 & 13 & 13 \\
\hline Deltaproteobacteria & 4 & 1 & 3 & 3 & 3 \\
\hline Gammaproteobacteria & 71 & 13 & 22 & 19 & 25 \\
\hline Spirochaetes & 3 & 0 & 1 & 1 & 1 \\
\hline Verrucomicrobia & 3 & 1 & 2 & 2 & 2 \\
\hline Unclassified bacterium & 7 & 2 & 2 & 2 & 2 \\
\hline Unclassified fungi & 65 & 5 & 16 & 7 & 12 \\
\hline Fungi & 132 & 38 & 67 & 53 & 65 \\
\hline
\end{tabular}


Compared to the dry SS1 site with an above ground community of mixed, woody plant types, the maximum number of OTUs was found in SS2 and SS4 (saturated sites) with marsh grass habitats. The soil site SS3, with a moisture content similar to SS1 but an above ground community of mixed grasses and some herbaceous plants, represented an intermediate ecosystem and the number of OTUs in SS3 were greater than SS1 but less than SS2 and SS4 (Table 3).

\subsubsection{Cellulolytic assemblages and their associations with abiotic factors}

The NMDS is an ordination analysis where species abundance within samples is plotted on the basis of distance or similarity matrix and it attempts to represent the pairwise similarity between samples in a $2 \mathrm{D}$ plot as closely as possible. The NMDS plot of cellulolytic community using Bray-Curtis similarity matrix showed similar grouping of SS2, SS3, and SS4 together with $70 \%$ similarity and SS1 as $60 \%$ similar to the other sites (Figure 3). When considering just the above ground vegetation cover for SS2, SS3, and SS4, these plant communities were described as grasslands ranging from mixed marsh grasses to mixed terrestrial grasses. On the other hand, the SS1 site was a mixed, woody plant community that resulted in its clustering away from the grass dominated habitats. The NMDS analyses for bacterial and fungal OTUs showed that bacterial as well fungal OTUs (Figure 3a-b) were similar across SS2, SS3, and SS4 soils. 


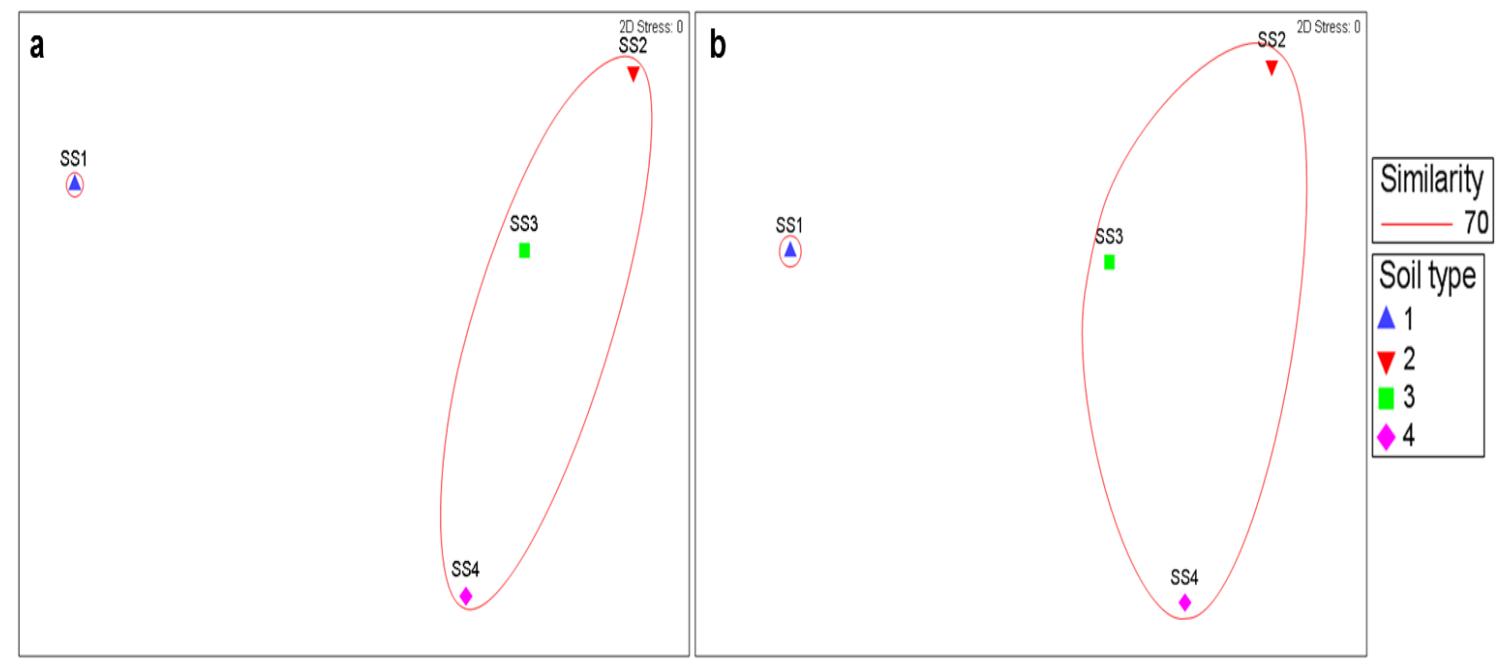

Figure 3: NMDS analysis for all cellulolytic OTUs across Miami-Dade County soils. Panel $\mathrm{a}$ and $\mathrm{b}$ depicts bacterial and fungal OTUs, respectively. Soil types are represented as symbols while red solid line showed $70 \%$ similarity.

The influence of abiotic factors on the species distribution within soil samples was determined using PERMANOVA. The non-parametric analysis utilized dissimilarity matrix of the species score between soil samples and partitioned the variation of the species within samples on the basis of abiotic factors. The PERMANOVA (adonis) analysis revealed percent silt $(\mathrm{p}<0.05)$ to be the only significant factor to correlate with celluloytic microbial community (Table 4). Mantel's test was also performed to calculate correlations between the two dissimilarity matrices of species abundance and abiotic factors. Mantel's test reports a Mantel's coefficient (r) and the value of $r$ can range from -1 to $1 ; r>0$ depicts positive correlation, $\mathrm{r}<0$ negative correlation, and $\mathrm{r}=0$ no correlation. In addition to percent silt, Mantel's correlation test also demonstrated moisture content as a soil physiochemical factor that had an influence on the cellulolytic community OTUs. However, bacterial and fungal cellulolytic OTUs individually showed significant correlation only with silt content (Table 5). 
Table 4: PERMANOVA results for the abundance of cellulolytic assemblages. 'All' represents the total microbial community. $\mathrm{R}^{2}$ value is the percent contribution of the abiotic factor in determining differences between abundances of OTUs across soil samples. Soil silt content was the major physical contributor in determining the differences amongst cellulolytic assemblages. Significant values $(\mathrm{p}<0.05)$ are in boldface.

\begin{tabular}{|l|c|c|c|}
\hline Soil physicochemical factors & All & Bacteria & Fungi \\
\hline Moisture (\%) & 0.51 & 0.50 & 0.56 \\
\hline Organic content (\%) & 0.42 & 0.40 & 0.49 \\
\hline pH & 0.14 & 0.15 & 0.13 \\
\hline Sand (\%) & 0.48 & 0.44 & 0.54 \\
\hline Clay (\%) & 0.30 & 0.26 & 0.37 \\
\hline Silt (\%) & $\mathbf{0 . 6 6}$ & $\mathbf{0 . 6 8}$ & $\mathbf{0 . 6 4}$ \\
\hline
\end{tabular}

Table 5: Mantel's test correlation for the abundance of cellulolytic organisms.

The ' $r$ ' correlation values represent the positive or negative correlation of the abiotic factor in determining the differences between cellulolytic guilds in the soils. Mantel's correlation revealed percent moisture and percent silt as the significant factors for the distribution of all cellulolytic OTUs while soil silt content was the significant parameter influencing the bacterial and fungal OTUs individually. Significant values $(\mathrm{p}<0.05)$ are typed in bold.

\begin{tabular}{|l|c|c|c|}
\hline Soil physicochemical factors & All & Bacteria & Fungi \\
\hline Moisture (\%) & $\mathbf{0 . 3 8}$ & 0.28 & 0.52 \\
\hline Organic content (\%) & 0.14 & -0.01 & 0.47 \\
\hline $\mathrm{pH}$ & -0.69 & -0.55 & -0.86 \\
\hline Sand (\%) & 0.28 & 0.14 & 0.52 \\
\hline Clay (\%) & -0.22 & -0.32 & 0.03 \\
\hline Silt (\%) & $\mathbf{0 . 8 6}$ & $\mathbf{0 . 8 8}$ & $\mathbf{0 . 5 9}$ \\
\hline
\end{tabular}

Moisture content, organic content, and percent silt were selected to perform CCA analysis as these abiotic factors showed the maximum variation influencing microbial composition. The CCA analyses can indicate a correlation between the abiotic factors to the biotic distributions. The site distribution (the different symbols) plotted are representative of the OTU gene abundances present at that site, whereas the added abiotic vectors showed the factors that may influence those distributions. The longer the vector 
line, the more influence that factor may have on the biotic distributions. The percent on CCA axis is the percent contribution of each axis to the distribution of the constraint variable (abiotic factors). For example, the CCA plot for bacteria (Figure 4a) indicate that organic matter, moisture, and percent silt (high to low values) correlated positively with axis 1 meaning that abundance of bacterial taxa in SS4 correlates to high values of the abiotic factors organic matter, moisture content, and percent silt. The abiotic factor silt content showed highest correlation to SS2 followed by moisture content and organic matter. The sample SS1 depicts negative correlation with respect to axis 1 and suggests bacterial abundance in SS1 corresponds to low moisture, percent silt, and organic matter (Figure 4a) whereas sample SS3 depicted intermediate influence of abiotic factors and clustered closely to SS2 and SS4. The grouping of SS3 relatively closer to SS2 and SS4 compared to SS1 could be a result of influence from grassy vegetation in combination with other properties regulated by plant communities (Figure 4a). For fungal OTUs, the site SS4 demonstrated a higher correlation to organic content, followed by, moisture content, and percent silt. However, SS1 and SS3 clustered closer on the basis of fungal OTUs away from the vector lines of abiotic parameters showing negative correlations (Figure 4b) of the abiotic factors on fungal cellulolytic OTUs in samples SS1 and SS3. 


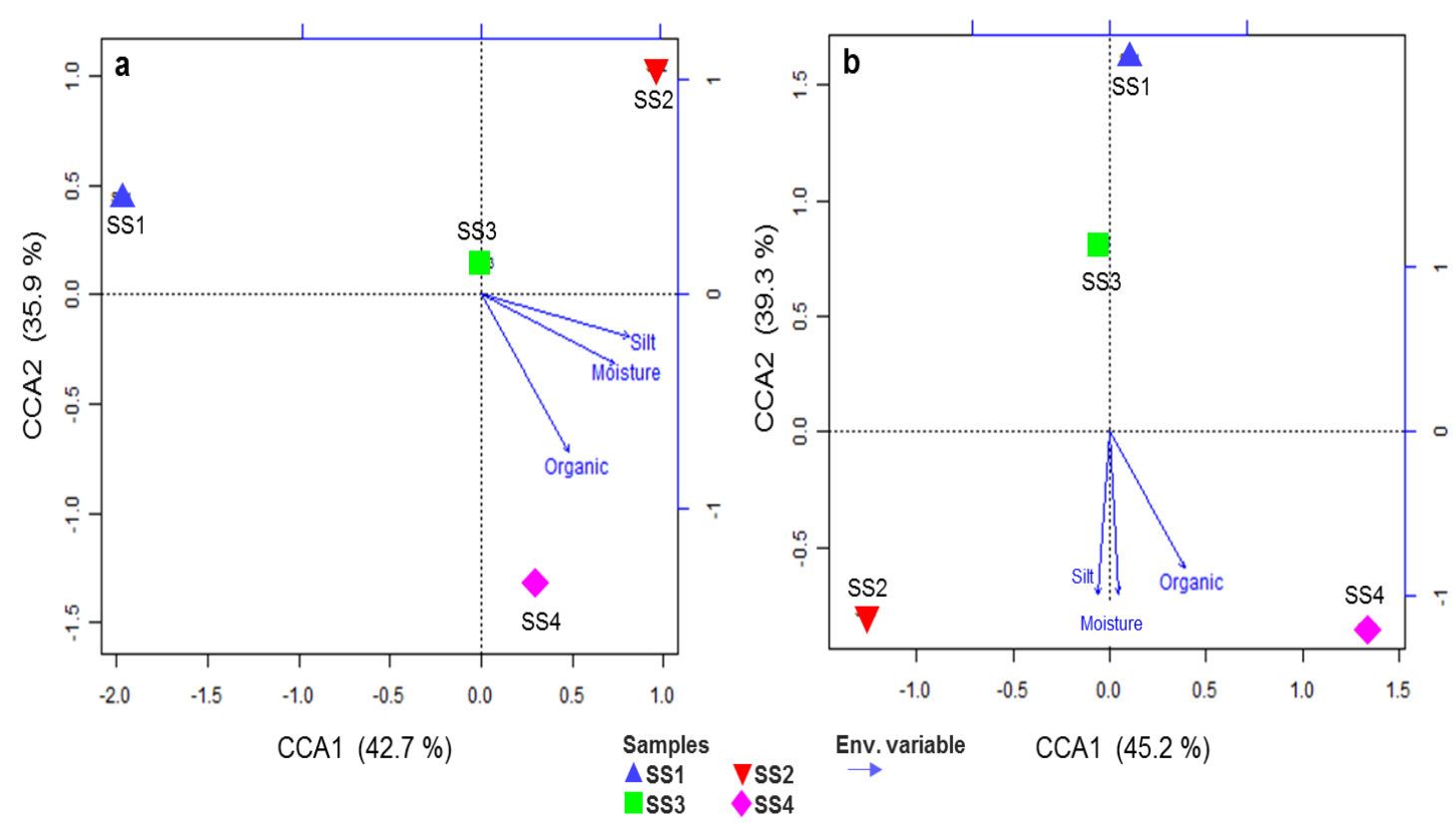

Figure 4: CCA for cellulolytic community gene abundance across Miami-Dade County sampling sites using soil factors.

The soil factors used were as soil moisture, organic content, and percent silt. Panel a and b represent bacterial and fungal OTUs, respectively. The samples SS2 and SS4 were positively correlated with the abiotic factors and percent constraint of the abiotic factors was $42.7 \%$ and $45.2 \%$ for bacterial and fungal OTUs, respectively. The samples SS1 and SS3 were the sites that were negatively influenced by all the three abiotic factors.

\subsection{Discussion}

The role of vegetation type or individual plant species in shaping the microbial communities has been demonstrated across various ecosystems (Hawkes et al. 2005; Wallenstein et al. 2007; Millard and Singh 2010). Considering cellulose is an important component of plant material, its breakdown is the one of the primary steps in the carbon cycle, and plays a significant role in the carbon sequestration and mineralization within ecosystems. Cellulose degradation is more widely distributed in fungal species than cellulolytic bacterial groups (Lynd et al. 2002). However in the current study, distribution of bacterial as well as fungal OTUs were similar across three soil types (SS2, SS3, and SS4) as depicted by the ordination plots. The relative proportion of cellulolytic fungal 
OTUs was lower than bacterial OTUs and the fungal taxonomic lineages belonged only to Ascomycota and Basidomycota. This is a limitation of the design of the microarray and the complete representation of the fungal OTUs known to co-inhabit with forest trees and grasses was not possible in a fixed, closed system like the microarray.

While a microarray by design may not be as completely inclusive as community shotgun metagenomics, it is a very comprehensive method that reflects the diversity and differences between samples. It provides not only taxonomic information but functional capacity on the basis of the gene probes represented on the arrays that can be associated directly with a gene's function versus a hypothetical, often vague association with unknown functions sometimes seen in metagenomic assays. The microarrays provide information on community functional redundancy as well as habitat differences as it detects Archaea, bacteria, fungi, viruses, protists, and other members of the soil food web (Zhou et al. 2015). Given that there are no 'universal primers' available for most functional genes, the arrays provide a valuable snapshot of the functional capacity of a soil community. It is, however, important that these microarrays are updated frequently.

On the basis of positives probes detected for cellulolytic OTUs, an important finding of the study was the differences in correlation of the bacterial and fungal cellulase gene abundances with the abiotic factors. According to CCA plot, bacterial OTUs in SS2, SS3, and SS4 grouped with respect to their vegetation type (marsh/mixed grasses) and positively correlated with percent silt, moisture, and organic matter for SS2 and SS4. Conversely, fungal OTUs in SS2 and SS4 positively correlated with percent silt, soil moisture, and organic content and SS1 and SS3 were negatively correlated with the soil physicochemical properties. The negative correlation of moisture content with SS1 and 
SS3 for fungal OTUs is not surprising as majority of the cellulolytic fungi are aerobic (Magan 2007), whereas many cellulolytic bacteria are facultative or obligate anaerobes and thrive in waterlogged soils_-SS2 and SS4 (Lynd et al. 2002).

In this study, the wooded sites had fewer soil fungi despite being dry, aerobic sites. Although many fungi are associated with the mycorrhiza of woody plants, much of the bulky plant material and roots were removed during sample preparation. Conversely, soilassociated fungal diversity was surprisingly high in the inundated sites (SS2 and SS4). Recently, Wu and colleagues (2015) demonstrated higher abundance of cellulolytic fungal community in peat soils with high soil water levels versus sandy soils. This observation could be a result of presence of fungal spores in the water-logged soils (Shearer 1993) in order to counteract the flooded conditions since fungi are known to require oxygenated soils to survive (Mosse et al. 1981) or transfer of fungal spores into flooded soils from terrestrial habitats (Wong et al. 1998).

In Miami-Dade County soils, both the cellulolytic bacterial and fungal communities were influenced by soil texture particularly related to the percent silt $\left(R^{2}=0.66, p<0.05\right)$. Finely textured soils favor microbial growth as they provide more surface area, waterholding capacity, and nutrient availability (Johnson et al. 2003; Dequiedt et al. 2011). In a study by Johnson et al. (2003), bacterial DNA fingerprints significantly correlated with soil texture across agricultural soils. Furthermore, Dequiedt et al. (2011) described a strong influence of soil texture on spatial bacterial composition as a property of land cover, soil management, and soil parental material. Vries and colleagues (2012) were the first one to document increased fungal biomass in association with higher organic matter and soil silt content across a range of English grasslands. 
Other studies have reported higher microbial biomass with increase in soil organic content (Fierer et al. 2009) and the influence of quantity and quality of soil organic content on composition of bacterial community (Millard and Singh 2010). The influence of organic matter on cellulolytic guilds was evident in Miami-Dade soils when SS2 and SS4 were positively correlated to the soil organic content and separated SS2 and SS4 (marsh/saw grasses) from the other sites. This suggested the 'quality' or tissue type of plant input into the system could influence the cellulolytic community members. For example, grasses are largely composed of cellulose versus the mixture of cellulose, lignin, tannins, and other organic substrates associated with woody plant tissue (Liao et al. 2006). This would indicate the quality of the litter influences which enzymes are needed (cellulases or ligninases) for these initial reactions in the carbon cycle.

The bacterial OTUs were more correlated with vegetation/habitat type followed by soil texture, moisture content, and organic content whereas fungal OTUs showed more influence from abiotic factors. Thus, the overall differences in species distribution across the four soil types were attributed to the abiotic factors contrary to the hypothesis that soils with mixed vegetation of woody trees would show higher abundance of cellulolytic assemblages. Drainage of saturated soils for agricultural expansion can cause a shift to aerobic cellulolytic guilds and accelerate carbon degradation resulting in soil carbon loss over time. Furthermore, agricultural practices can physically disrupt fungal hyphae and fungal abundances drop as crops are harvested each year, removing carbon that normally would be stored as plant root mass and used by fungi as a starting substrate (Broeckling et al. 2008). On the other hand, inundation of dry soils as a result of climatic changes such as sea level rise or heavy rainfall will shift the microbial composition to anaerobic guilds 
and decrease the rate of soil organic matter decomposition. According to Allison and Martiny (2008), microbial composition can continue to provide the same ecosystem services under disturbances if they are resistance, resilient, or functionally redundant. Since the diversity of cellulolytic community in dry as well as saturated Miami-Dade County soils was distributed across a wide range of taxonomic assemblages, the cellulolytic composition would be considered functionally redundant. Therefore, alterations in the cellulolytic community as a result of natural and anthropogenic perturbations should not lead to overall ecosystem function loss as depicted by Allison and Martiny's (2008) model. However, the rates of carbon decomposition and deposition could vary greatly in changing oxic and anoxic habitats that would result in overall shifts in the microbial assemblages and diversity.

\subsection{References}

Aerts, R. (1997). Climate, leaf litter chemistry and leaf litter decomposition in terrestrial ecosystems: A triangular relationship. Oikos, 439-449.

Allison, S. D., \& Martiny, J. B. (2008). Resistance, resilience, and redundancy in microbial communities. Proceedings of the National Academy of Sciences, 105 (Supplement 1), 11512-11519.

Allison, S. D., Lu, Y., Weihe, C., Goulden, M. L., Martiny, A. C., Treseder, K. K., \& Martiny, J. B. (2013). Microbial abundance and composition influence litter decomposition response to environmental change. Ecology, 94(3), 714-725.

Amundson, R. (2001). The carbon budget in soils. Annual Review of Earth and Planetary Sciences, 29(1), 535-562.

Anderson, M. J. (2001). A new method for non-parametric multivariate analysis of variance. Austral Ecology, 26(1), 32-46.

Bardgett, R. D., Bowman, W. D., Kaufmann, R., \& Schmidt, S. K. (2005). A temporal approach to linking aboveground and belowground ecology. Trends in Ecology \& Evolution, 20(11), 634-641. 
Berlemont, R., \& Martiny, A. C. (2013). Phylogenetic distribution of potential cellulases in bacteria. Applied and Environmental Microbiology, 79(5), 1545-1554.

Berlemont, R., Allison, S. D., Weihe, C., Lu, Y., Brodie, E. L., Martiny, J. B., \& Martiny, A. C. (2014). Cellulolytic potential under environmental changes in microbial communities from grassland litter. Frontiers in Microbiology, 5, 639.

Broeckling, C. D., Broz, A. K., Bergelson, J., Manter, D. K., \& Vivanco, J. M. (2008). Root exudates regulate soil fungal community composition and diversity. Applied and Environmental Microbiology, 74(3), 738-744.

Cebrian, J. (1999). Patterns in the fate of production in plant communities. The American Naturalist, 154(4), 449-468.

Clarke, K. R., Gorley, R. N. (2015). PRIMER v7: User Manual/Tutorial. PRIMER-E, Plymouth, 296.

Cornwell, W. K., Cornelissen, J. H., Amatangelo, K., Dorrepaal, E., Eviner, V. T., Godoy, O., Hobbie, S.E., Hoorens, B., Kurokawa, H., Pérez-Harguindeguy, N., \& Quested, H. M. (2008). Plant species traits are the predominant control on litter decomposition rates within biomes worldwide. Ecology Letters, 11(10), 10651071.

Dequiedt, S., Saby, N., Lelievre, M., Jolivet, C., Thioulouse, J., Toutain, B., Arrouays, D., Bispo, A., Lemanceau, P., \& Ranjard, L. (2011). Biogeographical patterns of soil molecular microbial biomass as influenced by soil characteristics and management. Global Ecology and Biogeography, 20(4), 641-652.

Fengel, D., \& Wegener, G. (1983). Wood: Chemistry, ultrastructure, reactions Walter de Gruyter.

Fierer, N., Strickland, M. S., Liptzin, D., Bradford, M. A., \& Cleveland, C. C. (2009). Global patterns in belowground communities. Ecology Letters, 12(11), 1238-1249.

Hawkes, C. V., Wren, I. F., Herman, D. J., \& Firestone, M. K. (2005). Plant invasion alters nitrogen cycling by modifying the soil nitrifying community. Ecology Letters, 8(9), 976-985.

Jobbágy, E. G., \& Jackson, R. B. (2000). The vertical distribution of soil organic carbon and its relation to climate and vegetation. Ecological Applications, 10(2), 423-436.

Joergensen, R. G., \& Wichern, F. (2008). Quantitative assessment of the fungal contribution to microbial tissue in soil. Soil Biology and Biochemistry, 40(12), 2977-2991. 
Johnson, M., Lee, K., \& Scow, K. (2003). DNA fingerprinting reveals links among agricultural crops, soil properties, and the composition of soil microbial communities. Geoderma, 114(3), 279-303.

Kögel-Knabner, I. (2002). The macromolecular organic composition of plant and microbial residues as inputs to soil organic matter. Soil Biology and Biochemistry, 34(2), 139-162.

Liao, J., Boutton, T., \& Jastrow, J. (2006). Storage and dynamics of carbon and nitrogen in soil physical fractions following woody plant invasion of grassland. Soil Biology and Biochemistry, 38(11), 3184-3196.

Lynd, L. R., Weimer, P. J., van Zyl, W. H., \& Pretorius, I. S. (2002). Microbial cellulose utilization: Fundamentals and biotechnology. Microbiology and Molecular Biology Reviews, 66(3), 506-77.

Magan, N. (2007). Fungi in extreme environments. In The Mycota IV, Environmental and Microbial Relationships. Edited by Kubicek CP, Druzhinina IS. Springer Verlag, 85-103.

Mantel, N. (1967). The detection of disease clustering and a generalized regression approach. Cancer Research, 27(2 Part 1), 209-220.

Melillo, J. M., Aber, J. D., \& Muratore, J. F. (1982). Nitrogen and lignin control of hardwood leaf litter decomposition dynamics. Ecology, 63(3), 621-626.

Millard, P., \& Singh, B. (2010). Does grassland vegetation drive soil microbial diversity? Nutrient Cycling in Agroecosystems, 88(2), 147-158.

Mills, D. K., Fitzgerald, K., Litchfield, C. D., \& Gillevet, P. M. (2003). A comparison of DNA profiling techniques for monitoring nutrient impact on microbial community composition during bioremediation of petroleum-contaminated soils. Journal of Microbiological Methods, 54(1), 57-74.

Mosse B, Stribley D, Le Tacon F (1981) Ecology of mycorrhizas and mycorrhizal fungi. In: Alexander M (ed) Advances in Microbial Ecology. Plenun Press, New York, pp 137-210.

Nobel, C., Drew, R., \& Slabaugh, J. (1996). Soil survey of Dade County area Florida. USDA. Natural Resources Conservation Service, Washington, DC.

Schulze, E. (2006). Biological control of the terrestrial carbon sink. Biogeosciences, 3(2), 147-166.

Shearer, C. A. (1993). The freshwater ascomycetes. Nova Hedwigia, 56(1), 33. 
Soil Survey Staff, Natural Resources Conservation Service, United States Department of Agriculture Web Soil Survey. Available online at http://websoilsurvey.nrcs.usda.gov/ Accessed [11/26/2012].

Štursová, M., Žifčáková, L., Leigh, M. B., Burgess, R., \& Baldrian, P. (2012). Cellulose utilization in forest litter and soil: identification of bacterial and fungal decomposers. FEMS Microbiology Ecology, 80(3), 735-746.

Sun, Y., \& Cheng, J. (2002). Hydrolysis of lignocellulosic materials for ethanol production: A review. Bioresource Technology, 83(1), 1-11.

Vries, F. T., Manning, P., Tallowin, J. R., Mortimer, S. R., Pilgrim, E. S., Harrison, K. A., Hobbs, P.J., Quirk, H., Shipley, B., Cornelissen, J.H., \& Kattge, J. (2012). Abiotic drivers and plant traits explain landscape-scale patterns in soil microbial communities. Ecology Letters, 15(11), 1230-1239.

Wallenstein, M. D., McMahon, S., \& Schimel, J. (2007). Bacterial and fungal community structure in Arctic tundra tussock and shrub soils. FEMS Microbiology Ecology, 59(2), 428-435.

Wang, J., Cao, P., Hu, H., Li, J., Han, L., Zhang, L., Zheng, Y.M., \& He, J. (2015). Altitudinal distribution patterns of soil bacterial and archaeal communities along Mt. Shegyla on the Tibetan Plateau. Microbial Ecology, 69(1), 135-145.

Wong, M. K., Goh, T. K., Hodgkiss, I. J., Hyde, K. D., Ranghoo, V. M., Tsui, C. K., Ho, W.H., Wong, W.S., \& Yuen, T. K. (1998). Role of fungi in freshwater ecosystems. Biodiversity \& Conservation, 7(9), 1187-1206.

Wu, L., Liu, X., Schadt, C. W., \& Zhou, J. (2006). Microarray-based analysis of subnanogram quantities of microbial community DNAs by using wholecommunity genome amplification. Applied and Environmental Microbiology, 72(7), 4931-4941.

Wu, L. S., Feng, S., Nie, Y. Y., Zhou, J. H., Yang, Z. R., \& Zhang, J. (2015). Soil cellulase activity and fungal community responses to wetland degradation in the Zoige Plateau, China. Journal of Mountain Science, 12(2), 471-482.

Xiong, J., Wu, L., Tu, S., Van Nostrand, J. D., He, Z., Zhou, J., \& Wang, G. (2010). Microbial communities and functional genes associated with soil arsenic contamination and the rhizosphere of the arsenic-hyperaccumulating plant Pteris vittata L. Applied and Environmental Microbiology, 76(21), 7277-7284.

Zhang, Y., Ling, J., Yang, Q., Wen, C., Yan, Q., Sun, H., Van Nostrand, J.D., Shi, Z., Zhou, J., \& Dong, J. (2015). The functional gene composition and metabolic potential of coral-associated microbial communities. Scientific Reports, 5, 16191. 
Zhou, J., He, Z., Yang, Y., Deng, Y., Tringe, S. G., \& Alvarez-Cohen, L. (2015). Highthroughput metagenomic technologies for complex microbial community analysis: open and closed formats. mBio, 6(1), e02288-14. 


\section{CHAPTER 3}

\section{METHANOGENS WITHIN THE SAWGRASS COMMUNITIES OF THE EVERGLADES AND BISCAYNE BAY WATERSHEDS}

This chapter has been published:

Kushwaha P, Zayas J, Oliva Y, Mendoza M, \& Mills D. Methanogens within the Sawgrass Communities of the Everglades and Biscayne Bay Watersheds. Microbiology of the Everglades Ecosystem. 2015 Mar 26:386.

\subsection{Introduction}

Over $10^{9}$ bacteria cells can be detected in a single gram of soil (Travers et al. 1987). This phenomenal abundance and biodiversity presents challenges to understanding soil microbial community structure and function, as the majority of environmental microbes cannot be cultured in the laboratory (Torsvik et al. 1990). Microbial metagenomics, the isolation of whole genomic DNA and subsequent clone library screening (Handelsman et al. 1998), and next-generation sequencing technologies (Sundquist et al. 2007) are current methods used by ecologists to establish differences between microbial communities (Daniel 2005, Kakirde et al. 2010) in a culture-independent manner. When microbial metagenomic analyses are applied to a soil sample, it can produce a unique and total genomic fingerprint that can be used to assess diversity as well as discern community dynamics and ecological interrelationships within the environment (Osborn et al. 2000, Horswell et al. 2002).

\subsection{Function versus structural biodiversity of microbial communities}

Although prokaryotic diversity limits are still unknown, microbial ecologists struggle with how to even define a prokaryotic species. Most prokaryotes cannot be 
cultured or studied as individual species. Currently, culture-independent methods define species-level taxa as operational taxonomic units (OTUs) based on full-length 16S rRNA gene sequences ( $\approx 1,500 \mathrm{bp}$ ). If OTUs of a queried sample share $\geq 97 \%$ sequence homology with known species, based on public databases such as GenBank, the two are considered

to be the same species (Stackebrandt and Goebel 1994, Stackebrandt and Ebers 2006). Herein lies the weakness of $16 \mathrm{~S}$ classification schemes. The ability to classify an unknown phylotype as a particular species based on $16 \mathrm{~S}$ gene sequences is only as informative as the known species in the database. In other words, novel uncultured microbial species (bacteria or Archaea) with few or no related sequences archived in the database are often misclassified using only 16S rRNA sequences (Fox et al. 1992). It is also possible that $16 \mathrm{~S}$ rRNA gene identification does not adequately reflect the inherent functional phenotype found in bacteria or archaea classified as the same species (Robinson et al. 2010). For example, Robinson et al. noted that Escherichia coli strains collected from various different environments were taxonomically identical (using the 16S rRNA, 99\% similarity) but had very different functional capabilities, ranging from pathogenic to commensal. Although it is important to characterize soil microbial community assemblages, given the variation within and among species it is ecologically important to understand the functional complexity of species and communities to sustain soil ecosystems and the ecosystem services they provide.

\subsection{Carbon cycling}

Microbes are important decomposers in the global carbon cycle. The breakdown of plant material and other detritus (Millard and Singh 2010) by microbes is the first step in supplying both belowground and aboveground communities with the necessary nutrients 
for growth (e.g., C, N, P, K, S). Aboveground vegetation is the major carbon source available and has been found to be one of the forces responsible for belowground microbial diversity (Marschner et al. 2001, Wieland et al. 2001). Cellulose degradation at the beginning of the decomposition cycle and methanogenesis at the end are important biochemical processes in aerobic and anaerobic carbon decomposition, respectively. Important to the anoxic or anaerobic soil ecosystems are methanogens (methane producing archaea) that can reduce the final products of the carbon cycle such as acetate, formate, $\mathrm{CO}_{2}$, methylamines, and methanol to methane. Understanding functional diversity (guilds) provides important information on the critical roles microbes play in biogeochemical cycles and nutrient partitioning within a system that cannot always be ascertained from 16S rRNA data (Torsvik and Øvreås 2002). An understanding of functional diversity of methanogens, therefore, would provide a better understanding of carbon cycle dynamics and methane release to the atmosphere. Subsequently, disruptions of the carbon cycle via anthropogenic perturbations and the global impact of such changes can be assessed.

\subsection{Biochemistry of methane formation}

There are several carbon substrates and pathways that ultimately result in methane production and several of the genes in the terminal steps of the pathways are highly conserved across all methanogens (Bapteste et al. 2005). Methane production from several different substrates is shown below (see Blaut 1994 for an in-depth review of methane biochemistry).

(1) $\mathrm{CO}_{2}+4 \mathrm{H}_{2} \rightarrow \mathrm{CH}_{4}+2 \mathrm{H}_{2} \mathrm{O}$

(2) $4 \mathrm{HCOO}^{-}+4 \mathrm{H}^{+} \rightarrow 3 \mathrm{CO}_{2}+\mathrm{CH}_{4}+2 \mathrm{H}_{2} \mathrm{O}$

(3) $4 \mathrm{CH}_{3} \mathrm{OH} \rightarrow 3 \mathrm{CH}_{4}+\mathrm{CO}_{2}+2 \mathrm{H}_{2} \mathrm{O}$ 
(4) $4\left(\mathrm{CH}_{3}\right)_{3} \mathrm{NH}^{+}+6 \mathrm{H}_{2} \mathrm{O} \rightarrow 9 \mathrm{CH}_{4}+3 \mathrm{CO}_{2}+4 \mathrm{NH}_{4}^{+}$

(5) $\mathrm{CH}_{3} \mathrm{COO}^{-}+\mathrm{H}^{+} \rightarrow \mathrm{CH}_{4}+\mathrm{CO}_{2}$

As methanogens cannot break down complex organic molecules for methane production, they rely on presence of other anaerobes in their habitat to breakdown organic molecules into simple sugars or fatty acids followed by fermentation by syntrophs to produce formate, acetate, hydrogen and carbon dioxide-the major substrates for methanogenesis. In addition, acetogens (acetate-producing bacteria) play an important role in this syntrophic association of methanogens, and thus assimilate hydrogen and formate effectively (Nazaries et al. 2013).

The pathway that is most widely distributed across all orders of methanogens is the seven-step hydrogenotropic pathway. In this pathway, carbon dioxide is used as the substrate that is reduced by a hydrogen molecule that acts as an electron donor (Reeve et al. 1997). Formate can be converted into carbon dioxide and, thus, utilizes the same pathway for methane production. Two other pathways that are involved in methanogenesis are the aceticlastic pathway and the methylotrophic pathway. Acetate is the substrate for the aceticlastic pathway, whereas, methanol and methyl-amines are employed as substrates for methylotropic pathway. Acetate is broken down into methyl and carbon monoxide (CO) in the aceticlastic pathway. The methyl group thus produced is linked to methanopterin before it is reduced to methane in two steps of enzymatic reactions, reactions that are homologous to the last two steps of the hydrogenotropic pathway. In the methylotropic pathway, either the C-1 compounds can be converted to three molecules of carbon dioxide using the reverse hydrogenotropic pathway in order to follow the forward 
pathway to release three molecules of methane. Alternatively, C-1 compounds can be directly reduced to methane following the last step of hydrogenotropic pathway.

These three pathways converge at the last step where methyl-coenzyme $\mathrm{M}$ reductase catalyzes the conversion of methyl-CoM to methane (Bapteste el al. 2005). One enzyme, methyl-coenzyme $M$ reductase, universally conserved, catalyzes the last step in the methanogenic cycle. Therefore, the gene, $\operatorname{mcr}$, that encodes for the alpha subunit is often used to taxonomically classify methanogens (Reeve et al. 1997). This gene is ubiquitous to all methanogens regardless of the carbon substrates utilized earlier in methanogenesis pathways. However, it is not uniform in sequence across taxa (Blaut 1994).

\subsection{The Everglades and Biscayne Bay Watersheds}

The greater Florida Everglades Watershed is a unique freshwater marsh ecosystem that begins with the northern border at the Kissimmee River where the flow of water moves south toward Florida Bay and the Gulf of Mexico (Galloway et al. 1999). It is the largest freshwater marsh ecosystem in the North America. This flow-dependent, low-nutrient ecosystem has been greatly impacted by agricultural nutrient inputs, principally phosphorus, and extensive water management that has disrupted the natural water flow (Davis et al. 1994, Sklar et al. 2005, McVoy et al. 2011). In addition, rainfall during Florida's wet season acts as the main source of freshwater input into the Everglades ecosystem where many soil microhabitats remain saturated or soil moisture remains high year round. This chronic, elevated soil moisture maintains an anoxic habitat for functional guilds such as the methanogenic archaea. The ability to convert carbon compounds from, for example, hydrogen and $\mathrm{CO}_{2}$, to methane are contained within the unique enzyme 
(methyl-coenzyme $\mathrm{M}$ reductase) found exclusively, to date, in methanogens (Ermler et al. 1997).

Because of the immediate and long-term effects humans have on this unique ecosystem, the largest restoration effort in US history is underway (WRDA 2000) to try to mitigate the problems associated with excess nutrient inputs that phosphorus and drainage canals have had on the ecosystem. Although the visible shift from sawgrass-dominated prairies to cattail plant communities is easily noted at impacted sites (Hagerthy et al. 2008), less is known about the belowground impact on the microbes responsible for carbon cycling in the system.

\subsection{Effects of phosphorus on methanogenesis}

There have been several studies that looked at the impact that excess nutrients have on the Everglades microbial communities (Pennanen et al. 1998, Bell et al. 2009) and specifically, the methanogens. Castro and colleagues (2004) studied the agricultural phosphorus runoff into the Everglades and the impact it had on the microbial community structure and function. The above ground plant biomass shifted from Cladium sawgrass dominating the wetland plains to dense cattail plant communities in the eutrophic areas of Water Conservation Area 2A (WCA-2A). This, in turn, changed the amount and type of carbon input into the system via detritus and root exudates and increased the organic content of the soils. These trophic shifts caused a dramatic change in the belowground biogeochemical cycling. Overall microbial activity increased as well as sulfate reduction rates and methanogenesis. By looking not only at the $16 \mathrm{~S}$ rRNA phylogenetic marker but also the methyl-coenzyme $\mathrm{M}$ reductase, alpha subunit gene ( $m c r A$ )--the functional marker - the studies could assess the nutrient impact on the terminal step of carbon cycling. 
Compared to oligotrophic control sites, methane production in the eutrophic zones increased dramatically. There was also an increase in the biodiversity of methanogens in the eutrophic zone compared to the oligotrophic sites. They also found the $16 \mathrm{~S}$ clone libraries were more diverse than that of the functional libraries, not surprisingly so, since methanogenesis is limited to a few specialized archaeal clades. Looking at the $m c r A$ clone libraries, they observed an obvious shift in the dominant clades and some minor clades both across the nutrient gradients and to a lesser extent, during seasons. This suggested that the nutrient pollution was affecting both the structure and the activity in the methanogenic community. Eutrophic soil was dominated by clusters related to the Methanomicrobiales (clusters MRC-5, 6, 7) and a summer appearance (rainy season) of clusters aligned with Methanobacteriales, Methanosaeta and one unknown cluster that did not align with any archived sequences. There was also a change in the dominant phylotypes as well as the appearance and disappearance of other minor clades. Shannon's diversity indices showed a decrease in diversity between the eutrophic and the oligotrophic site but little change within the sites based on season (Castro et al. 2004).

\subsection{Effects of cellulose degradation on methanogenesis}

In another study at the same Everglades sites as the Castro 2004 study, Uz and Ogram (2006) looked at the cellulose degrading communities, specifically Clostridium spp. and set up soil microcosms from the eutrophic, transitional and oligotrophic sites. Sulfate reducers and methanogens depend on fermentation products and those populations were greater in number in the eutrophic and transitional zones versus the oligotrophic sites. They found the functional guilds of sulfate reducers and hydrogen-scavenging methanogens were significantly affected by the nutrient status of the soils versus the plant type or residue. 
Plant type did not seem to have an effect on the cellulolytic clostridia populations but did seem to influence the fermentation guilds and syntrophs responsible for the $\mathrm{C}-1$ substrates needed for methanogenesis (Uz and Ogram 2006).

Therefore, enhanced knowledge of the carbon cycle and the functional guilds responsible for the carbon cycling can be very useful for understanding anthropogenic impact on the Everglades ecosystem. In addition to understanding impacts after the fact, important base line data on the functional guilds should also be gathered so as to better understand the consequences of any remediation strategy to return the impacted lands back to their "natural" state (Lovley 2003).

\subsection{Restoration effects on methanogen communities}

Phosphorus reductions and restored hydrology efforts in the Everglades are ongoing and will have important implications for soil microbial community structure and processing of carbon. It is therefore important to monitor the changes to the belowground communities that are so integral to the overall recovery, resilience and health of this ecosystem. As hydrology is restored, it becomes even more critical to monitor the baseline functional capabilities of methanogens in both restored and impacted areas of the Everglades. In addition, physical impoundment by canal levies has created anaerobic habitats that are now flooded year-round. Removal of these levies will dramatically change both aboveground plant community and belowground microbial populations. With reduction in phosphorous, hydrological changes, and removal of levies, nutrient flow through the system can impact plant communities and thus, the carbon input into the system. This in turn can affect the rates of microbial metabolism and the pathways used, 
their ability (or lack of ability) to adapt to the disturbance and the changing pool of carbon available in the restored Everglades.

Shifts in plant type and the resulting detritus (Millard and Singh 2010) will drive changes in microbial community functional diversity, available electron acceptors, carbon biotransformations and ultimately, shifts in the metabolic products and substrates available to the methanogenic communities. Shifts along a nutrient gradient in the northern Everglades (Chauhan and Ogram 2006) were dominated by the aceticlastic methanogens in the eutrophic habitat and changed to a more hydrogenotrophic dominated communities in the oligotrophic zones. Therefore, the substrates used for methane production changed with the plant and nutrient levels. Smith et al. (2007) followed the recovery (and subsequent decline of some methanogen functional groups) of Hole-in-the-Donut site within the Everglades after eradication efforts removed invasive plants. Using cultureindependent gene analyses of the methyl coenzyme $\mathrm{M}$ reductase genes $(\mathrm{mcr} A)$ and clone libraries, they showed a dominance of the hydrogenotrophic methanogens of the orders Methanobacteriales and Methanococcales and decline in the relative abundance of Methanobacteriales $m c r A$ genes that were correlated with the recovery time of the site. These limited studies indicate a growing need to more clearly understand the intrinsic functional ecology of the Everglades microbes driving essential biogeochemical cycles (Smith et al. 2007).

\subsection{Current ongoing study}

Functional ecology studies of the Miami-Dade County soils in the Everglades and Biscayne watersheds-soils that will be impacted by changes in hydrology from the restoration effort- are ongoing within our research group. The diversity of methanogens 
is of interest to our group as part of a larger soil ecological study. Based on the hypothesis that soil type structures the microbial community that occupies a soil (Bossio et al. 1998, Fierer and Jackson 2006), the question can be asked, does it also drive the functional diversity within the soil or is function redundant within structure?

In order to assess this question, two different soil types (with similar above ground habitats), Lauderhill Dania-Pahokee (listed as soil type 2, transect, KNT in this study) and Perrine -Biscayne-Pennsuco (soil type 4, transect, CS), in Miami-Dade County, Florida (Figure 5), were compared using the $m c r A$ clone libraries and sequencing. The soil samples were collected in 2010. The objective of this particular study was to assess the methylcoenzyme M reductase $(\mathrm{mcr} A)$ gene diversity in two different parent soil types with similar habitats-saturated and dominated by marsh grasses. As the terminal step in methanogenesis is catalyzed by the highly conserved methyl-coenzyme M reductase, the null hypothesis would be that no differences in the $m c r A$ gene diversity and its taxonomic associations would be seen, regardless of soil type.

BLAST analyses and subsequent sequence alignment and phylogenetic tree construction were performed (Figure 6) on mcrA clone library. The neighbor joining consensus tree was derived from mcrA DNA sequences aligned using MUSCLE within Mega 5.0 software (http://www.megasoftware.net/) and bootstrap values from 1000 iterations are shown. 


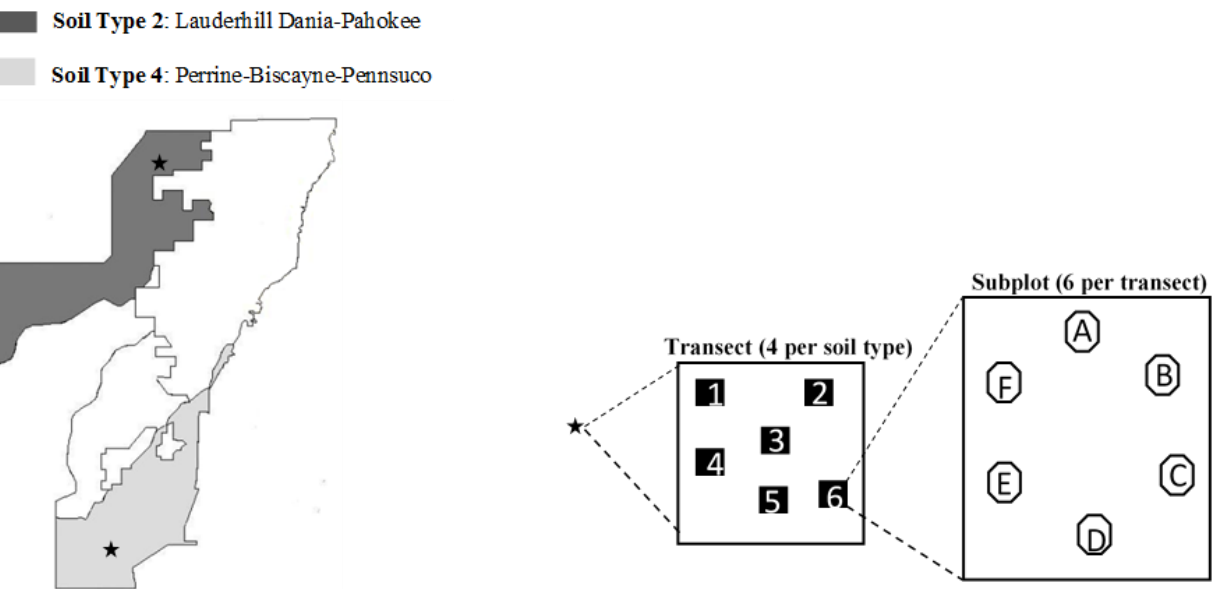

Figure 5: A schematic map of the two soil types in Miami-Dade, County, Florida. Stars indicate the sampling sites and the blown up schematic, the sampling scheme.

The tree used aligned sequences from this current study, two other previously discussed Florida Everglades studies (Castro et al. 2004, Smith et al. 2007, shown in the tree as the DQ and AY sequences), other uncultured methanogens and sequences of six reference methanogens from archival databases.

\subsubsection{Dominance of unknown $m c r A$ sequences in the Florida Everglades soils}

Methanogens are classified into five orders: Methanococcales, Methanopyrales, Methanobacteriales, Methanomicrobiales, and Methanosarcinales. All the five orders are identified as having hydrogenotropic pathway. However, aceticlastic and methylotropic pathways are restricted to Methanosarcinales. On the basis of Bergey's taxonomy, methanogens are grouped into two classes: 1) Methanopyrales, Methanobacteriales, and Methanococcales; and 2) Methanosarcinales, and Methanomicrobiales (Garitty 2001). 


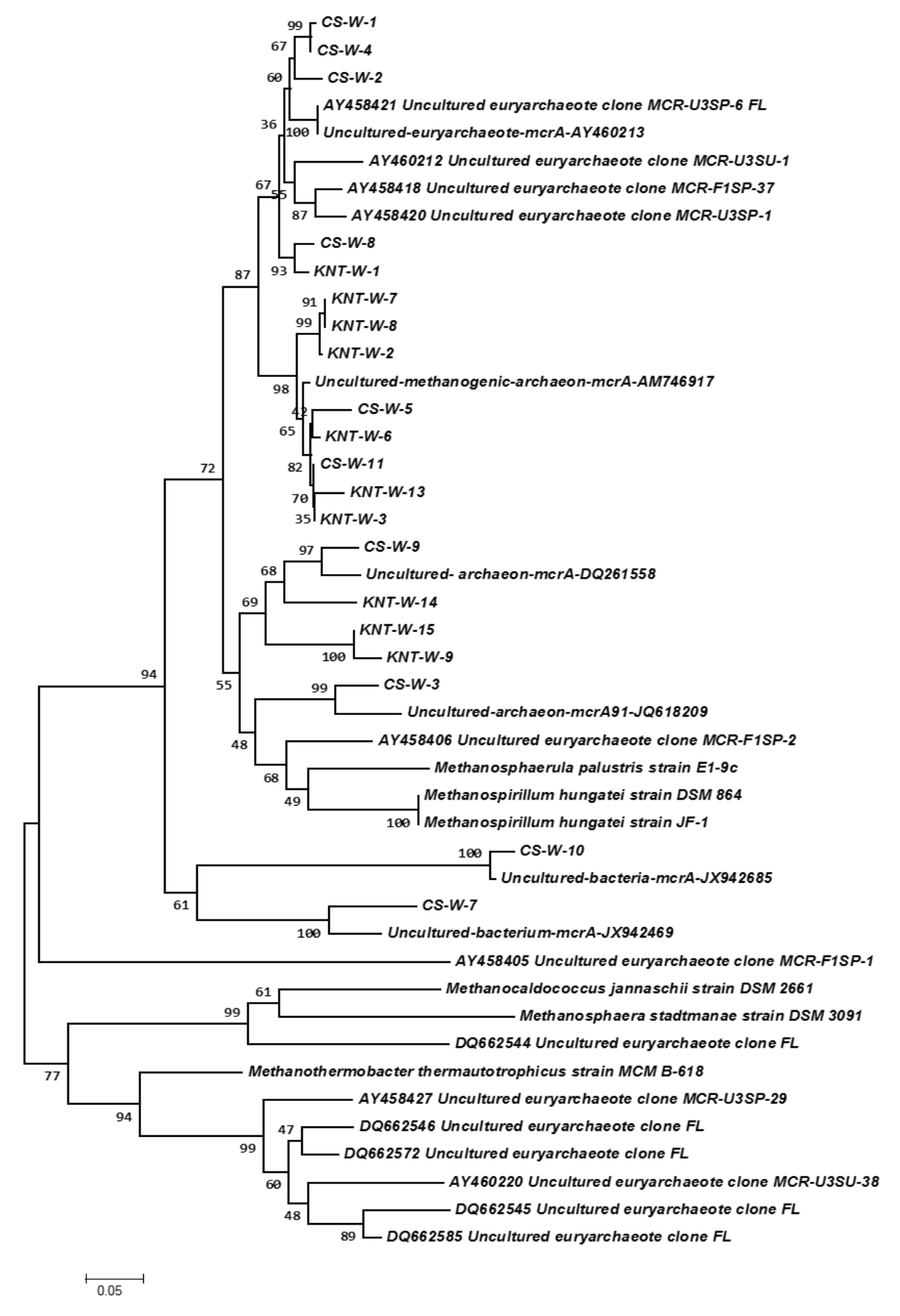

Figure 6: BLAST analyses and subsequent sequence alignment and phylogenetic tree construction were derived from mcrA DNA sequences and were then aligned with MUSCLE.

The Neighbor Joining, linearized tree used aligned sequences from the current study, two other Florida Everglades studies (DQ and AY sequences), other uncultured methanogens and sequences of six reference methanogens. 
To date few studies (Castro et al. 2004, Castro et al. 2005, Smith et al. 2007) have assessed functional genes in methanogens in the Everglades, perhaps because of the limitations in growing the archaeal species using traditional culturing methods.

In the current study, there were two major clades that associated with known reference sequences (Figure 6). Some of the sequences from the other Florida studies (labeled with AY or DQ in the tree) more closely aligned with Methanothermobacter thermautotrophicus but yet many were not associated with any known reference samples. The KNT and CS labeled sequences from our study associated almost exclusively with either uncultured archaea or with the uncultured euryarchaeote from oligotrophic soils in the northern Everglades. While some of the clones from the two soil types examined in Miami-Dade County grouped together with a particular soil type, there was overlap in the clones from the different soil types.

\subsection{Discussion and conclusions}

There are substantial amounts of data supporting the claim that microbial community structure is driven by soil type (Bossio et al. 1998, Dunbar et al. 2000, Marschner et al. 2001). However, evidence is lacking as to whether methanogenesis is also driven by soil type alone or is influenced more by habitat-selective factors. Many of the sequences derived from this study and others (Smith et al. 2007) are from unknown phylotypes and demonstrated the unknown biodiversity of $m c r A$ genes in the Everglades and Biscayne watersheds. Results from these studies do not clearly define soil as the only determinant of phenotypic diversity. Many of the $m c r A$ sequences did cluster more closely with one soil type, but not exclusively. There is a clear lack of knowledge about these critical guilds and their functions in any wetland soils, as seen by the many novel gene 
sequences not associated with any known $m c r A$ sequences in the database. In the case of methanogenensis, the dominant anaerobic habitat conditions may more heavily influence the functional guilds than the soil's chemical and abiotic drivers.

In the studies conducted by Castro et al. (2004) and Uz and Orgam (2006), nutrient pollution in form of phosphorous coupled with hydrological alteration, influenced the $m c r A$ gene diversity with shifts in the dominant sequences. In the presence of excess nutrients, nutrient limitations within microbial communities are lifted, and competitive exclusion is no longer a driver. What these changes mean in terms of ecosystem function is unknown. Will restored hydrology alone 'restore' the functional integrity of soil methanogens in the Everglades soil? Are the phosphorus legacies going to continue to affect the carbon cycling in these soils? Does functional gene diversity infer different levels of enzymatic efficiency? Or is the diversity representative of a long evolutionary history of this ancient process? It is essential to find answers to any long term effect that the phosphorous pollution and subsequent change in hydrology may have on carbon cycling in the Everglades soil and devise a method to use methanogen diversity to monitor these changes.

These cumulative results are indicative of how little is still known about the evolutionary affiliation of microbes driving such critical biochemical functions as methanogenesis. The limitation of assessing only the $16 \mathrm{~S}$ rDNA composition of the community is that metabolic capacity and function are often inferred from known phylotypes and yet, many of the $m c r A$ gene sequences from this study and others had no known phylogenetic affiliation in the databases. To date, a handful of genomes from culturable methanogens have been sequenced (Liu and Whitman 2008) but as studies are 
finding out, these genomes do not capture the overall functional gene diversity ( $m c r A$ ) of the methanogens in soils (Grosskopf et al. 1998).

Knowledge about the functional capabilities and diversity of these critical methanogen guilds could provide vital information with regards to the recovery effort of the Everglades. Therefore, it may be more informative to screen for functional guilds and genes rather than structural genes in order to understand the true restoration impact on ecosystem services. Understanding the baseline functional ecology of currently undisturbed sites within the Everglades restoration areas will allow for better assessment of the overall impact, recovery and resilience of the belowground microbial communities-communities that are so critical to the health of the ecosystem (i.e., the interdependency of the syntrophic bacteria that supply the hydrogen substrates for methanogenesis) (Walker et al. 2012).

The global carbon cycle is solely dependent on microbes. Microbial communities participate in the carbon cycle by either fixing carbon from the atmosphere or supplementing plant growth, or degrading organic materials in the environment. Responsibility of releasing carbon as a greenhouse gas solely lies in the functional capacity of microbes and the establishment a balanced ecosystem. Clean water, healthy soils and suppression of diseases are all benefits of healthy soil systems.

The microbiology of the Everglades should be at the core of the Everglades health assessment and more studies are needed to better protect and understand this vast 'river of grass' and its contribution to South Florida's sustainability into the future. To better understand the sustainability, resilience and future impact of climate change, rising sea levels and most importantly, ecosystem services conferred by these microbes, infers 
functional gene ecology has to become an important facet in microbial community studies.

Perhaps it may even be more important than which microbes are present as genetic function links directly to carbon sequestration, methane and other green house emissions and can quickly signal how natural and anthropogenic disturbances impact these crucial ecosystem services (Nazaries et al. 2013). The Everglades is one of the largest wetlands in the North America and deserves protection for generations to come.

\subsection{References}

Bapteste, E., C. Brochier and Y. Boucher. 2005. Higher-level classification of the Archaea: evolution of methanogenesis and methanogens. Archaea 1: 353-363.

Bell, C., V. Acosta-Martinez, N.E. McIntyre, S. Cox, D.T. Tissue and J.C. Zak. 2009. Linking microbial community structure and function to seasonal differences in soil moisture and temperature in a Chihuahuan desert grassland. Microbial Ecol. 58: 827-842.

Blaut, M. 1994. Metabolism of methanogens. A. van Leeuw. 66: 187-208.

Bossio, D.A., K.M. Scow, N. Gunapala and K.J. Graham. 1998. Determinants of soil microbial communities: Effects of agricultural management, season, and soil type on phospholipid fatty acid profiles. Microbial Ecol. 36: 1-12.

Castro, H., A. Ogram and K.R. Reddy.2004. Phylogenetic characterization of methanogenic assemblages in eutrophic and oligotrophic areas of the Florida Everglades. Appl. Environ. Microbiol. 70: 6559-6568.

Castro, H., S. Newman., K.R. Reddy and A. Ogram. 2005. Distribution and stability of sulfate-reducing prokaryotic and hydrogenotrophic methanogenic assemblages in nutrient-impacted regions of the Florida Everglades. Appl. Environ. Microbiol. 71: 2695-2704.

Chauhan, A. and A. Ogram. 2006. Phylogeny of acetate-utilizing microorganisms in soils along a nutrient gradient in the Florida Everglades. Appl. Environ. Microbiol. 72: 6837-6840.

Daniel, R. 2005. The metagenomics of soil. Nat. Rev. Microbiol 3: 470-478.

Davis, S.M., L.H. Gunderson, W.A. Park, J.R. Richardson and J.E. Mattson. 1994. Landscape dimension, composition, and function in a changing Everglades 
ecosystem, p. 419-444.In S. M. Davis and J. C. Ogden [eds.], Everglades: The ecosystem and its restoration. St. Lucie Press, Delray Beach.

Dunbar, J., L.O. Ticknor and C. R . Kuske. 2000. Assessment of microbial diversity in four southwestern United States soils by $16 \mathrm{~S}$ rRNA gene terminal restriction fragment analysis. Appl. Environ. Microbiol. 66: 2943-2950.

Ermler, U., W. Grabarse, S. Shima, M. Goubeaud and R.K. Thauer. 1997. Crystal structure of methyl-coenzyme $M$ reductase: The key enzyme of biological methane formation. Science 278: 1457-1462.

Fierer, N. and R.B. Jackson. 2006. The diversity and biogeography of soil bacterial communities. Proc. Natl. Acad. Sci. U S A 103: 626-631.

Fox, G.E., J.D. Wisotzkey and P. Jr. Jurtshuk. 1992. How close is close: 16S rRNA sequence identity may not be sufficient to guarantee species identity. Int. J. Syst. Bacteriol. 42: 166-170.

Galloway, D., D.R. Jones and S.E. Ingebritsen. 1999. Land subsidence in the United States. USGS 1182: 95-106.

Garrity, G. 2001. Bergey's manual of systematic bacteriology 721. Springer-Verlag, New York, $721 \mathrm{p}$.

Grosskopf, R., P.H. Janssen and W. Liesack. 1998. Diversity and structure of the methanogenic community in anoxic rice paddy soil microcosms as examined by cultivation and direct 16S rRNA gene sequence retrieval. Appl. Environ. Microbiol. 64: 960-969.

Hagerthy, S.E., S. Newman, K. Rutchey, E.P. Smith and J. Godin. 2008. Multiple regime shifts in a subtropical peatland: Community specific thresholds to eutrophication. Ecol. Monographs 78: 547-565.

Handelsman, J., M.R. Rondon, S.F. Brady, J. Clardyand and R.M. Goodman. 1998. Molecular biological access to the chemistry of unknown soil microbes: a new frontier for natural products. Chem. Biol. 5: R245-R249.

Horswell, J., S.J. Cordiner, E.W. Maas, T.M. Martin, K.B.W. Sutherland, T. Speir, B. Nogales and A.M. Osborn. 2002. Forensic comparison of soils by bacterial community DNA profiling. J. Forensic Sci. 47: 350-353.

Kakirde, K.S., L.C. Parsley and M.R. Liles. 2010. Size does matter: Application-driven approaches for soil metagenomics. Soil Biol. Biochem. 42: 1911-1923.

Liu, Y. and W.B. Whitman. 2008. Metabolic, phylogenetic, and ecological diversity of the methanogenic archaea. Ann. NY Acad. Sci. 1125:171-189. 
Lovley, D.R. 2003. Cleaning up with genomics: applying molecular biology to bioremediation. Nat. Rev. Microbiol. 1: 35-44.

Marschner, P., C.H. Yang, R. Liebereia and D.E. Crowleyb. 2001. Soil and plant specific effects on bacterial community composition in the rhizosphere. Soil Biol. Biochem. 33: 1437-1445.

McVoy, C.W., W.P. Said, J. Obeysekera, J.A. VanArman and T.W. Dreschel. 2011. Landscapes and hydrology of the predrainage Everglades. University Press of Florida.

Millard, P. and B. Singh. 2010. Does grassland vegetation drive soil microbial diversity? Nutr.Cycl. Agroecosys. 88: 147-158.

Nazaries, L., Y. Pan, L. Bodrossy, E.M. Baggs, P. Millard, J.C. Murrell and B.K. Singh. 2013. Evidence of microbial regulation of biogeochemical cycles from a study on methane flux and land use change. Appl. Environ. Microbiol. 79: 4031-4040.

NRCS, U. 2009. Soil Survey of Dade County Area, Florida.

Osborn, A.M., E.R.B. Moore and K.N. Timmis. 2000. An evaluation of terminal-restriction fragment length polymorphism (T-RFLP) analysis for the study of microbial community structure and dynamics. Environ. Microbiol. 2: 39-50.

Pennanen, T., H. Fritze, P. Vanhala, O. Kiikkila, S. Neuvonen and E. Baath. 1998. Structure of a microbial community in soil after prolonged addition of low levels of simulated acid rain. Appl. Environ. Microbiol. 64: 2173-2180.

Pereyra, L.P., S.R. Hiibel, M.V. Prieto Riquelme, K.F. Reardon and A. Pruden. 2010. Detection and quantification of functional genes of cellulose- degrading, fermentative, and sulfate-reducing bacteria and methanogenic archaea. Appl. Environ. Microbiol. 76: 2192-2202.

Reeve, J.N., J. Nölling, R.M. Morgan and D.R. Smith. 1997. Methanogenesis: genes, genomes, and who's on first? J. Bacteriol. 179: 5975-5986.

Robinson, C.J., B.J. Bohannan and V. B. Young. 2010. From structure to function: the ecology of host-associated microbial communities. Microbiol. Mol. Biol. Rev. 74:453-476.

Sklar, F. H., M.J. Chimney, S. Newman, P. McCormick, D. Gawlik, S. Miao, ,C. McVoy, W. Said, J. Newman, C. Coronado, G. Crozier, M. Corvela and K. Rutchey. 2005. The ecological-societal underpinnings of Everglades restoration. Front. Ecol. Environ. 3: 161-169. 
Smith, J.M., H. Castro and A. Ogram. 2007. Structure and function of methanogens along a short-term restoration chronosequence in the Florida Everglades. Appl. Environ. Microbiol.73: 4135-4141.

Stackebrandt, E. and B.M. Goebel. 1994. Taxonomic note: a place for DNA-DNA reassociation and $16 \mathrm{~S}$ rRNA sequence analysis in the present species definition in bacteriology. Int. J. Syst. Bacteriol. 44: 846-849.

Stackebrandt, E. and J. Ebers. 2006. Taxonomic parameters revisited: tarnished gold standards. Microbiol. Today 33: 152-155.

Sundquist, A., S. Bigdeli, R. Jalili, M.L. Druzin, S. Waller, K.M. Pullen, Y.Y. El-Sayed, M.M. Taslimi, S. Batzoglou and M. Ronaghi. 2007. Bacterial flora-typing with targeted, chip-based Pyrosequencing. BMC Microbiol. 7: 108-118.

Torsvik, V. and L. Øvreås. 2002. Microbial diversity and function in soil: from genes to ecosystems. Curr. Opin. Microbiol. 5: 240-245.

Travers, R.S., P.A. Martin and C.F. Reichelderfer. 1987. Selective process for efficient isolation of soil Bacillus spp. Appl. Environ. Microbiol. 53: 1263-1266.

Uz, I. and A.V. Ogram. 2006. Cellulolytic and fermentative guilds in eutrophic soils of the Florida Everglades. FEMS Microbiol. Ecol. 57: 396-408.

Walker, C.B., A.M. Redding-Johanson, E.E. Baidoo, L. Rajeev, Z. He, E.L. Hendrickson, M.P. Joachimiak, S. Stolyar, A.P. Arkin, J.A. Leigh, J. Zhou, J.D. Keasling, A. Mukhopadhyay and D.A. Stahl. 2012. Functional responses of methanogenic archaea to syntrophic growth. ISME J. 6: 2045-2055.

Water Resources Development Act. 2000. Pub. L. No.106-541, 114 Stat. 2711.

Wieland, G., R. Neumann and H. Backhaus. 2001. Variation of microbial communities in soil, rhizosphere, and rhizoplane in response to crop species, soil type, and crop development. Appl. Environ. Microbiol. 67: 5849-5854. 


\section{CHAPTER 4}

\section{INFLUENCE OF ABIOTIC FACTORS ON THE METHANOGENIC $m c r A$ GENE ACROSS OXIC AND ANOXIC MIAMI-DADE COUNTY, FLORIDA SOILS}

\subsection{Introduction}

Methanogenic archaea are strict anaerobes most often found in highly reduced and water-logged soils and sediments and the guts of ruminants and other warm blooded animals (Dalal et al. 2008; Yu et al. 2008). The terminal product of methanogenesis is methane $\left(\mathrm{CH}_{4}\right)$, a greenhouse gas associated with climate change (Le Mer and Roger 2001). Methanogens, however, are difficult to culture in the laboratory because of their fastidious growth requirements (Head et al. 1998). This greatly limits the approaches that can be used to better understand the existing methanogenic diversity, their functional niches, relationships within their natural environment, and the ecosystem services they provide. Methanogens are critical contributors to anaerobic soil organic matter decomposition (Kayranli et al. 2010), and yet little is known about their in situ diversity and their vulnerability to disturbances that impact the balance between carbon loss $\left(\mathrm{CH}_{4}\right.$ emission $)$ or carbon sequestration in a system.

The Florida Everglades are the largest freshwater wetlands in North America (Galloway et al. 1999), and these wetlands and the lands in the adjoining watershed soils are a major biological $\mathrm{CH}_{4}$ source (145 Tg/year) (Conrad 2009). Historically, these wetland soils were drained for agricultural expansion (Light and Dineen 1994; Snyder and Davidsonn 1994) and presently represent the majority of arable land in Miami-Dade County, Florida. Such land-use changes have been documented to impact the rate of carbon dioxide $\left(\mathrm{CO}_{2}\right)$ and $\mathrm{CH}_{4}$ fluxes and have profound effects on soil microbial 
composition (Borneman and Triplett 1997; Smith et al. 2000; Zhou et al. 2008; Levine et al. 2011). The objective of the study was to characterize the current biodiversity and distribution of methanogenic guilds in soils of Miami-Dade County, Florida. The ongoing restoration efforts in the Florida Everglades, as well as the climatic changes such as sealevel rise, will greatly impact methanogens, subsequently affecting the microbial community co-inhabiting with the methanogens, particularly, methanotrophs and syntrophs. Therefore, an improved understanding of biogenic $\mathrm{CH}_{4}$ sources and sinks is essential to better mitigate anthropogenic-associated manipulations. These baseline data can then be used for future assessments of the impact on soil communities when disturbances occur.

Studies conducted in the Florida Everglades and Miami-Dade County soils have focused on methanogens predominately in saturated soil environments (Castro et al. 2004; Castro et al. 2005; Bae et al. 2015; Kushwaha et al. 2015). The methanogenic guilds were characterized using clone libraries of $m c r A$ gene that encodes for methyl-coenzyme M reductase alpha subunit (Lueders et al. 2001; Freitag and Prosser 2009; Steinberg and Regan 2009). The studies demonstrated a broad distribution of the methanogenic orders, Methanomicrobiales, Methanosarcinales, Methanocellales, Methanobacteriales, and Methanomassiliicoccales in the soils (Bae et al. 2015), yet many of the sequences were classified as uncultured archaea. Evidence of active methanogenesis and $\mathrm{CH}_{4}$ production has been reported from various oxic environments (von Fischer and Hedin 2007; Angel et al. 2012; Aschenbach et al. 2013), but not in the Everglades watershed. There remains a knowledge gap in characterizing the methanogenic guilds in South Florida, especially in 
dry soils that have high flood potential because of the anticipated sea level rise and increased rain fall.

Subsequently, it was hypothesized that the biodiversity of methanogens would vary across Miami-Dade County soils types on the basis of soil moisture content. Also, the methanogenic community would be functionally equivalent across Miami-Dade County soils. GeoChip-functional microarray array is a high throughput technique that allows rapid microbial functional gene profiling and has been widely used across varied environmental samples (He at al. 2012, Bai et al. 2013; Cong et al. 2015). In this study, GeoChip 5.0 functional microarrays were employed to characterize the mcrA gene diversity and taxonomic structure. The physical soil data were measured to determine what influence of various environmental factors may have on the $m c r A$ gene diversity in four different soil types within Miami-Dade County, Florida.

\subsection{Materials and methods}

\subsubsection{Soil sample collection, soil physicochemical properties, and DNA extraction}

Soil samples and soil physicochemical properties were collected from four different soil types of Miami-Dade County, Florida (Chapter 2). The DNA was extracted from replicates of each soil type and pooled as previously described (Chapter 2).

\subsubsection{GeoChip 5.0 functional array}

The pooled DNA was quantified and sent to IEG, University of Oklahoma, (Norman, OK) for microarray processing. The abundances of all positive probes for each sample were obtained from IEG in the form of signal intensity. The positive probes that were detected on the GeoChip functional microarray were queried for the methanogenesis marker, mcrA. The GenBank identifiers for mcrA were used to retrieve the protein 
sequences associated with each GeoChip microarray positive probes for the mcrA marker. The protein sequences were aligned using MUSCLE and a Maximum likelihood (ML) tree was constructed in Mega 6.0 software (http:// www.megasoftware.net/) with bootstrap values from 1000 iterations.

\subsubsection{Community comparisons and statistical analyses}

The relative abundance was calculated for all the detected $m c r A$ probes in each sample and then multiplied by the mean value for the total signal intensity of all $m c r A$ probes in all of the samples (Wang et al. 2015). Data were transformed using the natural logarithm plus 1 . The variation in the relative abundances of $m c r A$ probes across soil samples were visualized using the non-metric multidimensional scaling (NMDS) using Bray-Curtis similarity in PRIMER-E ver 7 (Clarke and Gorley 2015). To investigate the influence of abiotic factors on mcrA abundance, PERMANOVA with adonis function, Mantel's correlation analyses, and CCA were performed as described in Chapter 2.

\subsection{Results}

\subsubsection{Soil abiotic factors}

The collected soil abiotic data was the same as described in Table 2. Furthermore, physicochemical characteristics of the soil types were obtained from USDA soil survey and were described in Chapter 2 and are represented in supplementary Table S1.

\subsubsection{Microarray characterization of $m c r A$ probes}

Methanogenic guilds in Miami-Dade County soils were characterized using $m c r A$ probe targets detected on GeoChip functional microarray. Out of the total $182 \mathrm{mcr}$ A related probes present on GeoChip functional microarray, 68 probes were identified in Miami- 
Dade County soils. The number of probes detected for SS1, SS2, SS3, and SS4 were 29, 46, 49, and 47, respectively.

The lineages of many of the positive probes on the microarray were associated with uncultured archaea or uncultured euryarchaeotes, which is not surprising as most methanogens are recalcitrant to culturing and have yet to be taxonomically identified. The $m c r A$ protein sequences (retrieved from NCBI identifiers for each probe) with $>80 \%$ sequence similarity were grouped together into a single operational taxonomic unit (OTU) prior to construction of the phylogenetic tree. The ML tree showed eight major sub-clusters belonging to the seven methanogenic orders: Methanosarcinales, Methanocellales, Methanococcales, Methanobacteriales, Methanopyrales, Methanomassiliicoccales, and Methanomicrobiales (Figure 7). All known sequences were grouped with respect to their taxonomic order classification. After characterizing the uncultured archaeon sequences detected in Miami-Dade County to the reference methanogenic order sequences based on the ML tree (Figure 7, Table 6), the number of detected mcrA OTUs at the order level was lower in SS1 than in SS2, SS3, and SS4 (Table 6). 


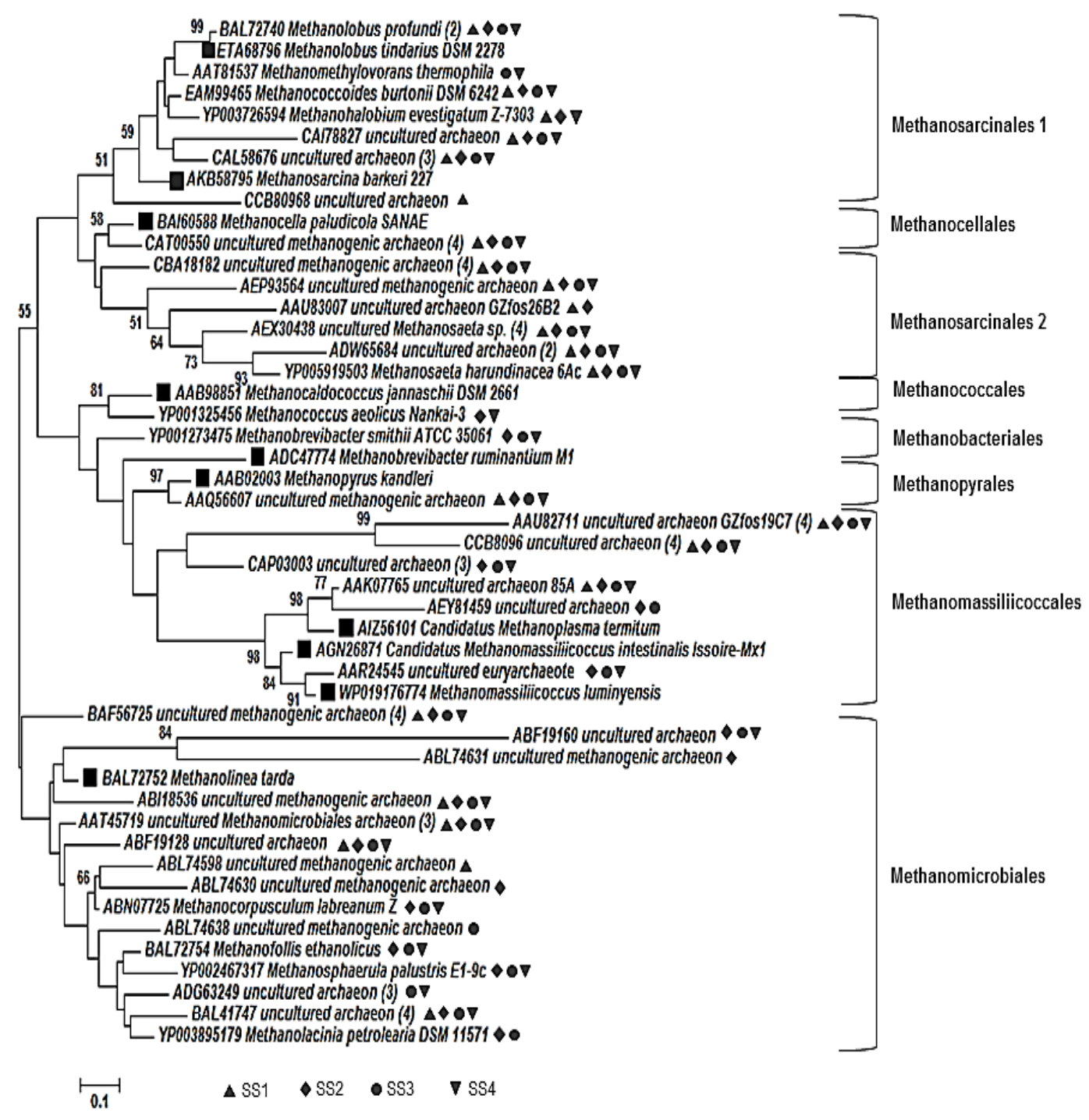

Figure 7: Maximum-likelihood tree of the mcrA protein sequences detected on GeoChip functional microarray for the Miami-Dade County soils.

The reference sequences are labeled with square symbol, while the sequences detected in the soil samples are represented by the symbol key. The bootstrap values $>50$ are shown for 1,000 iterations. The scale bar represents $10 \%$ change in protein sequence. The sequences clustered according to the methanogenic orders. The sequences belonging to all methanogenic orders were present at all four sites with the exception to Methanococcales that was present only in SS2 and SS4. 
Table 6: Representation of the mcrA OTUs (protein sequences) with archived, known species.

The 'Cluster ID' represents the association of the mcrA OTUs with the clusters in the phylogenetic tree (Figure 7). The clusters include the seven taxonomic methanogen orders: Methanosarcinales (MS1 and MS2), Methanocellales (MC), Methanococcales (MCC), Methanobacteriales (MB), Methanopyrales (MP), Methanomassiliicoccales (MM), and Methanomicrobiales (MMB).

\begin{tabular}{|c|c|c|c|c|c|c|}
\hline \multirow{2}{*}{$\begin{array}{l}\text { OTU } \\
\text { ID }\end{array}$} & \multicolumn{4}{|c|}{$\begin{array}{c}\text { Study site } \\
\text { \# of positive probes }\end{array}$} & \multirow{2}{*}{$\begin{array}{c}\text { Cluster } \\
\text { ID }\end{array}$} & \multirow[t]{2}{*}{ Closest related species (accession number) } \\
\hline & SS1 & SS2 & SS3 & SS4 & & \\
\hline 1 & 1 & 2 & 2 & 2 & MS1 & Methanobolus profundi (BAL72740) \\
\hline 2 & 0 & 0 & 1 & 1 & MS1 & $\begin{array}{l}\text { Methanomethylovorans thermophila } \\
\text { (AAT81537) }\end{array}$ \\
\hline 3 & 1 & 1 & 1 & 1 & MS1 & $\begin{array}{l}\text { Methanococcoides burtonii DSM } 6242 \\
\text { (EAM99465) }\end{array}$ \\
\hline 4 & 1 & 1 & 0 & 1 & MS1 & $\begin{array}{l}\text { Methanohalobium evestigatum Z-7303 } \\
\text { (YP003726594) }\end{array}$ \\
\hline 5 & 1 & 1 & 1 & 1 & MS1 & uncultured archaeon \\
\hline 6 & 1 & 3 & 2 & 2 & MS1 & uncultured archaeon \\
\hline 7 & 1 & 0 & 0 & 0 & MS1 & uncultured archaeon \\
\hline 8 & 2 & 3 & 2 & 4 & $\mathrm{MC}$ & $\begin{array}{l}\text { Methanocella paludicola SANAE } \\
\text { (BAI60588) }\end{array}$ \\
\hline 9 & 1 & 1 & 1 & 1 & MS2 & $\begin{array}{l}\text { Methanosaeta harundinacea 6Ac } \\
\text { (YP005919503) }\end{array}$ \\
\hline 10 & 2 & 1 & 3 & 2 & MS2 & $\begin{array}{l}\text { uncultured Methanosaeta sp. } \\
\text { (AEX30438) }\end{array}$ \\
\hline 11 & 1 & 1 & 2 & 1 & MS2 & $\begin{array}{l}\text { Methanosaeta harundinacea } 6 A c \\
\text { (YP005919503) }\end{array}$ \\
\hline 12 & 2 & 2 & 3 & 3 & MS2 & uncultured archaeon \\
\hline 13 & 1 & 1 & 1 & 1 & MS2 & uncultured archaeon \\
\hline 14 & 1 & 1 & 0 & 0 & MS2 & uncultured archaeon \\
\hline 15 & 0 & 1 & 0 & 1 & MCC & $\begin{array}{l}\text { Methanococcus aeolicus Nankai-3 } \\
\text { (YP001325456) }\end{array}$ \\
\hline 16 & 0 & 1 & 1 & 1 & MB & $\begin{array}{l}\text { Methanobrevibacter smithii ATCC } 35061 \\
\text { (YP001273475) }\end{array}$ \\
\hline 17 & 1 & 1 & 1 & 1 & $\mathrm{MP}$ & Methanopyrus kandleri (AAB02003) \\
\hline 18 & 1 & 1 & 1 & 1 & MM & $\begin{array}{l}\text { Candidatus Methanoplasma termitum } \\
\text { (AIZ56101) }\end{array}$ \\
\hline 19 & 0 & 1 & 1 & 0 & MM & $\begin{array}{l}\text { Candidatus Methanoplasma termitum } \\
\text { (AIZ56101) }\end{array}$ \\
\hline 20 & 0 & 1 & 1 & 1 & MM & $\begin{array}{l}\text { Methanomassiliicoccus luminyensis } \\
\text { (WP019176774) }\end{array}$ \\
\hline 21 & 2 & 2 & 2 & 3 & MM & uncultured archaeon \\
\hline
\end{tabular}




\begin{tabular}{|c|c|c|c|c|c|c|}
\hline 22 & 1 & 3 & 2 & 2 & MM & uncultured archaeon \\
\hline 23 & 1 & 2 & 2 & 3 & $\mathrm{MM}$ & uncultured archaeon \\
\hline 24 & 0 & 1 & 1 & 1 & MMB & $\begin{array}{l}\text { Methanocorpusculum labreanum } Z \\
\text { (ABN07725) }\end{array}$ \\
\hline 25 & 1 & 0 & 0 & 0 & MMB & $\begin{array}{l}\text { Methanocorpusculum labreanum } Z \\
\text { (ABN07725) }\end{array}$ \\
\hline 26 & 0 & 1 & 0 & 0 & MMB & $\begin{array}{l}\text { Methanocorpusculum labreanum Z } \\
\text { (ABN07725) }\end{array}$ \\
\hline 27 & 0 & 1 & 1 & 1 & MMB & Methanofollis ethanolicus (BAL72754) \\
\hline 28 & 0 & 1 & 1 & 1 & MMB & $\begin{array}{l}\text { Candidatus Methanosphaerula palustris } \\
\text { E1-9c (YP002467317) }\end{array}$ \\
\hline 29 & 0 & 1 & 1 & 0 & MMB & $\begin{array}{l}\text { Methanolacinia petrolearia DSM } 11571 \\
\text { (YP003895179) }\end{array}$ \\
\hline 30 & 1 & 1 & 2 & 3 & MMB & $\begin{array}{l}\text { Methanolacinia petrolearia DSM } 11571 \\
\text { (YP003895179) }\end{array}$ \\
\hline 31 & 0 & 1 & 1 & 1 & MMB & Methanolinea tarda (BAL72752) \\
\hline 32 & 0 & 1 & 0 & 0 & MMB & Methanolinea tarda (BAL72752) \\
\hline 33 & 2 & 2 & 3 & 2 & MMB & $\begin{array}{l}\text { uncultured Methanomicrobiales } \\
\text { (AAT45719) }\end{array}$ \\
\hline 34 & 1 & 3 & 3 & 2 & MMB & uncultured archaeon \\
\hline 35 & 1 & 1 & 1 & 1 & MMB & uncultured archaeon \\
\hline 36 & 1 & 1 & 1 & 1 & MMB & uncultured archaeon \\
\hline 37 & 0 & 0 & 1 & 0 & MMB & uncultured archaeon \\
\hline 38 & 0 & 0 & 3 & 1 & MMB & uncultured archaeon \\
\hline
\end{tabular}

On the basis of the use of substrates such as acetate, $\mathrm{H}_{2} / \mathrm{CO}_{2}$, formate, methanol, and methyl-related groups, methanogenesis has been classified into three pathways: acetoclastic, hydrogenotrophic, and methylotrophic (Ferry 1999; Deppenmeier 2002). Other gene probes encoding for enzymes participating in the methanogenesis pathway were also detected on the microarray and supported the evidence for the methanogenic guilds in the four Miami-Dade County soils (Table 7). 
Table 7: Number of gene probes associated with methanogenesis detected across the Miami-Dade County soils.

The number of probes present on the GeoChip 5.0 for each gene is depicted in "\# Probes GeoChip" column and total number of probes detected across Miami-Dade County soils are represented as "\# Positive probes" while the number of probes identified for each soil sample were represented in the columns SS1, SS2, SS3, and SS4.

\begin{tabular}{|c|c|c|c|c|c|c|c|}
\hline Gene Probes & Enzyme & $\begin{array}{l}\text { \# Probes } \\
\text { on } \\
\text { GeoChip }\end{array}$ & $\begin{array}{c}\text { \# of } \\
\text { Positive } \\
\text { probes }\end{array}$ & SS1 & SS2 & SS3 & SS4 \\
\hline ackA* & Acetate kinase & 3 & 1 & 0 & 0 & 1 & 1 \\
\hline$a c s^{*}$ & $\begin{array}{l}\text { AMP-forming acetyl-CoA } \\
\text { synthetase }\end{array}$ & 3 & 1 & 0 & 1 & 1 & 1 \\
\hline$c d h C^{*}$ & $\begin{array}{l}\text { CO dehydrogenase/acetyl-CoA } \\
\text { synthase }\end{array}$ & 10 & 3 & 0 & 1 & 1 & 2 \\
\hline$f m d B \_f w d B^{* *}$ & $\begin{array}{l}\text { Formylmethanofuran } \\
\text { dehydrogenase }\end{array}$ & 68 & 19 & 6 & 12 & 12 & 14 \\
\hline$f t r^{* *}$ & $\begin{array}{l}\text { Formylmethanofuran-- } \\
\text { tetrahydromethanopterin } \\
\text { formyltransferase }\end{array}$ & 40 & 13 & 7 & 11 & 12 & 11 \\
\hline$m c h^{* *}$ & $\begin{array}{l}\text { Methenyltetrahydromethanopterin } \\
\text { cyclohydrolase }\end{array}$ & 39 & 13 & 7 & 10 & 7 & 10 \\
\hline$m e r^{* *}$ & $\begin{array}{l}5,10- \\
\text { methylenetetrahydromethanopterin } \\
\text { reductase }\end{array}$ & 19 & 12 & 4 & 9 & 6 & 9 \\
\hline$h m d^{* *}$ & $\begin{array}{l}\text { Coenzyme F420-dependent } \\
\mathrm{N}(5), \mathrm{N}(10) \text { - } \\
\text { methenyltetrahydromethanopterin } \\
\text { reductase }\end{array}$ & 22 & 9 & 1 & 6 & 4 & 5 \\
\hline$m t 2 * * *$ & $\begin{array}{l}\text { Methylcobalamin:coenzyme M } \\
\text { methyltransferase }\end{array}$ & 11 & 10 & 0 & 8 & 6 & 7 \\
\hline$m t a B * * *$ & $\begin{array}{l}\text { Methanol:cobalamin } \\
\text { methyltransferase, subunit B }\end{array}$ & 11 & 2 & 0 & 2 & 2 & 2 \\
\hline$m t a C^{* * *}$ & $\begin{array}{l}\text { Methyltransferase cognate } \\
\text { corrinoid protein }\end{array}$ & 24 & 2 & 0 & 1 & 0 & 1 \\
\hline$m t b C \_m t t C^{* * *}$ & Dimethylamine corrinoid protein & 10 & 6 & 3 & 4 & 4 & 4 \\
\hline$m t m B^{* * *}$ & $\begin{array}{l}\text { Monomethylamine } \\
\text { methyltransferase }\end{array}$ & 11 & 3 & 2 & 3 & 2 & 3 \\
\hline$m t t B * * *$ & Trimethylamine methyltransferase & 16 & 1 & 1 & 1 & 1 & 1 \\
\hline$m t x X^{* * * *}$ & Methyltransferase mtx subunit $\mathrm{X}$ & 1 & 4 & 1 & 1 & 2 & 2 \\
\hline$m r t H^{* * * *}$ & $\begin{array}{l}\text { Tetrahydromethanopterin } \mathrm{S} \text { - } \\
\text { methyltransferase subunit } \mathrm{H}\end{array}$ & 50 & 18 & 5 & 14 & 11 & 12 \\
\hline$h d r B^{* * * *}$ & $\begin{array}{l}\text { Heterodisulfide reductase subunit } \\
\text { B }\end{array}$ & 82 & 25 & 9 & 18 & 16 & 21 \\
\hline$m c r A^{* * * *}$ & $\begin{array}{l}\text { Methyl-coenzyme M reductase, } \\
\text { alpha subunit }\end{array}$ & 182 & 68 & 29 & 46 & 49 & 47 \\
\hline
\end{tabular}

*Aceclastic methanogenesis pathway genes

** Hydrogenotrophic methanogenesis pathway genes

*** Methylotrophic methanogenesis pathway genes

**** Genes associated with all the three pathways 


\subsubsection{Methanogenic assemblages and the associations with abiotic factors}

The NMDS plots constructed using the relative abundance of $m c r A$ OTUs for each soil demonstrated that SS2, SS3, and SS4 were more similar in comparison to SS1 (Figure 8). The cluster analysis using complete linkage showed $60 \%$ similarity between SS2, SS3, and SS4 while SS1 was only 40\% similar to the other soil samples (Figure 8).

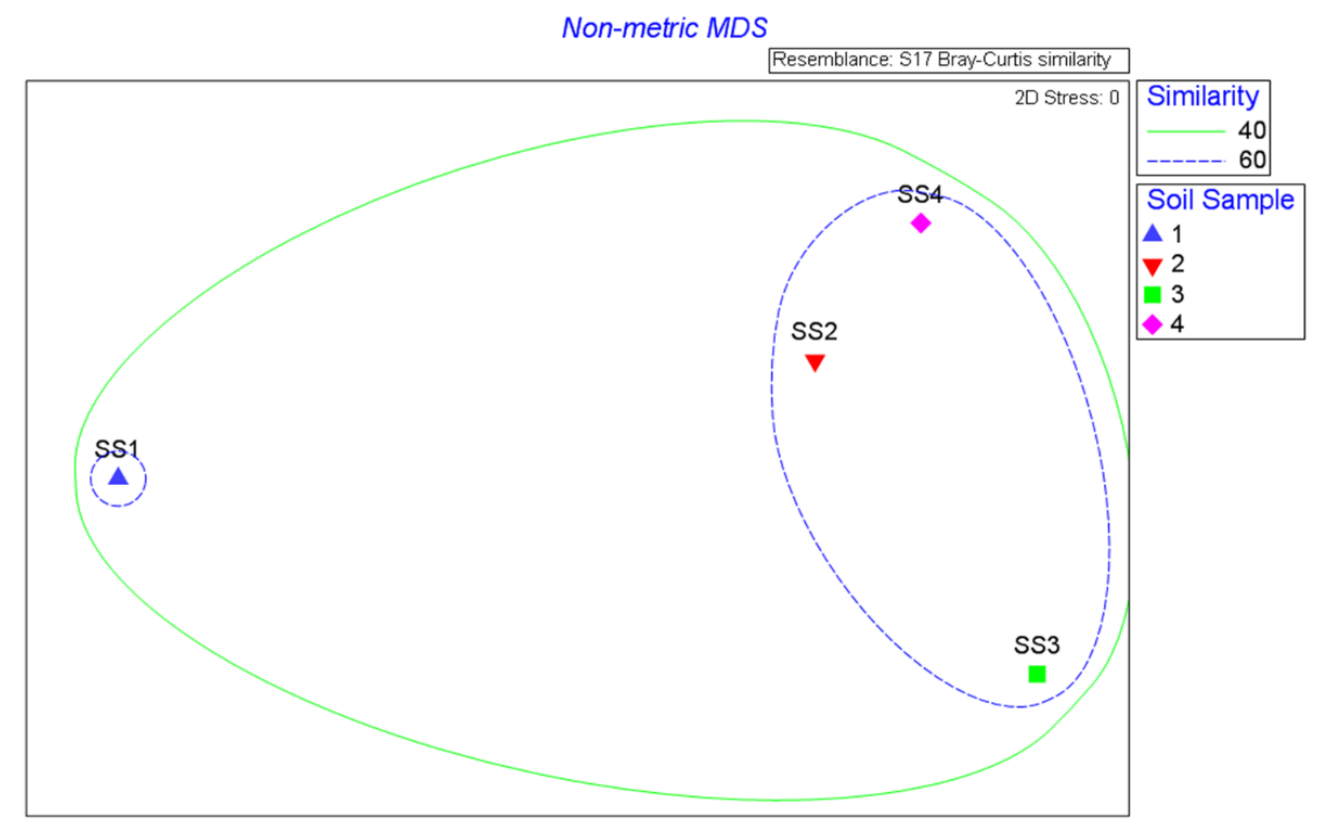

Figure 8: Non-metric multidimensional scaling (NMDS) of mcrA OTUs relative abundance across Miami-Dade County soils.

Blue solid line showed 60\% similarity between SS2, SS3, and SS4 whereas green dashed line represented SS1 as only 40\% similar to the other three soil samples.

The PERMANOVA (with adonis) and Mantel's test were performed to evaluate the influence of abiotic factors on the mcrA OTU abundances in soil samples. The dissimilarity between soil samples was significant $(\mathrm{p}<0.05)$, only influenced by moisture content (Table 8). Mantel's test showed weak positive correlations between $m c r A$ abundance and moisture content, percent sand, percent silt, as well as $\mathrm{pH}$, while weak negative correlations 
were observed with percent organic content and percent clay (Table 8). Thus, the positive correlations indicate that soil samples with similar abiotic properties support similar guild composition versus properties that were negatively correlated.

Table 8: PERMANOVA (adonis) and Mantel's test comparison of methanogenic assemblages and abiotic factors.

$\mathrm{R}^{2}$ value is the constrained percentage of the abiotic factor influencing the methanogenic taxonomic distribution across soil samples. The Mantel's correlation coefficient $r$ value depicts the positive or negative correlation of the abiotic factor to the methanogenic guilds distribution. Significant values $(\mathrm{p}<0.05)$ are depicted in bold text.

\begin{tabular}{|l|c|c|c|c|}
\hline \multirow{2}{*}{$\begin{array}{c}\text { Soil physicochemical } \\
\text { properties }\end{array}$} & \multicolumn{2}{c|}{ PERMANOVA (adonis) } & \multicolumn{2}{c|}{ Mantel's test } \\
\cline { 2 - 5 } & $\mathbf{R}^{\mathbf{2}}$ & $\mathbf{p}$ & $\mathbf{r}$ & $\mathbf{p}$ \\
\hline \% Moisture & 0.41 & $\mathbf{0 . 0 4}$ & 0.10 & 0.11 \\
\hline \% Organic Content & 0.35 & 0.33 & -0.34 & 0.55 \\
\hline pH & 0.24 & 0.63 & 0.24 & 0.12 \\
\hline \% Sand & 0.37 & 0.38 & 0.03 & 0.40 \\
\hline \% Clay & 0.24 & 0.71 & 0.10 & 0.29 \\
\hline \% Silt & 0.57 & 0.25 & -0.24 & 0.73 \\
\hline
\end{tabular}

The CCA ordination analyses were further performed to observe correlations between the moisture content, organic content, and percent silt and $m c r A$ distributions. Figure 9 indicated that percent silt, moisture content, and organic content had the highest correlations to the abundance of $m c r A$ genes in SS2 and SS4. The three tested abiotic factors together contributed to 44 percent of the methanogenic taxonomic variation across samples and is depicted by axis 1 on the CCA plot. The soil samples SS2 and SS4 with high moisture content grouped together whereas the dry soils did not cluster together. The grouping of dry soils SS1 and SS3 away from each other demonstrates that there may be additional factors regulating the potential methanogenic activity in dry soils. 


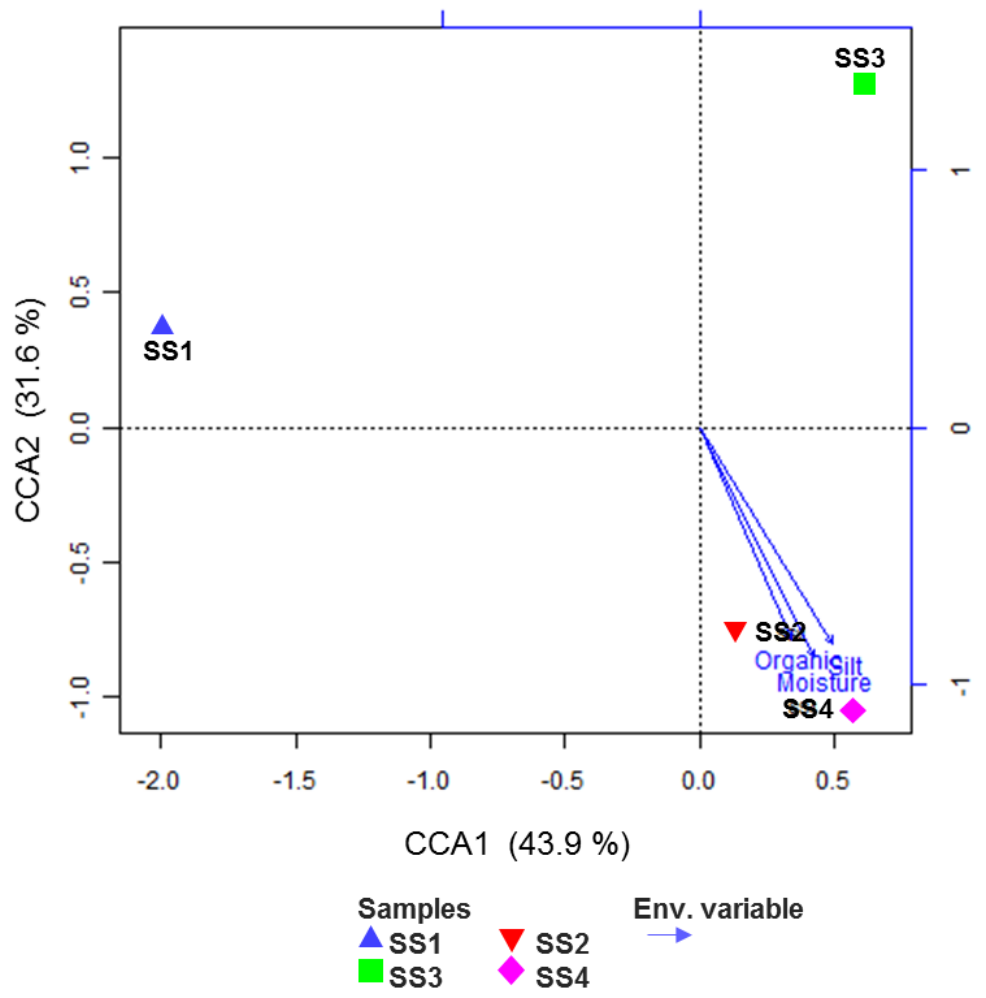

Figure 9: CCA for $m c r A$ gene across Miami-Dade County sampling sites using the soil factors soil moisture, organic content, and percent silt.

Soil samples SS2 and SS4 grouped closer together with soil organic content, moisture, and percent silt identified as the differential factors influencing the distribution.

\subsection{Discussion}

Methanogenesis is the last step in the carbon cycle and plays a significant role in $\mathrm{CH}_{4}$ production and carbon sequestration in wetlands as a result of slow degradation of soil organic matter. Land-usage and increased agricultural practices have been correlated with transformations in soil microbial diversity and the associated ecosystem functions (Borneman and Triplett 1997; Zhou et al. 2008; Levine et al. 2011). However, characterization of the methanogens and their associated biogeochemical functions is challenging because most are "uncultivated". Although culture-independent techniques are used, clone libraries associate the sequences with uncultured archaeon or euryarchaeote 
(Kushwaha et al. 2015) rather than with known methanogens. The GeoChip-based microarray techniques employed in this study provided a needed tool to study microbial community functional genes (Zhou et al. 2013).

Regardless of the soil types, Miami-Dade County soils contained representatives from six out of the seven methanogenic orders; however, soil moisture governed the distribution of these assemblages at the OTU level. Previous studies provided evidence of methanogens in oxic environments but in lower numbers than anaerobic soils (Peters and Conrad 1996; Hofmann et al. 2013; Angel et al. 2012). Similarly, the total abundance of $m c r A$ was lower in Miami-Dade County soils with $<30 \%$ moisture content (SS1 and SS3) compared to the water-logged soils with $>75 \%$ moisture content (SS2 and SS4). It has been proposed that aerated soils may contain anoxic microsites within soil aggregates or that seasonal moisture deposition may lead to moisture niches where methanogens can survive and function (Conrad 1995; Smith et al. 2007; Hofmann et al. 2013), albeit at reduced capacities. Numerous studies have demonstrated the correlation of moisture content with $m c r A$ abundance (Ma et al. 2012; Christiansen et al. 2016). Ma et al. (2012) showed decreased abundance of $m c r A$ and $\mathrm{CH}_{4}$ production in rice fields as a result of drainage, and overall $m c r A$ abundance diminished when subjected to dry/wet cycles in comparison to continuous flooding. Moreover, Christiansen et al. (2016) stated that, irrespective of the soil/forest type, soil moisture content, total $\mathrm{N}$, and $\mathrm{NO}_{3}{ }^{-}$concentrations were positively correlated with $m c r A$ abundance and $\mathrm{CH}_{4}$ production in upland soils. In the present study, ordination plots (NMDS and CCA) supported the clustering of soil samples on the basis of soil moisture content. 
Another finding in the current study was the high abundance of the hydrogenotrophic Methanomicrobiales in all Miami-Dade County soils, which supported studies conducted in the Florida Everglades (Chauhan et al. 2004; Castro et al. 2005; Smith et al. 2007; Bae et al. 2015). Keeping in mind that the design of the microarrays is a closed system (i.e., only those probes on the array will be possible to identify), the possibility of a probe design bias was not supported as Methanomicrobiales and Methanosarcinales had the most number of detected probes, even though number of probes for the three orders of Methanosarcinales, Methanobacteriales, and Methanomicrobiales were similar (6-9\%) on the microarray (Table S2).

The presence of the recently described order Methanomassiliicoccales within the class Thermoplasmata (Dridi et al. 2012; Paul et al. 2012; Oren and Garrity 2013) depicts the potential of $\mathrm{H}_{2}$-dependent methylotrophic methanogenesis in these soils (Borrel et al. 2014; Lang et al. 2015). Methylotrophic methanogenesis utilizes substrates such as methanol, methylamines, and methyl sulfides versus acetate (acetoclastic pathway) or $\mathrm{H}_{2} / \mathrm{CO}_{2}$ (hydrogenotrophic pathway). In wetlands, methane gas production is attributed primarily to the acetoclastic pathway followed by the hydrogenotrophic pathway (Holmes et al. 2014). However, the methylotrophic pathway is the primary pathway in ecosystems in which other bacterial communities compete with the methanogens for acetate or $\mathrm{H}_{2} / \mathrm{CO}_{2}$ (Zhuang et al. 2016). Recently, $\mathrm{H}_{2}$-dependent methylotrophic methanogenesis has been described in Methanomassiliicoccales that harbor a unique genomic profile; these methanogens lack the first six steps of the hydrogenotrophic pathway $\left(\mathrm{H}_{2} / \mathrm{CO}_{2}\right)$ as well as the oxidation steps of methylotrophic pathway (Borrel et al. 2013). Although genes associated with methylotrophic pathways were detected (Table 7), there were no 
taxanonmic probes on the GeoChip specific to $\mathrm{H}_{2}$-dependent methylotrophs. This is no doubt a result of the limitation of the GeoChip not having associated probes for these organisms, as Methanomassiliicoccales were only recently described in 2013 (Borrel et al. 2013). As more genomic information is forthcoming each year, the design of the microarray may not reflect the very newest taxonomic information. However, the advantage of the microarray is its ability to provide the much needed baseline functional diversity across soil microbial communities from a wide range of taxa and environments.

Under anaerobic conditions, biogenic $\mathrm{CH}_{4}$ formation not only depicts the presence of active methanogens but also other anaerobes that provide substrates for methanogenesis (Angel et al. 2012). Studies by Küsel and Drake (1994) and Degelmann et al. (2009) have indeed documented the occurrence and activity of such anaerobes in aerated soils, thereby illustrating the potential of anaerobic organic matter degradation in dry and oxic soils when subjected to flooded conditions. Flooded soils with higher water-table depth capture $\mathrm{CO}_{2}$ and emit $\mathrm{CH}_{4}$ (Whiting and Chanton 2001). On the other hand, drained soils are methane sinks, and any methane that is released is utilized by the methanotrophs as their energy source (Smith et al. 2000). As a result, the balance between $\mathrm{CO}_{2}$ and $\mathrm{CH}_{4}$ gas fluxes modulates the soil carbon sequestration as well as atmospheric emission of global warming gases (Kayranli et al. 2010).

Numerous studies have also reported $\mathrm{pH}$ to be an influential factor in shaping the methanogenic community (Horn et al. 2003; Hu et al. 2013; Hofmann et al. 2016) and a lower $\mathrm{pH}$ can cause a shift from acetoclastic to hydrogenotrophic methanogens (Horn et al. 2003). However, the $\mathrm{pH}$ of Miami-Dade County soils are very similar because of the high buffering capacity of the calcium carbonate content of most of the soils (Table S1). 
Therefore, $\mathrm{pH}$ was not a factor influencing the diversity of the guilds across the different soil types.

The results from the current study indicated that, regardless of the parent soil type, moisture content was the only significant factor $(\mathrm{p}<0.05)$ that shaped the methanogenic guilds. This study expands the previously published work on the $m c r A$ diversity in SS2 and SS4 soils (Chapter 3) and demonstrated the presence of the six orders of methanogens across the four Miami-Dade County soils. To our knowledge, $m c r A$ gene diversity and detection of genes associated with the three pathways of methanogenesis have not been previously reported for Miami-Dade County soils. In addition, Methanomassicoccalesrelated sequences that perform $\mathrm{H}_{2}$-dependent methylotrophic methanogenesis were characterized using ML phylogenetic trees for the first time in dry, oxic soils.

This study expands the knowledge base of $m c r A$ gene diversity and the metabolic potential of methanogens in Miami-Dade County soils. During disturbances even though microbial community may be altered, the associated ecosystem function is likely to remain the same if microbial community is resistant, resilient, or functionally redundant (Allison and Martiny 2008). The occurrence of methanogens in dry as well as saturated conditions depicts the functional redundancy of the methanogenic guilds despite the low activity and diversity of methanogens in dry soils. Additionally, the ability of anaerobic methanogens to survive under dry, oxic conditions depicts the resilience of methanogens to perturbations such as drainage but have the functional capacity to respond if soils are subjected to wet conditions (Allison and Martiny 2008). Although further studies need to be conducted in order to determine the functional activity of methanogens in Miami-Dade County soils and measure their precise contribution to atmospheric $\mathrm{CH}_{4}$ emissions, the current study was 
able to provide the current baseline of the methanogenic guilds in Miami-Dade County soils.

\subsection{References}

Allison, S. D., \& Martiny, J. B. (2008). Resistance, resilience, and redundancy in microbial communities. Proceedings of the National Academy of Sciences, 105 (Supplement 1), 11512-11519.

Angel, R., Claus, P., \& Conrad, R. (2012). Methanogenic archaea are globally ubiquitous in aerated soils and become active under wet anoxic conditions. The ISME Journal, $6(4), 847-862$.

Aschenbach, K., Conrad, R., Řeháková, K., Doležal, J., Janatková, K., \& Angel, R. (2013). Methanogens at the top of the world: occurrence and potential activity of methanogens in newly deglaciated soils in high-altitude cold deserts in the Western Himalayas. Frontiers in Microbiology, 4, 359.

Bae, H. S., Holmes, M. E., Chanton, J. P., Reddy, K. R., \& Ogram, A. (2015). Distribution, Activities, and Interactions of Methanogens and Sulfate-Reducing Prokaryotes in the Florida Everglades. Applied and Environmental Microbiology, 81(21), 74317442 .

Bai, S., Li, J., He, Z., Van Nostrand, J. D., Tian, Y., Lin, G., Zhou, J., \& Zheng, T. (2013). GeoChip-based analysis of the functional gene diversity and metabolic potential of soil microbial communities of mangroves. Applied Microbiology and Biotechnology, 97(15), 7035-7048.

Borneman, J., \& Triplett, E. W. (1997). Molecular microbial diversity in soils from eastern Amazonia: evidence for unusual microorganisms and microbial population shifts associated with deforestation. Applied and Environmental Microbiology, 63(7), 2647-2653.

Borrel, G., O’Toole, P. W., Harris, H. M., Peyret, P., Brugère, J. F., \& Gribaldo, S. (2013). Phylogenomic data support a seventh order of methylotrophic methanogens and provide insights into the evolution of methanogenesis. Genome Biology and Evolution, 5(10), 1769-1780.

Borrel, G., Parisot, N., Harris, H. M., Peyretaillade, E., Gaci, N., Tottey, W., Bardot, O., Raymann, K., Gribaldo, S., Peyret, P., \& O’Toole, P. W. (2014). Comparative genomics highlights the unique biology of Methanomassiliicoccales, a Thermoplasmatales-related seventh order of methanogenic archaea that encodes pyrrolysine. BMC Genomics, 15(1), 1. 
Castro, H., Ogram, A., \& Reddy, K. R. (2004). Phylogenetic characterization of methanogenic assemblages in eutrophic and oligotrophic areas of the Florida Everglades. Applied and Environmental Microbiology, 70(11), 6559-6568.

Castro, H., Newman, S., Reddy, K. R., \& Ogram, A. (2005). Distribution and stability of sulfate-reducing prokaryotic and hydrogenotrophic methanogenic assemblages in nutrient-impacted regions of the Florida Everglades. Applied and Environmental Microbiology, 71(5), 2695-2704.

Chauhan, A., Ogram, A., \& Reddy, K. R. (2004). Syntrophic-methanogenic associations along a nutrient gradient in the Florida Everglades. Applied and Environmental microbiology, 70(6), 3475-3484.

Christiansen, J. R., Levy-Booth, D., Prescott, C. E., \& Grayston, S. J. (2016). Microbial and environmental controls of methane fluxes along a soil moisture gradient in a pacific coastal temperate rainforest. Ecosystems, 1-16.

Clarke, K. R., Gorley, R. N. (2015). PRIMER v7: User Manual/Tutorial. PRIMER-E, Plymouth, 296.

Cong, J., Liu, X., Lu, H., Xu, H., Li, Y., Deng, Y., Li, D., \& Zhang, Y. (2015). Analyses of the influencing factors of soil microbial functional gene diversity in tropical rainforest based on GeoChip 5.0. Genomics Data, 5, 397-398.

Conrad, R. (1995). Soil microbial processes involved in production and consumption of atmospheric trace gases. Advances in Microbial Ecology, 14, 207-250.

Conrad, R. (2009). The global methane cycle: recent advances in understanding the microbial processes involved. Environmental Microbiology Reports, 1(5), 285292.

Dalal, R. C., Allen, D. E., Livesley, S. J., \& Richards, G. (2008). Magnitude and biophysical regulators of methane emission and consumption in the Australian agricultural, forest, and submerged landscapes: a review. Plant and Soil, 309(1-2), 43-76.

Degelmann, D. M., Kolb, S., Dumont, M., Murrell, J. C., \& Drake, H. L. (2009). Enterobacteriaceae facilitate the anaerobic degradation of glucose by a forest soil. FEMS Microbiology Ecology, 68(3), 312-319.

Deppenmeier, U. (2002). The unique biochemistry of methanogenesis. Progress in Nucleic Acid Research and Molecular Biology, 71, 223-283.

Dridi, B., Fardeau, M. L., Ollivier, B., Raoult, D., \& Drancourt, M. (2012). Methanomassiliicoccus luminyensis gen. nov., sp. nov., a methanogenic archaeon isolated from human faeces. International Journal of Systematic and Evolutionary Microbiology, 62(8), 1902-1907. 
Ferry, J. G. (1999). Enzymology of one-carbon metabolism in methanogenic pathways. FEMS Microbiology Reviews, 23(1), 13-38.

Freitag, T. E., \& Prosser, J. I. (2009). Correlation of methane production and functional gene transcriptional activity in a peat soil. Applied and Environmental Microbiology, 75(21), 6679-6687.

Galloway, D., Jones, D. R., \& Ingebritsen, S. E. (Eds.). (1999). Land subsidence in the United States.

He, Z., Piceno, Y., Deng, Y., Xu, M., Lu, Z., DeSantis, T., Andersen, G., Hobbie, S.E., Reich, P.B., \& Zhou, J. (2012). The phylogenetic composition and structure of soil microbial communities shifts in response to elevated carbon dioxide. The ISME Journal, 6(2), 259-272.

Head, I. M., Saunders, J. R., \& Pickup, R. W. (1998). Microbial evolution, diversity, and ecology: a decade of ribosomal RNA analysis of uncultivated microorganisms. Microbial Ecology, 35(1), 1-21.

Hofmann, K., Reitschuler, C., \& Illmer, P. (2013). Aerobic and anaerobic microbial activities in the foreland of a receding glacier. Soil Biology and Biochemistry, 57, 418-426.

Hofmann, K., Praeg, N., Mutschlechner, M., Wagner, A. O., \& Illmer, P. (2016). Abundance and potential metabolic activity of methanogens in well-aerated forest and grassland soils of an alpine region. FEMS Microbiology Ecology, 92(2), fiv171.

Holmes, M. E., Chanton, J. P., Bae, H. S., \& Ogram, A. (2014). Effect of nutrient enrichment on $813 \mathrm{CH} 4$ and the methane production pathway in the Florida Everglades. Journal of Geophysical Research: Biogeosciences, 119(7), 1267-1280.

Horn, M. A., Matthies, C., Küsel, K., Schramm, A., \& Drake, H. L. (2003). Hydrogenotrophic methanogenesis by moderately acid-tolerant methanogens of a methane-emitting acidic peat. Applied and Environmental Microbiology, 69(1), 7483.

Hu, H. W., Zhang, L. M., Yuan, C. L., \& He, J. Z. (2013). Contrasting Euryarchaeota communities between upland and paddy soils exhibited similar $\mathrm{pH}$-impacted biogeographic patterns. Soil Biology and Biochemistry, 64, 18-27.

Kayranli, B., Scholz, M., Mustafa, A., \& Hedmark, Å. (2010). Carbon storage and fluxes within freshwater wetlands: a critical review. Wetlands, 30(1), 111-124.

Küsel, K., \& Drake, H. L. (1994). Acetate synthesis in soil from a Bavarian beech forest. Applied and Environmental Microbiology, 60(4), 1370-1373. 
Kushwaha, P., Zayas, J., Oliva, Y., Mendoza, M., \& Mills, D. (2015). Methanogens within the Sawgrass Communities of the Everglades and Biscayne Bay Watersheds. Microbiology of the Everglades Ecosystem, 386-397.

Lang, K., Schuldes, J., Klingl, A., Poehlein, A., Daniel, R., \& Brune, A. (2015). New mode of energy metabolism in the seventh order of methanogens as revealed by comparative genome analysis of "Candidatus Methanoplasma termitum". Applied and Environmental Microbiology, 81(4), 1338-1352.

Le Mer, J., \& Roger, P. (2001). Production, oxidation, emission and consumption of methane by soils: a review. European Journal of Soil Biology, 37(1), 25-50.

Levine, U. Y., Teal, T. K., Robertson, G. P., \& Schmidt, T. M. (2011). Agriculture's impact on microbial diversity and associated fluxes of carbon dioxide and methane. The ISME Journal, 5(10), 1683-1691.

Light, S. S., \& Dineen, J. W. (1994). Water control in the Everglades: a historical perspective. Everglades: The Ecosystem and its Restoration, 5, 47-84.

Lueders, T., Chin, K. J., Conrad, R., \& Friedrich, M. (2001). Molecular analyses of methylcoenzyme $\mathrm{M}$ reductase $\alpha$-subunit ( $m c r A$ ) genes in rice field soil and enrichment cultures reveal the methanogenic phenotype of a novel archaeal lineage. Environmental Microbiology, 3(3), 194-204.

Ma, K., Conrad, R., \& Lu, Y. (2012). Responses of methanogen mcrA genes and their transcripts to an alternate dry/wet cycle of paddy field soil. Applied and Environmental Microbiology, 78(2), 445-454.

Oren, A., \& Garrity, G. M. (2013). List of new names and new combinations previously effectively, but not validly, published. International Journal of Systematic and Evolutionary Microbiology, 63(9), 3131-3134.

Paul, K., Nonoh, J. O., Mikulski, L., \& Brune, A. (2012). "Methanoplasmatales," Thermoplasmatales-related archaea in termite guts and other environments, are the seventh order of methanogens. Applied and Environmental Microbiology, 78(23), 8245-8253.

Peters, V., \& Conrad, R. (1996). Sequential reduction processes and initiation of $\mathrm{CH}_{4}$ production upon flooding of oxic upland soils. Soil Biology and Biochemistry, 28(3), 371-382.

Smith, K. A., Dobbie, K. E., Ball, B. C., Bakken, L. R., Sitaula, B. K., Hansen, S., Brumme, R., Borken, W., Christensen, S., Priemé, A., \& Fowler, D. (2000). Oxidation of atmospheric methane in Northern European soils, comparison with other ecosystems, and uncertainties in the global terrestrial sink. Global Change Biology, 6(7), 791-803. 
Smith, J. M., Castro, H., \& Ogram, A. (2007). Structure and function of methanogens along a short-term restoration chronosequence in the Florida Everglades. Applied and Environmental Microbiology, 73(13), 4135-4141.

Snyder, G. H., \& Davidson, J. M. (1994). Everglades agriculture: past, present, and future. Everglades: The Ecosystem and its Restoration, 85-115.

Steinberg, L. M., \& Regan, J. M. (2009). mcrA-targeted real-time quantitative PCR method to examine methanogen communities. Applied and Environmental Microbiology, 75(13), 4435-4442.

Von Fischer, J. C., \& Hedin, L. O. (2007). Controls on soil methane fluxes: Tests of biophysical mechanisms using stable isotope tracers. Global Biogeochemical Cycles, 21(2).

Wang, J. T., Cao, P., Hu, H. W., Li, J., Han, L. L., Zhang, L. M., Zheng, Y.M., \& He, J. Z. (2015). Altitudinal distribution patterns of soil bacterial and archaeal communities along Mt. Shegyla on the Tibetan Plateau. Microbial Ecology, 69(1), 135-145.

Whiting, G. J., \& Chanton, J. P. (2001). Greenhouse carbon balance of wetlands: methane emission versus carbon sequestration. Tellus B, 53(5), 521-528.

Yu, Z., García-González, R., Schanbacher, F. L., \& Morrison, M. (2008). Evaluations of different hypervariable regions of archaeal $16 \mathrm{~S}$ rRNA genes in profiling of methanogens by Archaea-specific PCR and denaturing gradient gel electrophoresis. Applied and Environmental Microbiology, 74(3), 889-893.

Zhou, X. Q., Wang, Y. F., Huang, X. Z., Hao, Y. B., Tian, J. Q., \& Wang, J. Z. (2008). Effects of grazing by sheep on the structure of methane-oxidizing bacterial community of steppe soil. Soil Biology and Biochemistry, 40(1), 258-261.

Zhou, J., Tu, Q., Wu, L., He, Z., Deng, Y., \& Van Nostrand, J. D. (2013). Metagenomic Insights of Microbial Feedbacks to Elevated $\mathrm{CO}_{2}$. In AGU Fall Meeting Abstracts, $1,1099$.

Zhuang, G. C., Elling, F. J., Nigro, L. M., Samarkin, V., Joye, S. B., Teske, A., \& Hinrichs, K. U. (2016). Multiple evidence for methylotrophic methanogenesis as the dominant methanogenic pathway in hypersaline sediments from the Orca Basin, Gulf of Mexico. Geochimica et Cosmochimica Acta, 187, 1-20. 


\section{CHAPTER 5}

\section{NETWORK ANALYSES TO DETERMINE CO-OCCURRENCE PATTERNS OF METHANOGENIC-RELATED GUILDS IN SOILS}

\subsection{Introduction}

In any ecosystem, biodiversity of species and their complex interactions regulate the biochemical functions and ecosystem services. To understand the ecosystem functions performed by these diverse organisms, studies have focused on characterization of the biodiversity using structural and functional gene markers (Torsvik and Øvreås 2002; Naeem et al. 2012). However, these studies do not always provide information on the complexity of the species interactions across ecosystems. Such interactions have been established across food webs and plant-animal interactions using ecological models (Bascompte et al. 2003; Cattin et al. 2004; Holland and Hastings 2008; Bastolla et al. 2009) but similar interactive-models for microbial species/community interactions were not so common until recently (Raes and Bork 2008). This could be because of the vast biodiversity of microbes, their un-cultivated status, and limited information on microbial competitive interactions (Raes and Bork 2008).

High-throughput techniques such as metagenomics and microarrays are being extensively employed to examine the yet unculturable microbial community diversity. These data have provided the opportunity to explore interactions within these microbial communities (Raes and Bork 2008). Correlations can be observed in gene expression profiles obtained using microarrays and it is probable that genes with similar expression patterns may group as complexes, or participate in various regulatory and signaling pathways (Ideker et al. 2002; Huang et al. 2007; Horvath and Dong 2008). Similarly, in 
soil ecosystems, the holistic functions of nutrient cycling and ecosystem stability are accomplished by multifaceted community members (Zhou et al 2010).

In order to study complex biological connections such as protein-protein, gene expression, metabolic networks, gene signaling, and food webs, mathematical models are used to depict these interactions. Similarly conceptual network analyses have been employed to analyze microbial network interactions and their functional capacity under different environments to determine microbial ecological relationships (Zhou et al. 2010; Zhou et al. 2011; Cong et al 2015). Considering the limited knowledge available about the microbial diversity and ecosystem functioning in highly diverse communities, more studies on microbial interactions need to be conducted in order to better understand the functional capacity of the soil ecosystems (Ruan et al. 2006; Fuhrman and Steele 2008; Chaffron et al. 2010, Barberán et al. 2012). Additionally, microbial communities respond more rapidly to external impacts than plant communities and subsequently, can cause critical shifts in ecosystem services (Lopez-Lozano et al. 2013) belowground before it is seen aboveground. Accordingly, network analyses approaches are promising to identify community interaction patterns and provide information that is not detected using widely used standard analytical techniques of microbial ecology (Proulx et al. 2005; Barberán et al. 2012).

Methanogens, specialized groups of anaerobic Archaea, along with other anoxic microorganisms regulate the production and atmospheric emission of the important greenhouse gas methane (IPCC, 2007; Eusufzai et al. 2010). The freshwater wetlands such as the Florida Everglades maintain anoxic environments for methanogens and are one of the major sources of global methane production (Conrad 2009). Recently methanogens were also described as the autochthonous members of dry, upland soils (Angel et al. 2012). 
Soil microbial methane production rates can be impacted with wetland degradation, drainage, and/or influence of saline inputs in to the freshwater habitats. Therefore, study of direct as well as indirect methanogenic interactions across ecosystems is essential to determine the existing methanogenic interactions in order to predict the impacts of the expected disturbances.

The objective of this study was to use correlation network analysis to characterize the differences between methanogenic guild interactions across Miami-Dade County soils compared to the Florida Everglades. Miami-Dade County soils, adjoining the Everglades National Park, are urbanized soils that were formed as a result of the historical drainage of the National Park's wetlands (Lord 1993). In this study, Miami-Dade County samples comprised of normally dry or saturated soils representing the oxic and anoxic habitats. On the other hand, Everglades' soils are considered saturated but also go through dry-wet hydroperiods throughout the year. Since methanogens are predominant in anoxic, inundated habitats, it was hypothesized that the genes related to methanogenesis would have tight community correlations and the intra-network interactions would be significantly different between the urbanized Miami-Dade soils and the preserved Everglades wetland soils. In addition, it was hypothesized that network analyses can be utilized as ecological models to address the impact of disturbances on the microbial community in Miami-Dade County soils.

\subsection{Methods}

\subsubsection{Soil sample collection}

Soil samples for Miami-Dade (MD) County were collected as described previously (Chapter 2). For the Florida Everglades (EG) samples, soil samples were collected along 
Shark River Slough and Taylor Slough during wet season in August 2014. Two soil samples were collected along freshwater and brackish habitats each across Shark River Slough and Taylor Slough for a total of four samples for Florida Everglades. Three replicates each were collected from freshwater and brackish habitat $(n=12)$.

\subsubsection{GeoChip 5.0 microarray analyses and correlation network analyses}

DNA was extracted from replicates of the MD and EG samples as previously described (Chapter 2) and then pooled together. DNA extracted from the soil samples was processed at the IEG and the signal intensities for the microarray were normalized and log transformed as described previously in Chapter 2. The Pearson correlations (rho values) between each gene (specific to an OTU) probe was calculated using the correlation calculator available at the Galaxy Metabiome pipeline (Brown, George Mason University, VA) for the MD and EG samples. The significant $(\mathrm{p}<0.05)$ rho values were selected and the data were imported into the software Cytoscape 3.4.0 to view individual network maps for MD and EG samples (Shannon et al. 2003). Network Analyzer in Cytoscape 3.4.0 (Shannon et al. 2003) was used to calculate network topology indices defined below.

Each gene probe is associated with a specific gene/OTU and is represented as a node (circle) in the network graph while the interactions between genes are depicted as edges (line). The average shortest path length denotes the shortest distance for all the pair of nodes in a network (Watts and Strogatz 1998). This signifies that the genes/OTUs are mapped on the network in such a manner that they have the shortest distance between each node. The interactions between the genes/OTUs that are closer to each other will be more common than the genes/OTUs that are farther away. Closeness centrality is calculated to measure how close one node is to all the other nodes in the network (Newman 
2003). Closeness centrality identified those OTUs that can interact more frequently with the other OTUs as they have the shortest paths to the other nodes. The values of closeness centrality are lower for OTUs with increased distance from other nodes. Clustering coefficient measures the degree to which nodes in a network tend to cluster together (Watts and Strogatz 1998) and how many clusters will be formed. This coefficient decides which genes/OTUs will cluster together in one sub-network versus the other. Degree represents the number of connections for each node in a network and is termed the degree of a node (Diestel 2005). Degree also denotes how many other genes/OTUs are linked to one gene/OTU and a node with more connections is considered important member in that network. Neighborhood connectivity of a node is defined as the average connectivity of all neighbors of that node (Maslov and Sneppen 2010).

\subsection{Results}

\subsubsection{Soil descriptions}

The Miami-Dade soils were a mixture of different soil types representing urbanuse soils while the Everglades samples were collected from within the Everglades National Park where most of the samples had minimum anthropogenic affect. Habitats within the Everglades varied from fresh water to brackish while only one site (SS4) in Miami-Dade samples had possible influence from brackish inputs (Table 9). 
Table 9: Site descriptions for Miami-Dade County and Everglades soils.

The table represents the GPS coordinates and general soil descriptors of the Miami-Dade County (MD) and Everglades (EG) soil collection sites.

\begin{tabular}{|c|c|c|c|c|c|c|}
\hline \multicolumn{2}{|c|}{ Soil Sites } & \multirow{2}{*}{$\begin{array}{l}\text { Location } \\
\mathrm{N} 25^{\circ} 45.261 \\
\mathrm{~W} 80^{\circ} 22.764\end{array}$} & \multirow{2}{*}{$\begin{array}{c}\text { Vegetation } \\
\text { Forest tree }\end{array}$} & \multirow{2}{*}{$\begin{array}{l}\text { Habitat } \\
\text { Urbanized }\end{array}$} & \multirow{2}{*}{$\begin{array}{c}\text { Climatology } \\
\text { Dry during } \\
\text { wet season }\end{array}$} & \multirow{2}{*}{$\begin{array}{c}\text { Geology } \\
\begin{array}{c}\text { Limestone } \\
\text { bedrock }\end{array}\end{array}$} \\
\hline \multirow{4}{*}{ MD } & SS1 & & & & & \\
\hline & SS2 & $\begin{array}{l}\text { N } 25^{\circ} 53.054 \\
W 80^{\circ} 28.822\end{array}$ & $\begin{array}{c}\text { Marsh } \\
\text { grasses- } \\
\text { Sawgrass }\end{array}$ & $\begin{array}{c}\text { Freshwater } \\
\text { wetland }\end{array}$ & $\begin{array}{l}\text { Inundated all- } \\
\text { year round }\end{array}$ & $\begin{array}{c}\text { Limestone } \\
\text { bedrock }\end{array}$ \\
\hline & SS3 & $\begin{array}{l}\mathrm{N} 25^{\circ} 41.351 \\
\mathrm{~W} 80^{\circ} 28.737\end{array}$ & $\begin{array}{l}\text { Marsh } \\
\text { grasses }\end{array}$ & Urbanized & $\begin{array}{l}\text { Dry during } \\
\text { wet season }\end{array}$ & $\begin{array}{c}\text { Limestone } \\
\text { bedrock }\end{array}$ \\
\hline & SS4 & $\begin{array}{l}\text { N } 25^{\circ} 20.509 \\
\text { W80 } 24.713\end{array}$ & $\begin{array}{c}\text { Mixture of } \\
\text { sawgrass and } \\
\text { mangrove } \\
\text { trees }\end{array}$ & $\begin{array}{c}\text { Freshwater } \\
\text { wetland } \\
\text { with } \\
\text { marine } \\
\text { influence }\end{array}$ & $\begin{array}{l}\text { Inundated all- } \\
\text { year round }\end{array}$ & $\begin{array}{c}\text { Marl over } \\
\text { limestone } \\
\text { bedrock }\end{array}$ \\
\hline \multirow{4}{*}{ EG } & EG1 & $\begin{array}{l}\mathrm{N} 25^{\circ} 32.59 \\
\mathrm{~W} 80^{\circ} 47.06\end{array}$ & $\begin{array}{c}\text { Sawgrass } \\
\text { dominated } \\
\text { marsh } \\
\text { interspersed } \\
\text { with } \\
\text { Eleocharis/ } \\
\text { Panicum } \\
\text { slough }\end{array}$ & $\begin{array}{c}\text { Freshwater } \\
\text { wetland }\end{array}$ & $\begin{array}{c}\text { Subtropical } \\
\text { moist, with } \\
\text { distinctive wet } \\
\text { and dry season }\end{array}$ & $\begin{array}{c}\text { Limestone } \\
\text { bedrock }\end{array}$ \\
\hline & EG2 & $\begin{array}{l}\mathrm{N} 25^{\circ} 24.35 \\
\mathrm{~W} 80^{\circ} 57.51\end{array}$ & $\begin{array}{l}\text { Mangrove } \\
\text { forest }\end{array}$ & $\begin{array}{l}\text { Mangrove } \\
\text { wetland, } \\
\text { low/dwarf } \\
\text { stature }\end{array}$ & $\begin{array}{c}\text { Subtropical } \\
\text { moist, with } \\
\text { distinctive wet } \\
\text { and dry season }\end{array}$ & $\begin{array}{c}\text { Limestone } \\
\text { bedrock }\end{array}$ \\
\hline & EG3 & $\begin{array}{l}\mathrm{N} 25^{\circ} 24.12 \\
\mathrm{~W} 80^{\circ} 36.24\end{array}$ & $\begin{array}{c}\text { Sparse } \\
\text { sawgrass } \\
\text { marsh }\end{array}$ & $\begin{array}{c}\text { Freshwater } \\
\text { wetland }\end{array}$ & $\begin{array}{c}\text { Subtropical } \\
\text { moist, with } \\
\text { distinctive wet } \\
\text { and dry season }\end{array}$ & $\begin{array}{c}\text { Limestone } \\
\text { bedrock }\end{array}$ \\
\hline & EG4 & $\begin{array}{l}\mathrm{N} 25^{\circ} 12.51 \\
\mathrm{~W} 80^{\circ} 38.56\end{array}$ & $\begin{array}{l}\text { Mangrove } \\
\text { forest }\end{array}$ & $\begin{array}{l}\text { Mangrove } \\
\text { wetland, } \\
\text { low/dwarf } \\
\text { stature }\end{array}$ & $\begin{array}{c}\text { Subtropical } \\
\text { moist, with } \\
\text { distinctive wet } \\
\text { and dry season }\end{array}$ & $\begin{array}{c}\text { Limestone } \\
\text { bedrock }\end{array}$ \\
\hline
\end{tabular}




\subsubsection{Correlation Analysis}

Twenty methanogenic pathway genes with 235 OTU-related positive gene probes were identified across $\mathrm{MD}$ and EG samples. These genes belonged to the three methanogenic pathways: acetoclastic (AC), hydrogenotrophic (HG), and methylotrophic (MT) and all converged to the common terminal step of methanogenesis. The node numbers of the individual functional genes were similar in the two studied soil ecosystems (Figure 10).

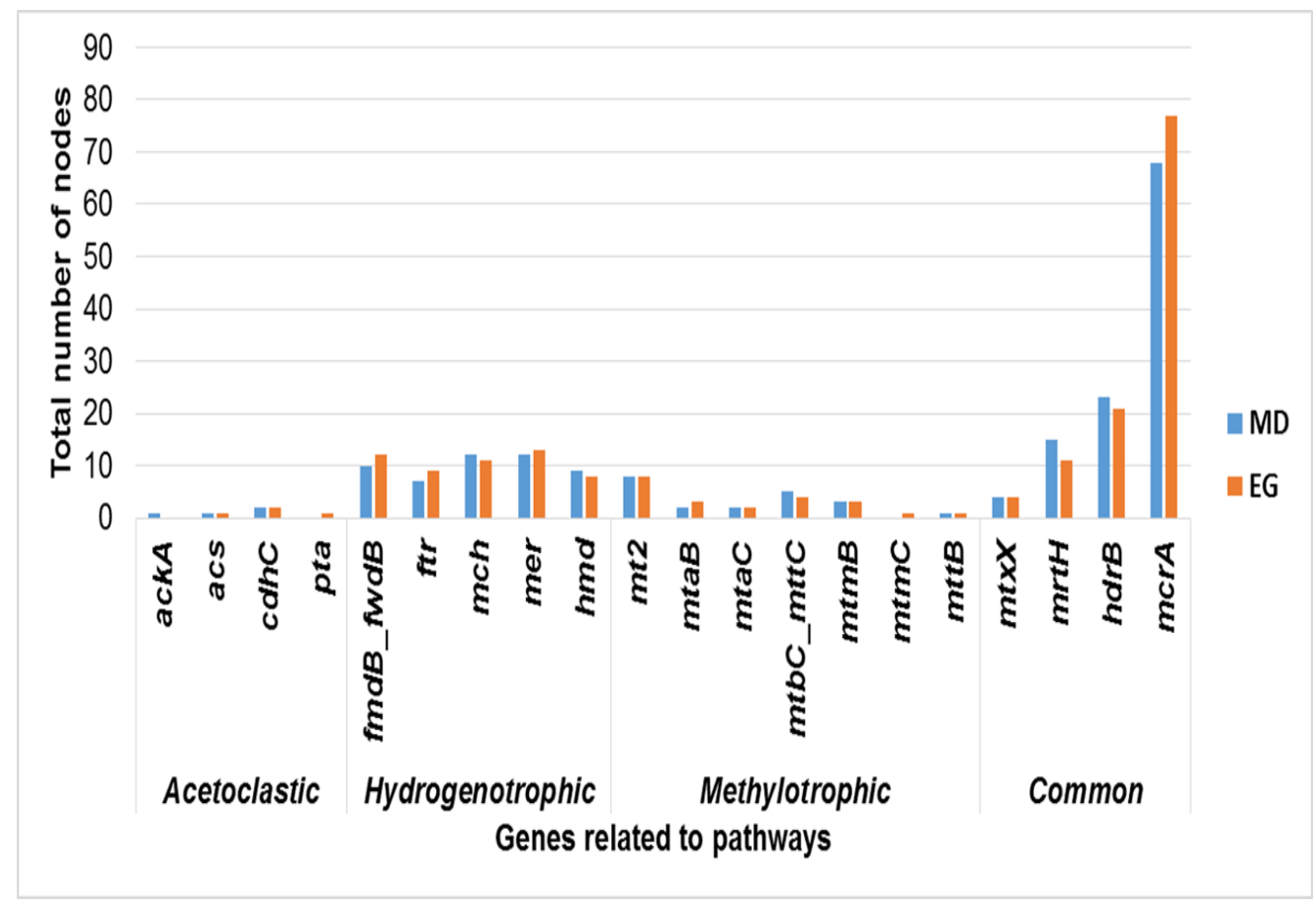

Figure 10: Distributions of major functional genes in the network under the MiamiDade (MD) and the Everglades soils (EG).

The total number of nodes were 185 and 191 for MD and EG, respectively.

However, significant differences in the network complexities were revealed by the

Pearson correlation coefficients ( $\mathrm{p}<0.05)$ with 2845 correlations in MD (Figure 11a) and 5316 correlations in EG (Figure 11b). 

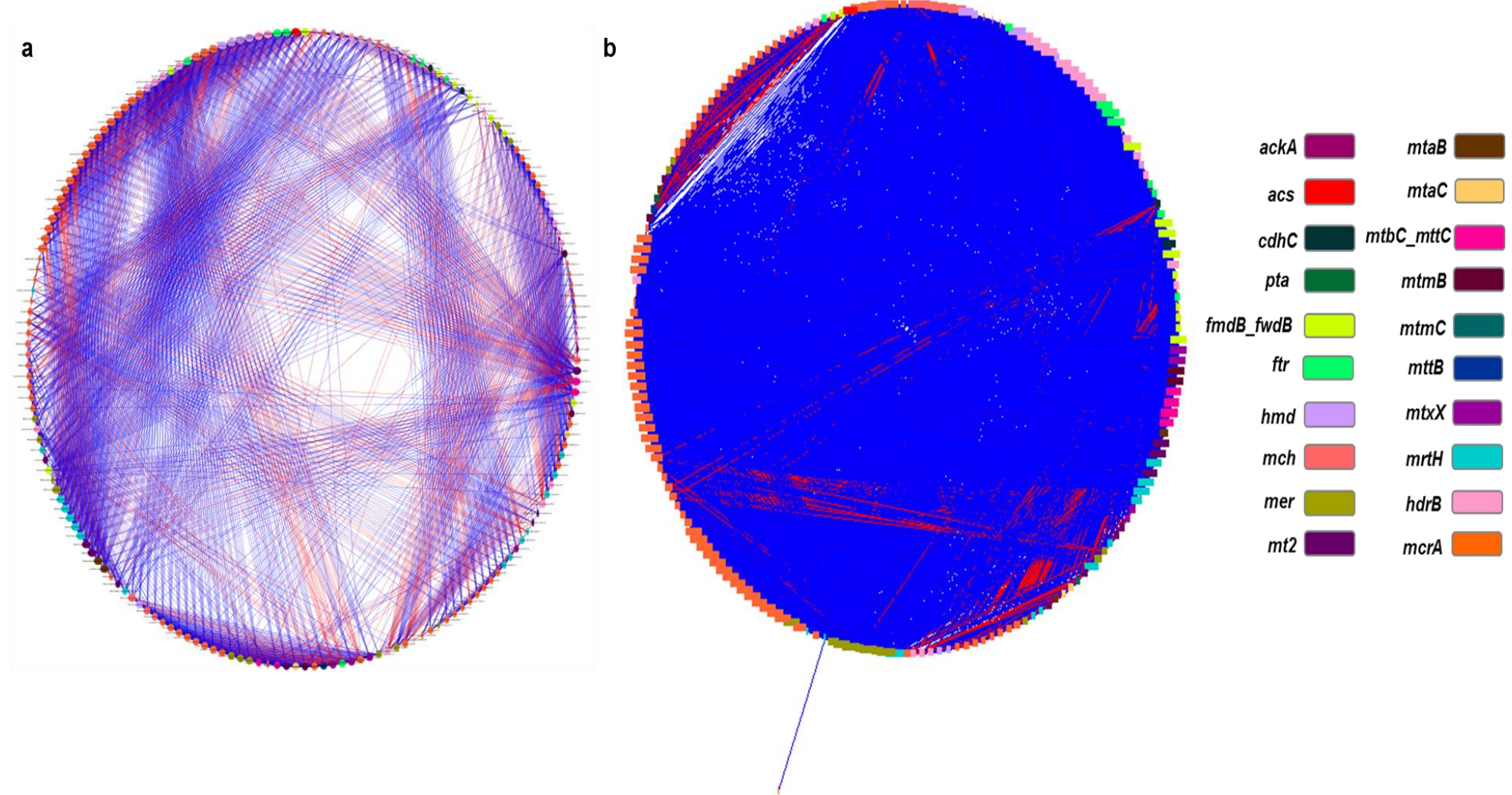

Figure 11: Correlation networks for a) Miami-Dade (MD) and b) Everglades (EG) samples.

The correlation network represents all genes that are associated with a correlation coefficient greater than 0.7 (negative or positive) and with a p-value $<0.05$. The square colored boxes on the edge of the circles represent the genes as the nodes in the network. Blue edges represent positive correlation between nodes and red edges represent negative correlations. 
The genes pta and $m t m C$ were only present in EG while ackA gene was only detected in MD sample. Furthermore, the network topology indices were significantly different using Student-t test (Table 10). The number of positive correlations between genes was relatively higher than were the negative correlations in both MD and EG samples (Figure 11). The positive correlation means high gene abundance in all the four samples within $\mathrm{MD}$ and $\mathrm{EG}$ whereas negative gene correlations depict low gene abundance within the four samples of MD and EG. Overall, the network connections for all the genes were predominately higher in the EG samples, i.e., higher abundance of methanogenic genes in EG.

Table 10: Major topological properties of the correlation network of methanogenic related genes in Miami-Dade (MD) and Everglades (EG).

Standard deviation for the network topological parameters is indicated as ' \pm '.

\begin{tabular}{|l|c|c|c|c|c|}
\hline $\begin{array}{c}\text { Study } \\
\text { site }\end{array}$ & $\begin{array}{c}\text { Network } \\
\text { size }^{\mathrm{a}}\end{array}$ & $\begin{array}{c}\text { Number } \\
\text { of edges }\end{array}$ & $\begin{array}{c}\text { Average } \\
\text { Shortest Path } \\
\text { Length }\end{array}$ & $\begin{array}{c}\text { Closeness } \\
\text { Centrality }\end{array}$ & $\begin{array}{c}\text { Neighborhood } \\
\text { Connectivity }\end{array}$ \\
\hline MD & 185 & 2845 & $2.64 \pm 0.20^{\mathrm{b}}$ & $0.38 \pm 0.03^{\mathrm{b}}$ & $31.38 \pm 8.94^{\mathrm{b}}$ \\
\hline EG & 192 & 5316 & $2.34 \pm 0.56^{\mathrm{b}}$ & $0.44 \pm 0.09^{\mathrm{b}}$ & $58.73 \pm 25.95^{\mathrm{b}}$ \\
\hline
\end{tabular}

Number of genes (i.e., nodes) in a network
Significant difference (p<0.001) between MD and EG

To better understand the relationships and simplify the networks, the analyses were re-focused on the genes involving the three methanogenic pathways and mcrA gene, the enzyme methyl coenzyme $\mathrm{M}$ reductase (MCR) alpha subunit, that encodes for terminal step in methanogenesis. The mcrA gene is present in all methanogens and catalyzes the last step of methane production. The network graph for the subset of the three pathways were also substantially different between MD and EG (Figure S1-S3). The network connectivity was significantly different between MD and EG for the three pathways, 
indicating that the network structures of the methanogenic communities were different (Table 11).

Table 11: Major topological properties of the correlation network of methanogenic pathway genes in Miami-Dade (MD) and Everglades (EG).

Acetoclastic, hydrogenotrophic, and methylotrophic pathways are represented as AC, HG, and MT, respectively. ' \pm ' denoted the standard deviation for the network topological parameters.

\begin{tabular}{|c|c|c|c|c|c|c|}
\hline Pathway & $\begin{array}{c}\text { Study } \\
\text { site }\end{array}$ & $\begin{array}{c}\text { Network } \\
\text { size }^{\mathrm{a}}\end{array}$ & $\begin{array}{c}\text { Number of } \\
\text { edges }\end{array}$ & $\begin{array}{c}\text { Average Shortest } \\
\text { Path Length }\end{array}$ & $\begin{array}{c}\text { Closeness } \\
\text { Centrality }\end{array}$ & $\begin{array}{c}\text { Neighborhood } \\
\text { Connectivity }\end{array}$ \\
\hline \multirow{2}{*}{ AC } & MD & 46 & 42 & $1.83 \pm 0.27^{\mathrm{b}}$ & $0.57 \pm 0.14^{\mathrm{b}}$ & $13.70 \pm 7.53^{\mathrm{b}}$ \\
\cline { 2 - 7 } & EG & 64 & 89 & $3.32 \pm 0.60^{\mathrm{b}}$ & $0.31 \pm 0.06^{\mathrm{b}}$ & $21.83 \pm 9.26^{\mathrm{b}}$ \\
\hline \multirow{2}{*}{ HG } & MD & 116 & 726 & $3.15 \pm 0.44^{\mathrm{c}}$ & $0.32 \pm 0.04^{\mathrm{c}}$ & $17.03 \pm 6.09^{\mathrm{c}}$ \\
\cline { 2 - 7 } & EG & 127 & 1550 & $2.55 \pm 0.80^{\mathrm{c}}$ & $0.44 \pm 0.17^{\mathrm{c}}$ & $34.04 \pm 15.88^{\mathrm{c}}$ \\
\hline \multirow{2}{*}{ MT } & MD & 74 & 298 & $3.62 \pm 1.09$ & $0.32 \pm 0.16$ & $14.74 \pm 8.25^{\mathrm{d}}$ \\
\cline { 2 - 7 } & EG & 96 & 519 & $3.52 \pm 0.79$ & $0.30 \pm 0.07$ & $24.42 \pm 13.08^{\mathrm{d}}$ \\
\hline
\end{tabular}

${ }^{\mathrm{a}}$ Number of genes (i.e., nodes) in a network

${ }_{\text {b,c,d }}$ Significant difference $(p<0.001)$ between MD and EG

The top genes for the three pathways with the highest connectivity in EG samples were compared to the same network connections in MD soils (Table 12). The network interactions for the acs (AC) and $m t 2$ (MT) genes were the highest in both MD and EG samples. However, the maximum number of HG pathway gene interactions were linked to hmd and mer genes in MD and EG, respectively. The number of network interactions of the other genes in EG were different from the corresponding genes in MD soils (Table 12). 
Table 12: Methanogenic pathways genes with the highest connectivity in Miami-Dade (MD) and Everglades (EG) soils.

Acetoclastic, hydrogenotrophic, and methylotrophic pathways are represented as AC, HG, and MT. The genes are 1: ackA (acetate kinase), 2: acs (AMP-forming Acetyl-CoA synthetase), 3: $c d h C$ (CO dehydrogenase/acetyl-CoA synthase), 4: pta (phosphoacetyl transferase), 5: $\quad f m d B \_f w d B$ (formylmethanofuran dehydrogenase), 6: $f t r$ (formylmethanofuran--tetrahydromethanopterin formyltransferase), 7: hmd (Coenzyme F420-dependent $\mathrm{N}(5), \mathrm{N}(10)$-methenyltetrahydromethanopterin reductase), 8: $m c h$ (methenyltetrahydromethanopterin cyclohydrolase), 9: $\quad$ mer $\quad(5,10-$ methylenetetrahydromethanopterin reductase), 10: $m t 2$ (methylcobalamin:coenzyme M methyltransferase), 11: mtaB (methanol:cobalamin methyltransferase, subunit B), 12: $m t b C \_m t t C$ (dimethylamine corrinoid protein), and 13: $m t m B$ (monomethylamine methyltransferase).

\begin{tabular}{|c|c|c|c|}
\hline Pathway & Known OTUs with highest connectivity & MD & EG \\
\hline \multirow{5}{*}{$\mathrm{AC}$} & Methanosarcina barkeri str. Fusaro ${ }^{1}$ & 5 & 0 \\
\hline & Methanosaeta harundinacea $6 \mathrm{Ac}^{2}$ & 21 & 32 \\
\hline & Methanosarcina mazei Go4 ${ }^{3}$ & 12 & 13 \\
\hline & Methanosaeta concilii GP6 ${ }^{3}$ & 4 & 29 \\
\hline & Methanosarcina mazei Go $3^{4}$ & 0 & 16 \\
\hline \multirow{21}{*}{ HG } & Methanolinea tarda NOBI-1 $1^{5}$ & 28 & 59 \\
\hline & Methanosarcina acetivorans $C 2 A^{5}$ & 21 & 59 \\
\hline & Methanosarcina barkeri str. Fusaro 5 & 19 & 60 \\
\hline & Methanoculleus marisnigri JR2 ${ }^{5}$ & 16 & 60 \\
\hline & Methanosphaerula palustris E1-9c & 18 & 63 \\
\hline & Methanosaeta concilii GP6 ${ }^{6}$ & 29 & 20 \\
\hline & Methanoplanus limicola DSM $2279^{6}$ & 29 & 50 \\
\hline & Methanosaeta harundinacea $6 A c^{6}$ & 23 & 61 \\
\hline & Methanosphaerula palustris E1-9c ${ }^{6}$ & 11 & 60 \\
\hline & Methanoplanus petrolearius DSM $11571^{7}$ & 29 & 20 \\
\hline & $\begin{array}{l}\text { Methanothermobacter thermautotrophicus str. } \\
\text { Delta } H^{7}\end{array}$ & 29 & 24 \\
\hline & Methanopyrus kandleri $\mathrm{AV} 19^{7}$ & 29 & 18 \\
\hline & Methanocaldococcus sp. FS406-227 & 29 & 52 \\
\hline & Methanococcus vannielii $S B^{7}$ & 15 & 59 \\
\hline & Methanocella paludicola SANAE ${ }^{8}$ & 24 & 44 \\
\hline & Methanosphaerula palustris E1-9c $c^{8}$ & 18 & 54 \\
\hline & Methanoregula boonei $6 A 8^{8}$ & 18 & 59 \\
\hline & Methanocella conradii $H Z 254^{8}$ & 18 & 59 \\
\hline & Methanosaeta thermophila $\mathrm{PT}^{8}$ & 8 & 60 \\
\hline & Methanoculleus marisnigri JRI ${ }^{8}$ & 18 & 62 \\
\hline & Methanosphaerula palustris E1-9c & 18 & 54 \\
\hline
\end{tabular}




\begin{tabular}{|c|c|c|c|}
\hline & Methanospirillum hungatei $\mathrm{JF}-1^{9}$ & 16 & 59 \\
\hline & Methanosarcina mazei Go $7^{9}$ & 18 & 59 \\
\hline & Methanocella arvoryzae $M R E 50^{9}$ & 9 & 63 \\
\hline & Methanosaeta concilii GP6 ${ }^{9}$ & 20 & 64 \\
\hline \multirow{11}{*}{ MT } & Methanosarcina acetivorans $C 2 A^{10}$ & 27 & 34 \\
\hline & Methanosarcina mazei Go6 $6^{10}$ & 21 & 42 \\
\hline & Methanosarcina mazei Go $8^{10}$ & 27 & 14 \\
\hline & Methanosarcina mazei Go9 $9^{10}$ & 6 & 44 \\
\hline & Methanosphaera stadtmanae DSM 3091 11 & 27 & 13 \\
\hline & Methanosarcina acetivorans $C 2 A^{12}$ & 27 & 45 \\
\hline & Methanococcoides burtonii DSM $6243^{12}$ & 27 & 37 \\
\hline & Methanosalsum zhilinae DSM $4017^{12}$ & 14 & 41 \\
\hline & Methanosalsum zhilinae DSM $4018^{12}$ & 14 & 41 \\
\hline & Methanohalophilus mahii DSM 5219 13 & 15 & 42 \\
\hline & Methanosarcina acetivorans $C 2 A^{13}$ & 13 & 44 \\
\hline
\end{tabular}




\subsubsection{Acetoclastic (AC) pathway genes}

The correlation network analysis for AC genes was the least complex, i.e. low number of connections, amongst the three pathways and resulted in 42 and 89 interactions in MD and EG samples, respectively (Table 11, Figure S1). The relative number of probes for acetoclastic genes on the GeoChip microarray were lower (3\% of all the methanogenesis related genes) but $47 \%$ of AC pathway gene probes were detected across MD and EG samples. Even though the design of the probes is one of the limitations of the using a microarray (a closed system), network analyses were able to show the differences between the two ecosystems. The genes acs had the maximum connections in both the samples followed by $c d h C$. The acetoclastic genes were specific to the genera Methanosarcina sp. and Methanosaeta sp. belonging to the order Methanosarcinales.

The genes $c d h C$ were selected to observe the neighboring nodes in MD and EG samples. The number of edges for the genes $c d h C$ (Figure 12) were greater in EG (Figure 12b) than MD (Figure 12a). All the gene correlations were positive in EG while one out of the four connections was negative correlation in MD. The negative correlation of $c h d C$ gene with $m c r A$ in MD was because of the presence of these genes in different MiamiDade soil types. Also, interaction between the genes $c d h C$ and acs was only observed in EG soils. Although $c d h C$ and acs shared many interactions with $m c r A$ genes, $c d h C$ gene also had few exclusive edges representing the significant correlations between $c h d C$ gene and $m c r A$ genes. 


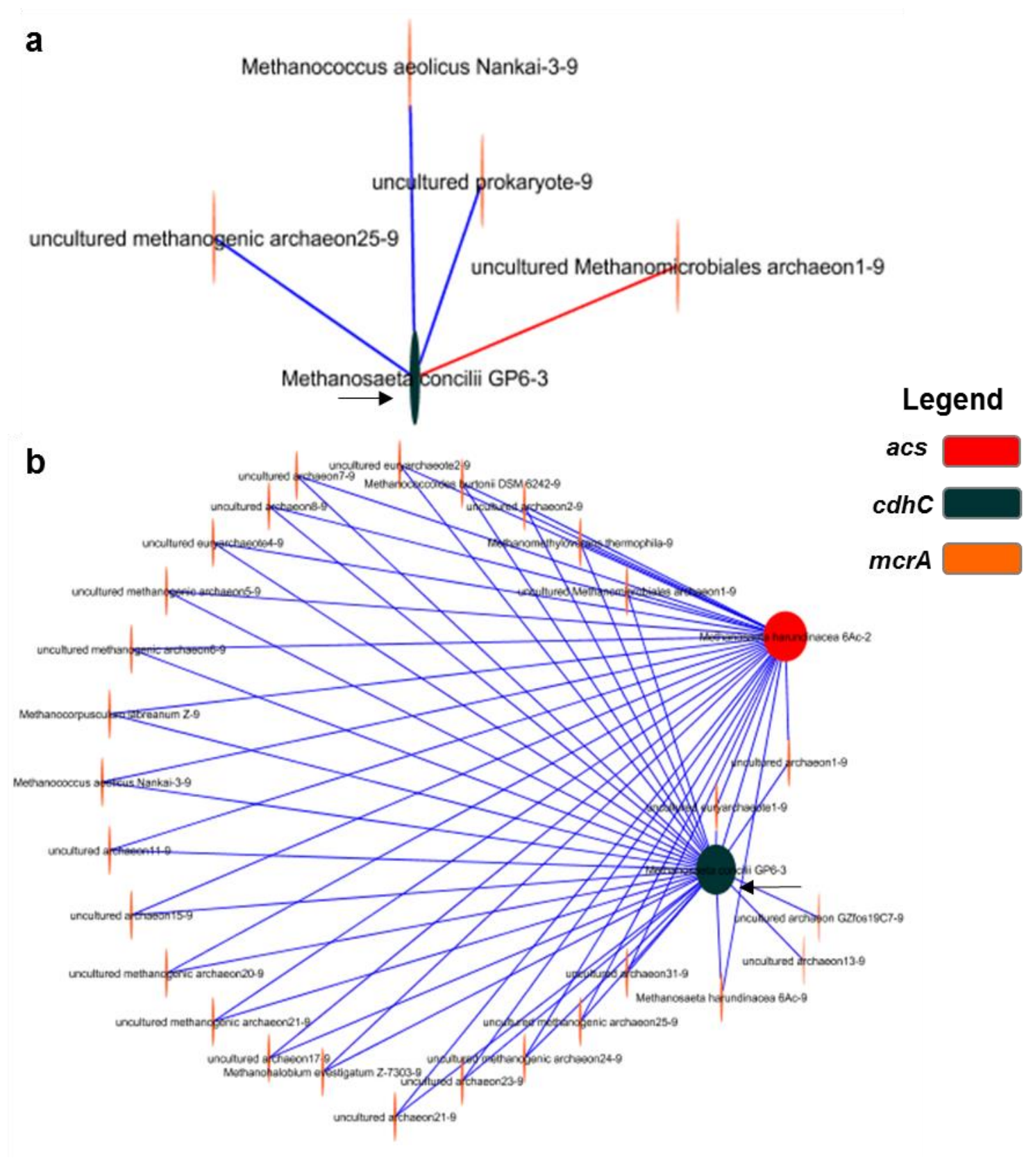

Figure 12: Subnetworks of AC pathway genes in a) MD and b) EG soils.

The number of edges for the genes $c d h C$ were higher in EG than MD. The gene pair correlations were positive (blue edges) in EG while one negative (red edges) correlations were observed in MD. The size of the node depicts the degree of interaction. 


\subsubsection{Hydrogenotrophic (HM) pathway genes}

Overall, the highest number of correlations was observed for HM pathway genes (Figure S2). The degree for the gene hmd (represented in the species Methanothermobacter thermautotrophicus str. Delta H, Methanopyrus kandleri AV19, Methanocaldococcus sp. FS406-22, Methanoplanus petrolearius DSM 11571) was the maximum in MD while gene mer (Methanosphaerula palustris E19c and Methanosaeta concilii GP6) had the highest correlations in EG sample. The different genes in the HM pathway were represented by the methanogens belonging to the orders of Methanobacteriales, Methanocellales, Methanococcales, Methanomicrobiales, Methanopyrales, and Methasarcinales. More negative correlations i.e., low gene abundance were observed in MD samples compared to AC and MT pathway interactions.

The gene $f m d B \_f w d B$ associated with different OTUs displayed different number of interactions with neighboring genes (Figure 13). The total interactions for Methanosphaerula palustris E1-9c were all positive interactions in EG (Figure 13b) whereas MD had six negative network interactions (Figure 13a). In HM pathway interactions, more network interactions were observed not only with $m c r A$ gene but also with other genes of HM pathway. The $f m d B \_f w d B$ (Methanosphaerula palustris E1-9c) in MD demonstrated correlations with $m e r, m c h$, and $h m d$ whereas EG in addition to mer, $m c h$, and $h m d$ genes showed interaction with ftr gene. 
a

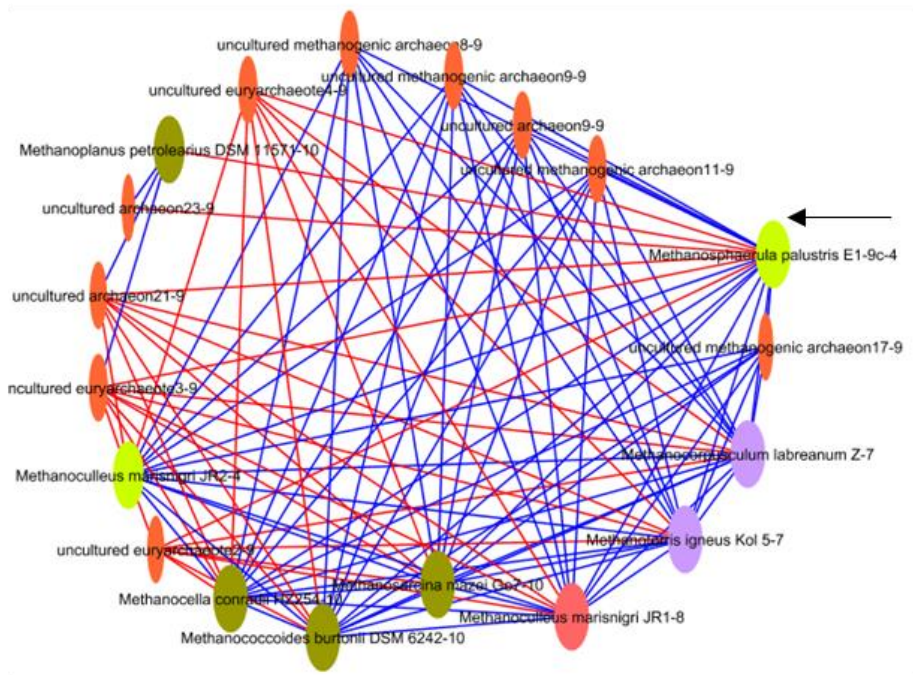

Legend

$f m d B_{-} f w d B$

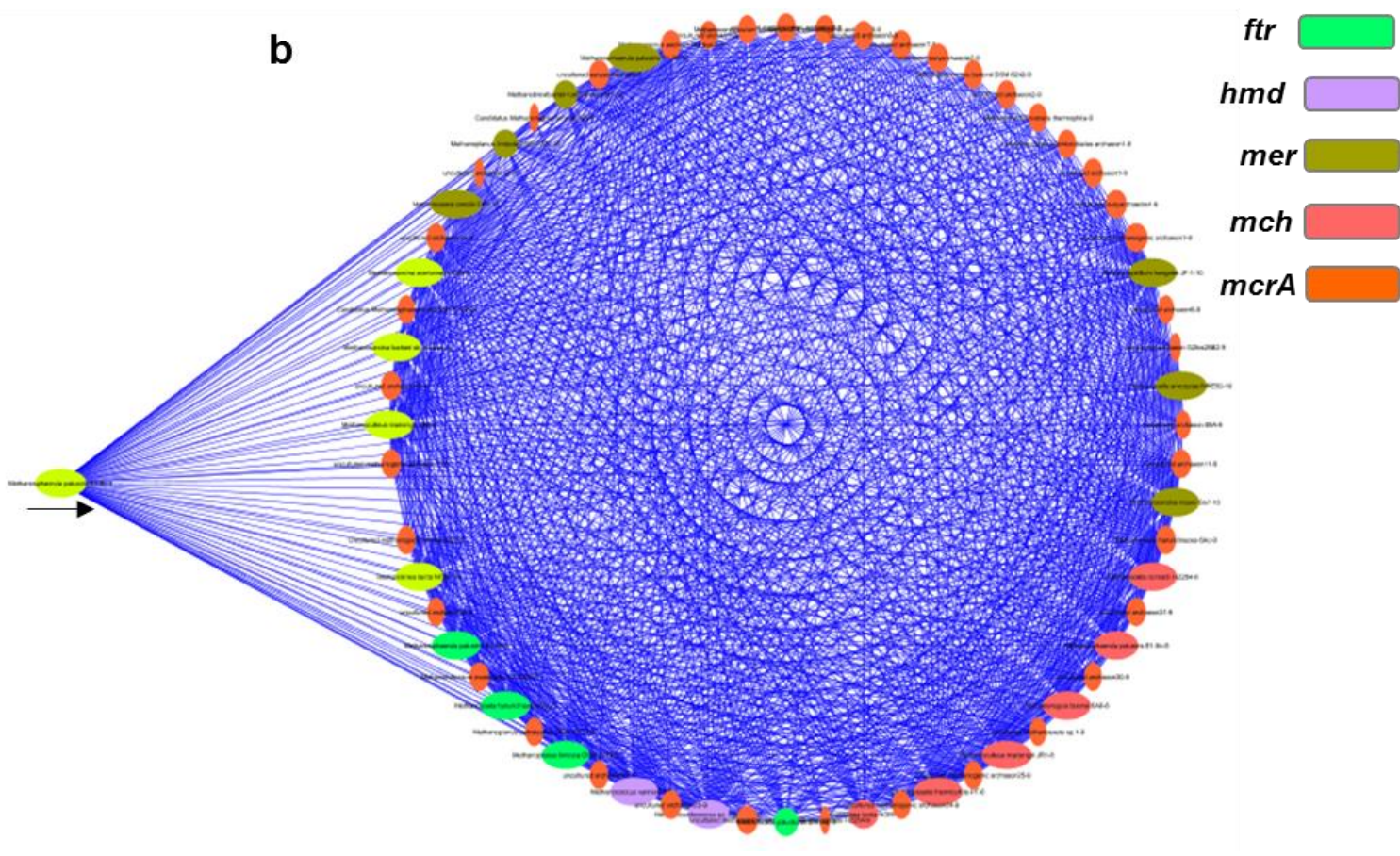

Figure 13: Subnetworks of HG pathway genes in a) MD and b) EG soils.

The number of edges for the gene $f m d B \_f w d B$ was higher in EG than MD. The gene pair correlations were positive (blue edges) in EG while six negative (red edges) correlations were observed in MD. The degree of interactions are depicted by the size of the node. 


\subsubsection{Methylotrophic (MT) pathway genes}

MT genes associations were greater than AC but less than HM genes. Similar to AC and HG genes, MT genes had a higher degree of distributions in EG versus MD samples (Figure S3). The majority of the genes in the network belonged to the order of Methanosarcinales including known methylotrophic methanogens such as Methanococcoides, Methanohalophilus, and Methanolobus. Additionally, Methanosphaera stadtmanae belonging to the order Methanobacteriales, capable of using methanol, was also detected in these soils.

The sub-networks within the major networks were observed for both MD and EG samples. Interestingly, these extended networks were a result of unique interactions between $m t m B$ and $m c r A$ gene in $\mathrm{MD}$ as well as EG samples. The number of gene connections in EG for the gene $m t m B$ (represented by Methanosarcina acetivorans $C 2 A$ ) were higher and all positive correlation compared to the interactions in MD (Figure 14). Furthermore, $m t m B$ gene showed interactions with the genes $m t 2, m t t B, m t m B, m t a C$ in MD while $m t a B, m t 2, m t b C \_m t t C$ in $\mathrm{EG}$. 


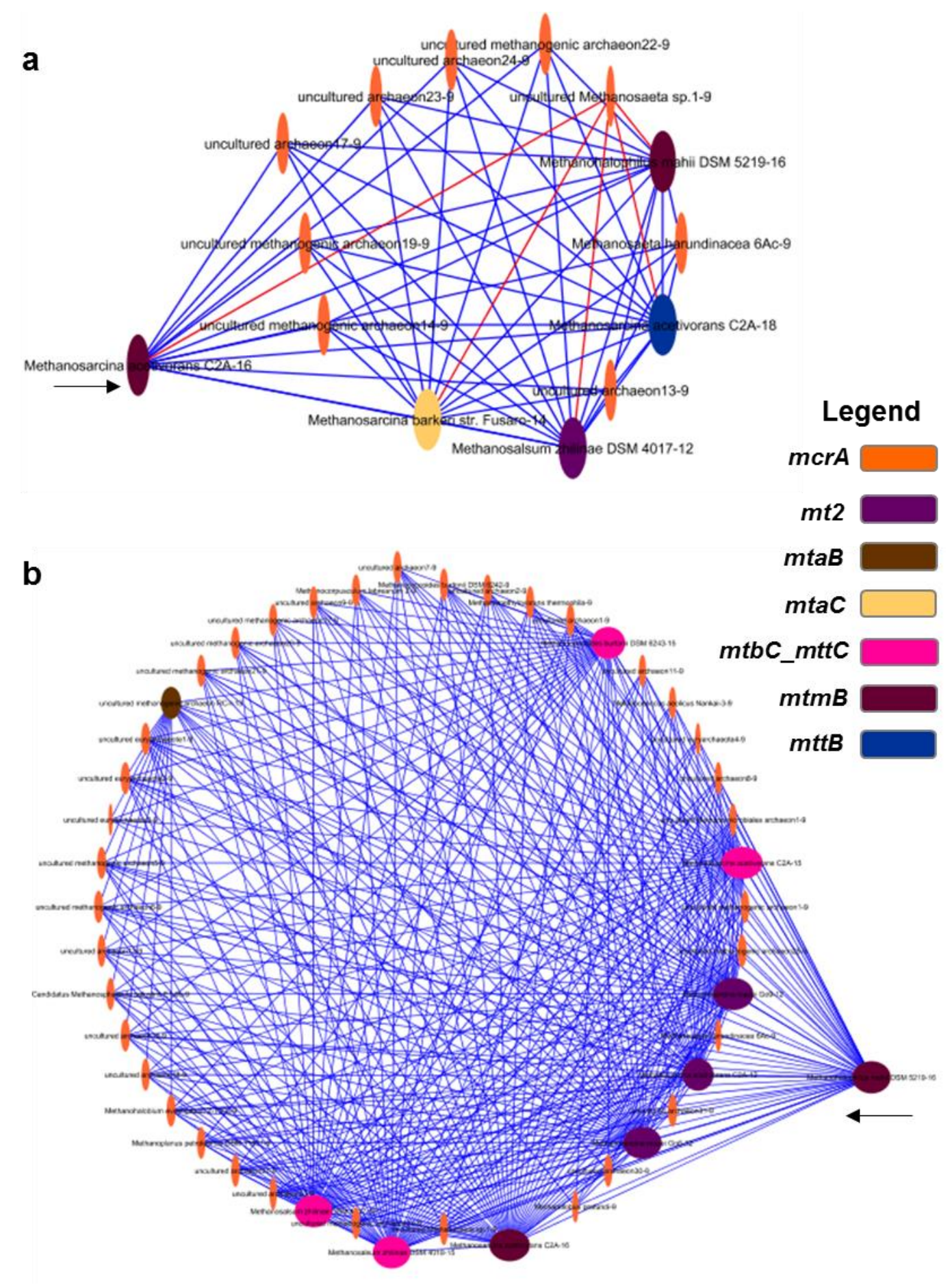

Figure 14: Subnetworks of MT pathway genes in a) MD and b) EG soils.

The number of edges in EG for the gene $m t m B$ were double the interactions in MD. The blue edges represented positive gene pair correlations while red edges showed negative correlations. The size of the node represents the degree of interactions. 


\subsection{Discussion}

Methanogenesis is a complex process owing to the different substrates that can be utilized to produce methane. The current study is the first detailed gene correlation network analyses of co-occurrence of methanogens using the methanogenesis pathway genes for the Florida Everglades and the adjoining Miami-Dade County soils. These network analyses highlight the impact of historical effects such as drainage and human activities in shaping the methanogenic communities across MD soils versus the preserved EG ecosystem. The methanogenic guilds interaction were independent of their taxonomic associations suggesting the probable effect of environmental factors in regulating the methanogenic interactions across the two ecosystems (Burke et al. 2011; Banerjee et al. 2016).

Consequently, the significant differences in the methanogenic interactions could be accredited to the differences in inundation and/or seasonal saturation of the soils, as methanogens are sensitive to changes in moisture content (Christiansen et al. 2016). According to Chambers and colleagues (2016), the microbial communities that function in brackish soils already adapted to pulses of salinity are also primarily governed by inundation. In the present study, the abundance of methanogenic OTUs was higher in all the four inundated sites of EG irrespective of their salt content, whereas MD soils had lower methanogenic abundances in the two dry sites. Thus, indicating an effect of moisture content on the methanogenic relative abundance and subsequently the network interactions.

Although the majority of the interactions were positively correlated, the negative associations (low abundance) between the methanogens and the genes could be a result of 
competition for methanogeneic substrates or resource partitioning (Blagodatskaya and Kuzyakov 2008) by other non-methanogenic members of the community. Blagodatskaya and Kuzyakov (2008) found that the most active microbial group respond first to the addition of substrates and their activity is prolonged because of the availability of substrates in addition to the native soil organic matter. Since the saturated EG soils would have higher carbon content, they can support a more robust methanogenic community. The lower number of negative correlations in EG soils could be attributed to less competition between the methanogenic guilds owing to the higher substrate availability in EG samples. In addition, the higher number of network interactions in EG are probably more reflective of the higher diversity and abundance of methanogenic guilds in this ecosystem.

The activity of hydrogenotrophs is essential in ecosystems as they have synergistic relationships with many bacterial groups. In order to sustain their syntrophs, methanogens have to consume hydrogen and create the partial pressure of hydrogen necessary for their survival (Conrad 1999). These symbiotic associations, in turn, maintain ecosystem stability and prevent any disturbances in the anaerobic organic matter mineralization. The maximum number of associations between $m c r A$ gene and the other pathways genes were identified in the hydrogenotrophic pathway depicting the broad diversity of hydrogenotrophs (Borrel et al. 2011; Rosenzweig and Ragsdale 2011). Although majority of the methanogens are hydrogenotrophs, the higher diversity of hydrogenotrophs in MD and EG samples could also be attributed to more genes in the hydrogenotrophic pathway as well as the GeoChip microarray design with higher proportion of hydrogenotrophic pathway gene probes (30\% of the all methanogenesis genes). Furthermore, hydrogenotrophic pathway genes $f w d, m t d, m c h$, and mer were identified in three species 
of Methanosaeta that are characterized as obligate acetoclastic methanogens. These genes have been characterized as phylogenetically closer to methylotrophic methanogens and their function was attributed to methyl oxidation rather than reduction of $\mathrm{CO}_{2}$ into methane in the hydrogenotrophic pathway (Zhu et al. 2012).

Compared to acetoclastic and hydrogenotrophic pathway, methane production via methylotrophic pathway is significant in marine and hypersaline environments compared to the freshwater wetlands (García-Maldonado et al. 2012). The methylotrophic methanogens detected in this study Methanococcoides burtonii, Methanosalsum zhilinae, Methanohalophilus mahii, and Methanohalobium evestigatum are halophilic Archaea (Orphan et al. 2008; García-Maldonado et al. 2012). The sulfate-reducers in high sulfate, marine environments, compete with methanogens for acetate and $\mathrm{H}_{2} / \mathrm{CO}_{2}$ and therefore, methanogens cannot use these substrates for methanogenesis (Canfield and Des Marais 1991). The Florida Everglades wetlands are subjected to saline influence via wind-driven estuarine and tidal oceanic inputs (Table 9), thereby, suggesting the occurrence of methylotrophic pathway in the Everglades. However, presence of halophilic Archaea in MD soils with minimum oceanic inputs (only at site SS4; Table 9) has to be further investigated.

Studies on methanogen diversity and the associated methane emissions conducted across brackish habitats in UK demonstrated presence of acetoclastic and hydrogenotrophic methanogens (Purdy et al. 2002; Banning et al. 2005). Correspondingly, in the present study parallel methanogenic guilds were detected across freshwater and brackish EG sites. Even though brackish environments could have sulfate inputs during high tides that favor sulfate-reducers, the dynamic environment also assists in striking the 
balance between sulfate-reduction and methanogenesis (Purdy et al. 2002). A recent study conducted in southwest Florida depicted that methane emissions from intermittently flooded sites were not significantly different in a created freshwater marsh, a restored brackish marsh, and a natural freshwater marsh (Li \& Mitch 2016). Thus, the differences in methanogenic networks between MD and EG could be a result of different management practices in these ecosystems.

In conclusion, the current study was able to explore the overall co-occurrence of methanogenic pathways and demonstrated drastic differences in methanogenic gene networks between the urbanized Miami-Dade County soils that were historically drained (Lord 1993) versus the inundated "pristine" Everglades wetland. The network graphs portrayed the snapshot of current methanogenic guilds interactions and how urbanization and drainage have decreased diversity and the number of interactions in Miami-Dade County soils. The impact of disturbances can modify the microbial composition but the ecosystem function remains the same if microbial community is either resistance, resilience, or functionally redundant (Allison and Martiny 2008). Considering similar number of genes/OTUs in Miami-Dade as well as Everglades soils, the methanogenic composition modeled in these networks support the hypothesis of being functionally redundant but very much reduced in the urbanized Miami-Dade soils. The other hypothesis by Allison and Martiny (2008) states disturbances can change the microbial composition to such as extent that the ecosystem function is lost. The extreme dissimilarities in the models presented here could be illustrating that the methanogenic guilds are at a threshold for tolerating external perturbations beyond which the ecosystem services could be lost in Miami-Dade soils. The network analyses were successful in displaying impacts on the 
functional capacity of the methanogenic communities as a result of drainage and urbanization, and the network analyses can serve as ecological baseline models to study the potential future impact of natural and anthropogenic stressors on these critical microbial guilds.

\subsection{References}

Allison, S. D., \& Martiny, J. B. (2008). Resistance, resilience, and redundancy in microbial communities. Proceedings of the National Academy of Sciences, 105 (Supplement 1), 11512-11519.

Angel, R., Claus, P., \& Conrad, R. (2012). Methanogenic Archaea are globally ubiquitous in aerated soils and become active under wet anoxic conditions. The ISME Journal, 6(4), 847-862.

Banerjee, S., Kirkby, C. A., Schmutter, D., Bissett, A., Kirkegaard, J. A., \& Richardson, A. E. (2016). Network analysis reveals functional redundancy and keystone taxa amongst bacterial and fungal communities during organic matter decomposition in an arable soil. Soil Biology and Biochemistry, 97, 188-198.

Banning, N., Brock, F., Fry, J. C., Parkes, R. J., Hornibrook, E. R., \& Weightman, A. J. (2005). Investigation of the methanogen population structure and activity in a brackish lake sediment. Environmental Microbiology, 7(7), 947-960.

Barberán, A., Bates, S. T., Casamayor, E. O., \& Fierer, N. (2012). Using network analysis to explore co-occurrence patterns in soil microbial communities. The ISME Journal, 6(2), 343-351.

Bascompte, J., Jordano, P., Melian, C. J., \& Olesen, J. M. (2003). The nested assembly of plant-animal mutualistic networks. Proceedings of the National Academy of Sciences, 100(16), 9383-9387.

Bastolla, U., Fortuna, M. A., Pascual-García, A., Ferrera, A., Luque, B., \& Bascompte, J. (2009). The architecture of mutualistic networks minimizes competition and increases biodiversity. Nature, 458(7241), 1018-1020.

Blagodatskaya, E, \& Kuzyakov, Y. (2008). Mechanisms of real and apparent priming effects and their dependence on soil microbial biomass and community structure: Critical review. Biology and Fertility of Soils, 45(2), 115-131.

Borrel, G., Jézéquel, D., Biderre-Petit, C., Morel-Desrosiers, N., Morel, J., Peyret, P., Fonty, G., \& Lehours, A. (2011). Production and consumption of methane in freshwater lake ecosystems. Research in Microbiology, 162(9), 832-847. 
Burke, C., Steinberg, P., Rusch, D., Kjelleberg, S., \& Thomas, T. (2011). Bacterial community assembly based on functional genes rather than species. Proceedings of the National Academy of Sciences, 108(34), 14288-14293.

Canfield, D. E., \& Des Marais, D. J. (1991). Aerobic sulfate reduction in microbial mats. Science, 251(5000), 1471.

Cattin, M., Bersier, L., Banašek-Richter, C., Baltensperger, R., \& Gabriel, J. (2004). Phylogenetic constraints and adaptation explain food-web structure. Nature, 427(6977), 835-839.

Chaffron, S., Rehrauer, H., Pernthaler, J., \& von Mering, C. (2010). A global network of coexisting microbes from environmental and whole-genome sequence data. Genome Research, 20(7), 947-959.

Chambers, L. G., Guevara, R., Boyer, J. N., Troxler, T. G., \& Davis, S. E. (2016). Effects of salinity and inundation on microbial community structure and function in a mangrove peat soil. Wetlands, 36(2), 361-371.

Christiansen, J. R., Levy-Booth, D., Prescott, C. E., \& Grayston, S. J. (2016). Microbial and environmental controls of methane fluxes along a soil moisture gradient in a pacific coastal temperate rainforest. Ecosystems, 1-16.

Cong, J., Yang, Y., Liu, X., Lu, H., Liu, X., Zhou, J., Li, D., Yin, H., Ding, J., \& Zhang, Y. (2015). Analyses of soil microbial community compositions and functional genes reveal potential consequences of natural forest succession. Scientific Reports, 5.

Conrad, R. (1999). Contribution of hydrogen to methane production and control of hydrogen concentrations in methanogenic soils and sediments. FEMS Microbiology Ecology, 28(3), 193-202.

Conrad, R. (2009). The global methane cycle: Recent advances in understanding the microbial processes involved. Environmental Microbiology Reports, 1(5), 285292.

Correlation and CDNP analysis: Robert E. Brown, George Mason University Microbiome Analysis Center.

Diestel, R. (2000). Graph theory \{graduate texts in mathematics; 173\} Springer-Verlag Berlin and Heidelberg GmbH \& amp.

Eusufzai, M. K., Tokida, T., Okada, M., Sugiyama, S., Liu, G. C., Nakajima, M., \& Sameshima, R. (2010). Methane emission from rice fields as affected by land use change. Agriculture, Ecosystems \& Environment, 139(4), 742-748. 
Fuhrman, J. A., \& Steele, J. A. (2008). Community structure of marine bacterioplankton: Patterns, networks, and relationships to function. Aquatic Microbial Ecology, 53(1), 69-81.

García-Maldonado, J. Q., Bebout, B. M., Celis, L. B., \& López-Cortés, A. (2012). Phylogenetic diversity of methyl-coenzyme $\mathrm{M}$ reductase ( $m c r A)$ gene and methanogenesis from trimethylamine in hypersaline environments. International Microbiology, 15(1), 33-41.

Holland, M. D., \& Hastings, A. (2008). Strong effect of dispersal network structure on ecological dynamics. Nature, 456(7223), 792-794.

Horvath, S., \& Dong, J. (2008). Geometric interpretation of gene coexpression network analysis. Public Library of Science Computational Biology, 4(8), e1000117.

Huang, Y., Li, H., Hu, H., Yan, X., Waterman, M. S., Huang, H., \& Zhou, X. J. (2007). Systematic discovery of functional modules and context-specific functional annotation of human genome. Bioinformatics (Oxford, England), 23(13), i222-9.

Ideker, T., Ozier, O., Schwikowski, B., \& Siegel, A. F. (2002). Discovering regulatory and signaling circuits in molecular interaction networks. Bioinformatics (Oxford, England), 18 Suppl 1, S233-40.

Li, X., \& Mitsch, W. J. (2016). Methane emissions from created and restored freshwater and brackish marshes in southwest Florida, USA. Ecological Engineering, 91, 529536.

Lopez-Lozano, N. E., Heidelberg, K. B., Nelson, W. C., García-Oliva, F., Eguiarte, L. E., \& Souza, V. (2013). Microbial secondary succession in soil microcosms of a desert oasis in the Cuatro Cienegas Basin, Mexico. PeerJ, 1, e47.

Lord, L. A. (1993). Guide to Florida environmental issues and information Florida Conservation.

Maslov, S., \& Sneppen, K. (2002). Specificity and stability in topology of protein networks. Science (New York, N.Y.), 296(5569), 910-913.

Naeem, S., Duffy, J. E., \& Zavaleta, E. (2012). The functions of biological diversity in an age of extinction. Science, 336(6087), 1401-1406.

Newman, M. E. (2005). A measure of betweenness centrality based on random walks. Social Networks, 27(1), 39-54.

Orphan, V., Jahnke, L., Embaye, T., Turk, K., Pernthaler, A., Summons, R., \& Des Marais, D. (2008). Characterization and spatial distribution of methanogens and methanogenic biosignatures in hypersaline microbial mats of Baja California. Geobiology, 6(4), 376-393. 
Proulx, S. R., Promislow, D. E., \& Phillips, P. C. (2005). Network thinking in ecology and evolution. Trends in Ecology \& Evolution, 20(6), 345-353.

Purdy, K. J., Munson, M. A., Nedwell, D. B., \& Embley, T. M. (2002). Comparison of the molecular diversity of the methanogenic community at the brackish and marine ends of a UK estuary. FEMS Microbiology Ecology, 39(1), 17-21.

Raes, J., \& Bork, P. (2008). Molecular eco-systems biology: Towards an understanding of community function. Nature Reviews Microbiology, 6(9), 693-699.

Rosenzweig, A., \& Ragsdale, S. W. (2011). Methods in methane metabolism, part a: Methanogenesis Academic Press.

Ruan, Q., Dutta, D., Schwalbach, M. S., Steele, J. A., Fuhrman, J. A., \& Sun, F. (2006). Local similarity analysis reveals unique associations among marine bacterioplankton species and environmental factors. Bioinformatics (Oxford, England), 22(20), 2532-2538.

Shannon, P., Markiel, A., Ozier, O., Baliga, N. S., Wang, J. T., Ramage, D., Amin, N., Schwikowski, B., Ideker, T. (2003). Cytoscape: A software environment for integrated models of biomolecular interaction networks. Genome Research, 13(11), 2498-2504.

Solomon, S. (2007). Climate change 2007-the physical science basis: Working group I contribution to the fourth assessment report of the IPCC Cambridge University Press.

Torsvik, V., \& Øvreås, L. (2002). Microbial diversity and function in soil: from genes to ecosystems. Current Opinion in Microbiology, 5(3), 240-245.

Wang, J., Cao, P., Hu, H., Li, J., Han, L., Zhang, L., Zheng, Y. M., \& He, J. (2015). Altitudinal distribution patterns of soil bacterial and archaeal communities along mt. Shegyla on the Tibetan Plateau. Microbial Ecology, 69(1), 135-145.

Watts, D. J., \& Strogatz, S. H. (1998). Collective dynamics of 'small-world'networks. Nature, 393(6684), 440-442.

Zhou, J., Deng, Y., Luo, F., He, Z., Tu, Q., \& Zhi, X. (2010). Functional molecular ecological networks. mBio, 1(4), e00169-10.

Zhou, J., Deng, Y., Luo, F., He, Z., \& Yang, Y. (2011). Phylogenetic molecular ecological network of soil microbial communities in response to elevated $\mathrm{CO}_{2} . \mathrm{mBio}$, 2(4),e00121-11.

Zhu, J., Zheng, H., Ai, G., Zhang, G., Liu, D., Liu, X., \& Dong, X. (2012). The genome characteristics and predicted function of methyl-group oxidation pathway in the obligate aceticlastic methanogens, Methanosaeta spp. PLoS One, 7(5), e36756. 


\section{CHAPTER 6}

\section{CONCLUSION AND FUTURE DIRECTIONS}

In most terrestrial ecosystems, soil organic matter contributes to the major carbon pool (Amundson 2001), and its mineralization accounts for $\mathrm{CO}_{2}$ and $\mathrm{CH}_{4}$ gas fluxes into the atmosphere (IPCC 2007). The balance between soil carbon storage and emission of greenhouse gasses is maintained by microbial biogeochemical processes. Several environmental and anthropogenic factors have been identified that impact the microbial structural and functional diversity and subsequently disrupt the carbon-balance (Houghton 2007; Langley et al. 2009). The current research showed the functional diversity of cellulolytic microorganisms as well as methanogens, critical guilds in the first and last step of carbon cycle, across Miami-Dade County, Florida soils. Furthermore, the influence of vegetation as well as abiotic factors was also established for these guilds.

Cellulose degradation is a complex process involving numerous enzymes such as endoglucanases, exoglucanases, and $\beta$-glucosidases. The widespread diversity and redundancy of cellulolytic organisms suggest this is a critical function in carbon breakdown across varied environmental conditions (Berlemont and Martiny 2013). The functional redundancy of the cellulases was observed by detection of major taxonomic assemblages in all the four Miami-Dade County soils types. Ordination as well statistical analyses demonstrated different factors affecting the distribution of cellulolytic bacterial and fungal community across Miami-Dade County soils. The major influence on bacterial community was shown by vegetation type whereas soil texture, moisture content, and soil organic content influenced the fungal community. 
Cellulose hydrolysis provides necessary substrates for other lineages such as acidogens, acetogens, and methanogens to carry out anaerobic organic matter mineralization. As methanogenesis, is the last step in the anaerobic food chain, the availability of organic substances is the limiting factor for methane production. Using the methyl coenzyme M reductase alpha subunit genetic marker $(\mathrm{mcr} A)$, this study was able to characterize methanogens in Miami-Dade County soils belonging to the six out of seven methanogenic orders including Methanomassicoccales, the recently described order (Borrel et al. 2013). To our knowledge, this study was the first one to describe occurrence of methanogenic guilds in oxic conditions in Miami-Dade County soils and the adjoining areas of the Florida Everglades. Furthermore, detection of genes associated with the three methanogenesis pathways: acetoclastic, hydrogenotrophic, and methylotrophic, portrays the ability of methanogens to perform methanogenesis according to the availability of the substrate.

Recently, network analyses have been used to establish co-occurrence patterns of microbial community and their associated interactions (Zhou et al. 2010; Zhou et al. 2011; Cong et al 2015; Banerjee et al. 2016). In the present study, the approach of correlation network analysis was employed to characterize interactions of methanogenesis pathway genes in the Florida Everglades as well as the adjoining Miami-Dade County soils. Although the number of methanogenic OTUs was similar across the two ecosystems, the network topology parameters showed significant differences amongst the three methanogenesis pathway genes. The differences in network interactions could be a result of the urbanized Miami-Dade County soils that have been under increasing anthropogenic disturbances when compared to the "pristine", less disturbed soils from Everglades 
National Park. Additionally, methylotrophic methanogens detected in the study were halophilic Archaea. The occurrence of halophiles in the Everglades samples were expected because of the wind-driven estuarine and tidal oceanic saline inputs. However, their presence in Miami-Dade soils is an interest for further investigation.

There are two contrasting hypotheses that have been used to explain the underlying basis of the association between species diversity and ecosystem services: functional dissimilarity and functional redundancy. The functional dissimilarly describes an increase in ecosystem function with increase in biodiversity whereas functional redundancy states that the ecosystem function are performed by diverse microbes and the function will continue to be accomplished even if only limited species are participating (Strickland et al. 2009). Furthermore, under disturbances microbial composition and the associated ecosystem function are determined on the basis of microorganisms' ability to be resistant, resilient or, functionally redundant (Allison and Martiny 2008). The results from this study demonstrated the functional redundancy of the cellulolytic microbial community and methanogens but showed varying diversity of these functional guilds across oxic and anoxic habitats. Historically, the former Florida Everglades wetlands soils were drained for agricultural expansion (Light and Dineen 1994; Snyder and Davidsonn 1994) and Miami-Dade County soils are representative of the drained and urbanized soils. The profound variations in the methanogenic guilds network interactions between the Everglades wetlands and Miami-Dade soils reflect the dramatic changes since drainage of these ecosystems 75 years ago and it also helps illustrates that the current microbial function may be at its threshold - a tipping point — to be able to continue performing the ecosystem processes if stressed further. The continued drainage of wetlands because of 
anthropogenic pressures of increased agriculture and urbanization will no doubt continue to impact the structural as well as functional microbial composition. A radical consequence of extreme disturbances may be the breakthrough of that ecological threshold, the loss of functional redundancy, and thereby altering the microbial composition culminating in disuprtion of ecosystem functions. This observation supports one of the hypotheses proposed by Allison and Martiny (2008) in their disturbance model that stated disturbance can drastically modify the microbial composition and completely lose the ecosystem function. Therefore, future studies should investigate the activity of functional guilds under different disturbances to determine the direct impact of perturbations on microbial ecosystem function.

In addition to the disturbances from urbanization, Miami-Dade County and the adjoining Everglades and Biscayne National watersheds, are expected to be impacted by the predicted climate change resulting in increased temperature and subsequent drought or altered precipitation pattern causing heavy rainfall or flood flashing. Several predictive models that are employed to study effects of climate change on ecosystem processes do not include the microorganisms in their models owing the large uncharacterized microbial biodiversity and their uncultivated status (Bodelier 2011). The inclusion of microbial data in ecological models is critical because: 1) flux of global warming gases such $\mathrm{CO}_{2}$ and $\mathrm{CH}_{4}$ have been linked to the microbial communities, 2) certain ecosystem processes are performed by specialized microorganisms such as methane production, and 3) environmental as well as soil abiotic properties have been described to structure microbial composition across various ecosystems (Nazaries et al. 2013). Accordingly, future research should study the impacts of urbanization as well as climate change on the 
microbial composition in order to better estimate the changes in ecosystem services and furnish needed data to help maintain stable ecosystems. Microbial interactions should also be targeted as there is either competition for substrates or microorganisms are interdependent on each other for provision of energy sources.

\subsection{References}

Allison, S. D., \& Martiny, J. B. (2008). Resistance, resilience, and redundancy in microbial communities. Proceedings of the National Academy of Sciences, 105 (Supplement 1), 11512-11519.

Amundson, R. (2001). The carbon budget in soils. Annual Review of Earth and Planetary Sciences, 29(1), 535-562.

Banerjee, S., Kirkby, C. A., Schmutter, D., Bissett, A., Kirkegaard, J. A., \& Richardson, A. E. (2016). Network analysis reveals functional redundancy and keystone taxa amongst bacterial and fungal communities during organic matter decomposition in an arable soil. Soil Biology and Biochemistry, 97, 188-198.

Berlemont, R., \& Martiny, A. C. (2013). Phylogenetic distribution of potential cellulases in bacteria. Applied and Environmental Microbiology, 79(5), 1545-1554.

Bodelier, P. L. (2011). Interactions between nitrogenous fertilizers and methane cycling in wetland and upland soils. Current Opinion in Environmental Sustainability, 3(5), 379-388.

Borrel, G., O'Toole, P. W., Harris, H. M., Peyret, P., Brugere, J. F., \& Gribaldo, S. (2013). Phylogenomic data support a seventh order of methylotrophic methanogens and provide insights into the evolution of methanogenesis. Genome Biology and Evolution, 5(10), 1769-1780.

Cong, J., Yang, Y., Liu, X., Lu, H., Liu, X., Zhou, J., Li, D., Yin, H., Ding, J., \& Zhang, Y. (2015). Analyses of soil microbial community compositions and functional genes reveal potential consequences of natural forest succession. Scientific Reports, 5.

Houghton, R. (2007). Balancing the global carbon budget. Annual Review of Earth and Planetary Sciences, 35, 313-347.

Langley, J. A., McKinley, D. C., Wolf, A. A., Hungate, B. A., Drake, B. G., \& Megonigal, J. P. (2009). Priming depletes soil carbon and releases nitrogen in a scrub-oak ecosystem exposed to elevated $\mathrm{CO}_{2}$. Soil Biology and Biochemistry, 41(1), 54-60. 
Light, S. S., \& Dineen, J. W. (1994). Water control in the Everglades: a historical perspective. In: Everglades: The Ecosystem and its Restoration, CRC Press, Boca Raton, 47-84.

Nazaries, L., Murrell, J. C., Millard, P., Baggs, L., \& Singh, B. K. (2013). Methane, microbes and models: fundamental understanding of the soil methane cycle for future predictions. Environmental Microbiology, 15(9), 2395-2417.

Snyder, G. H., Davidsonn, J. M. (1994). Everglades agriculture: past, present, and future. In: Everglades: The Ecosystem and its Restoration, CRC Press, Boca Raton, 85115.

Solomon, S. (2007). Climate change 2007-the physical science basis: Working group I contribution to the fourth assessment report of the IPCC Cambridge University Press.

Strickland, M. S., Lauber, C., Fierer, N., \& Bradford, M. A. (2009). Testing the functional significance of microbial community composition. Ecology, 90(2), 441-451.

Zhou, J., Deng, Y., Luo, F., He, Z., Tu, Q., \& Zhi, X. (2010). Functional molecular ecological networks. mBio, 1(4), e00169-10.

Zhou, J., Deng, Y., Luo, F., He, Z., \& Yang, Y. (2011). Phylogenetic molecular ecological network of soil microbial communities in response to elevated $\mathrm{CO}_{2}$. mBio, 2(4),e00121-11. 


\section{APPENDICES}

Table S1: Site descriptions. The table represents the soil type, GPS coordinates, and soil descriptors of the soil collection sites as obtained by USDA web soil survey area of interest (AOI) queries (Noble et al. 1996; http://websoilsurveynrcsusdagov/). Numbers in parentheses denote the data collected in this study.

\begin{tabular}{|c|c|c|c|c|}
\hline Soil type & Urban Land-Udorthents & $\begin{array}{l}\text { Lauderhill-Dania- } \\
\text { Pahokee }\end{array}$ & $\begin{array}{c}\text { Rock Outcrop- } \\
\text { Biscayne-Chekika }\end{array}$ & $\begin{array}{l}\text { Perrine-Biscayne- } \\
\text { Pennsuco }\end{array}$ \\
\hline Soil Descriptors & SS1 & SS2 & SS3 & SS4 \\
\hline Range & $\begin{array}{c}\text { Extends along the } \\
\text { Atlantic Costal Ridge } \\
\text { south to Black Creek } \\
\text { Canal and the Barrier } \\
\text { Islands }\end{array}$ & $\begin{array}{l}\text { Extends west from the } \\
\text { Atlantic coastal ridge } \\
\text { into the Everglades }\end{array}$ & $\begin{array}{c}\text { Encompasses } \\
\text { outcrops of Miami } \\
\text { oolitic limestone and } \\
\text { Biscayne and } \\
\text { Chekika soils }\end{array}$ & $\begin{array}{l}\text { Low coastal plains to } \\
\text { the south and south east } \\
\text { of the Atlantic Coastal } \\
\text { Ridge, adjacent to } \\
\text { Biscayne Bay, and in } \\
\text { transverse glades }\end{array}$ \\
\hline $\begin{array}{l}\text { Composition of } \\
\text { soils }\end{array}$ & $\begin{array}{l}\text { Covers } 34.9 \% \text { of the } \\
\text { survey area; } 70 \% \text { is } \\
\text { urban land, } 23 \% \text { is } \\
\text { Udorthents, and } 7 \% \text { is } \\
\text { soils of minor extent }\end{array}$ & $\begin{array}{c}\text { Covers } 17 \% \text { of total } \\
\text { survey area; } 41 \% \text { is } \\
\text { Lauderhill, } 34 \% \text { is } \\
\text { Dania, } 22 \% \text { is Pahokee, } \\
\text { and } 3 \% \text { is soils of minor } \\
\text { extent }\end{array}$ & $\begin{array}{l}\text { Covers } 15 \% \text { of total } \\
\text { survey area; } 39 \% \text { is } \\
\text { Rock outcrop, } 25 \% \text { is } \\
\text { Biscayne, } 18 \% \text { is } \\
\text { Chekika, and } 18 \% \text { is } \\
\text { soils of minor extent }\end{array}$ & $\begin{array}{c}\text { Covers } 17 \% \text { of survey } \\
\text { area; } 45 \% \text { is Perrine } \\
\text { soils, } 38 \% \text { is Biscayne } \\
\text { soils, } 10 \% \text { is Pennsuco, } \\
\text { and } 7 \% \text { is soils of minor } \\
\text { extent }\end{array}$ \\
\hline $\begin{array}{l}\text { GPS coordinates } \\
\text { of study sites }\end{array}$ & $\mathrm{N} 25^{\circ} 45.261 \mathrm{~W} 80^{\circ} 22.764$ & $\begin{array}{l}\mathrm{N} 25^{\circ} 53.054 \\
\mathrm{~W} 80^{\circ} 28.822 \\
\end{array}$ & $\begin{array}{l}\mathrm{N} 25^{\circ} 41.351 \\
\mathrm{~W} 80^{\circ} 28.737 \\
\end{array}$ & $\begin{array}{l}\mathrm{N} 25^{\circ} 20.509 \\
\mathrm{~W} 80^{\circ} 24.713 \\
\end{array}$ \\
\hline Vegetation & $\begin{array}{l}\text { Mixed vegetation with } \\
\text { woody trees }\end{array}$ & $\begin{array}{c}\text { Marsh grasses } \\
\text { predominantly saw } \\
\text { grass } \\
\end{array}$ & Mixed grasses & $\begin{array}{c}\text { Marsh grasses } \\
\text { predominantly saw } \\
\text { grass } \\
\end{array}$ \\
\hline $\mathrm{CaCO}_{3}(\%)$ & 60 & 80 & 80 & 60 \\
\hline $\begin{array}{l}\begin{array}{l}\text { Electrical } \\
\text { Conductivity } \\
(\mathbf{m m h o} / \mathrm{cm})\end{array} \\
\end{array}$ & 0.1 & 6 & 6 & 2 \\
\hline
\end{tabular}




\begin{tabular}{|c|c|c|c|c|}
\hline $\begin{array}{l}\text { Cation-Exchange } \\
\text { Capacity } \\
(\mathrm{meq} / \mathbf{1 0 0} \mathrm{g})\end{array}$ & 26.5 & 161.6 & 159.0 & 161.6 \\
\hline $\begin{array}{l}\text { pH (1 to } 1 \\
\text { Water) } \neq\end{array}$ & $7.9(7.5)$ & $8.2(7.4)$ & $7.9(7.9)$ & $8.2(\mathbf{7 . 4 )}$ \\
\hline $\begin{array}{l}\text { Organic Matter } \\
(\%)^{\ddagger}\end{array}$ & $6.5(12)$ & $85(24)$ & $85(\mathbf{1 3})$ & $75(41)$ \\
\hline Sand $(\%) \ddagger$ & $43(\mathbf{8 1})$ & $10(41)$ & 97 (76) & $93(46)$ \\
\hline Clay $(\%) \neq$ & $31(\mathbf{1 8})$ & $23.5(24)$ & $17.5(16)$ & $23.5(22)$ \\
\hline Silt $(\%) \ddagger$ & 50.9 (0.62) & $80(34)$ & $82(7.5)$ & $70.5(32)$ \\
\hline Surface Texture & Extremely gravelly loam & Marly silt loam & $\begin{array}{l}\text { Gravelly marly silt } \\
\text { loam }\end{array}$ & Gravelly sand \\
\hline $\begin{array}{l}\text { Water Content, } \\
15 \text { Bar }(\%)\end{array}$ & 12 & 45 & 45 & 45 \\
\hline $\begin{array}{l}\text { Water Content, } \\
\text { One-Third Bar } \\
(\%)\end{array}$ & 22.5 & 90 & 90 & 90 \\
\hline Drainage Class & $\begin{array}{c}\text { Somewhat poorly } \\
\text { drained }\end{array}$ & Very poorly drained & Poorly drained & Very poorly drained \\
\hline $\begin{array}{l}\text { Depth to Water } \\
\text { Table }(\mathrm{cm})\end{array}$ & 92 & 0 & 15 & 0 \\
\hline
\end{tabular}


Table S2: Number of methanogenic order specific probes. Total number of probes present on the GeoChip 5.0 are depicted in "\#GeoChip probes" column and total number of probes detected across Miami-Dade County soils are represented as "\# Detected probes".

\begin{tabular}{|l|c|c|c|c|c|c|}
\hline $\begin{array}{c}\text { Methanogenic } \\
\text { Orders }\end{array}$ & $\begin{array}{c}\text { \# GeoChip } \\
\text { probes }\end{array}$ & $\begin{array}{c}\text { \# Detected } \\
\text { probes }\end{array}$ & SS1 & SS2 & SS3 & SS4 \\
\hline Methanosarcinales & 11 & 7 & 6 & 5 & 5 & 6 \\
\hline Methanocellales & 3 & 0 & 0 & 0 & 0 & 0 \\
\hline Methanococcales & 4 & 1 & 0 & 1 & 0 & 1 \\
\hline Methanobacteriales & 11 & 1 & 0 & 1 & 1 & 1 \\
\hline Methanopyrales & 1 & 0 & 0 & 0 & 0 & 0 \\
\hline Methanomicrobiales & 16 & 7 & 2 & 5 & 7 & 5 \\
\hline Uncultured archeon & 136 & 52 & 21 & 34 & 36 & 34 \\
\hline
\end{tabular}


A
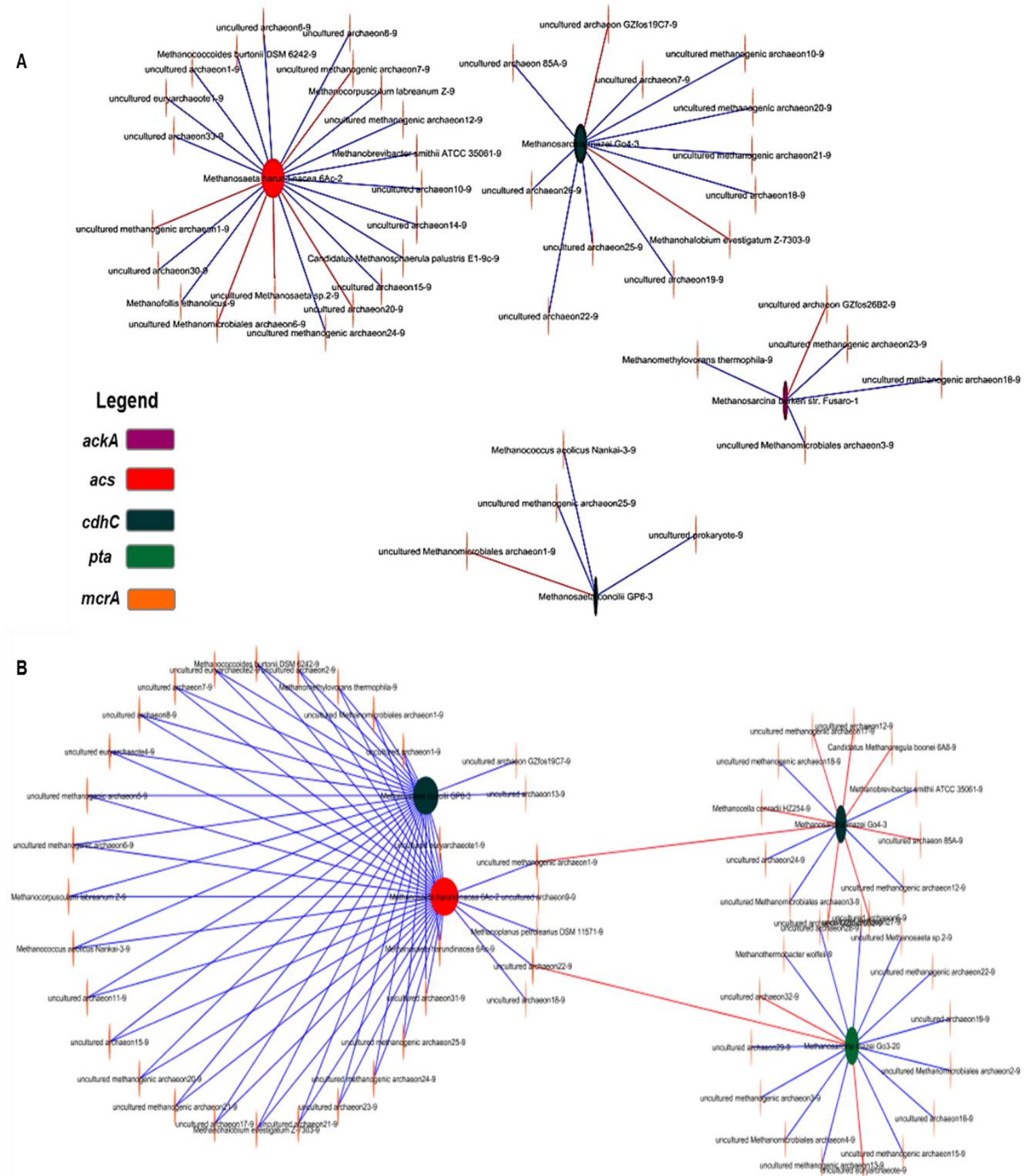

Figure S1: Network interactions of AC pathway genes with $m c r A$ in a) MD and b) EG samples. The network represents the significant gene pair correlations $(p<0.05)$. Blue edge means a positive relationship and red depicts negative relationships between nodes. 
A

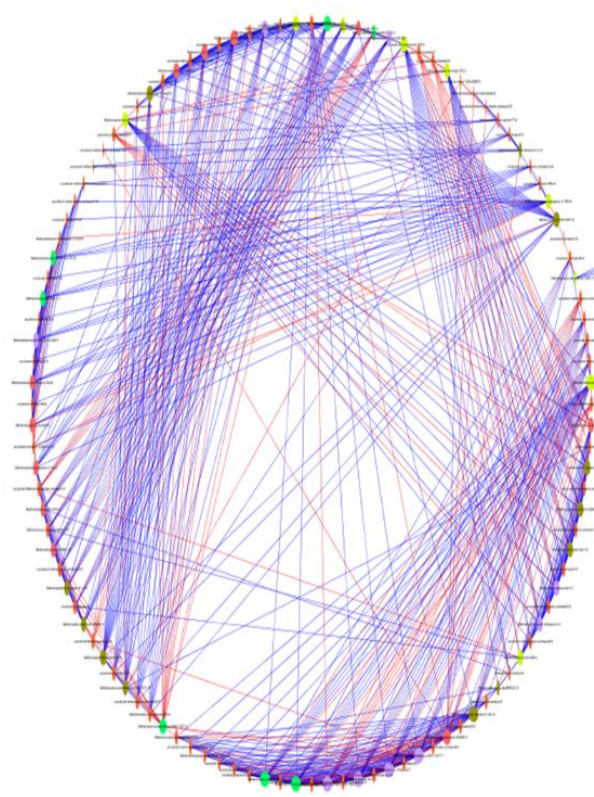

B

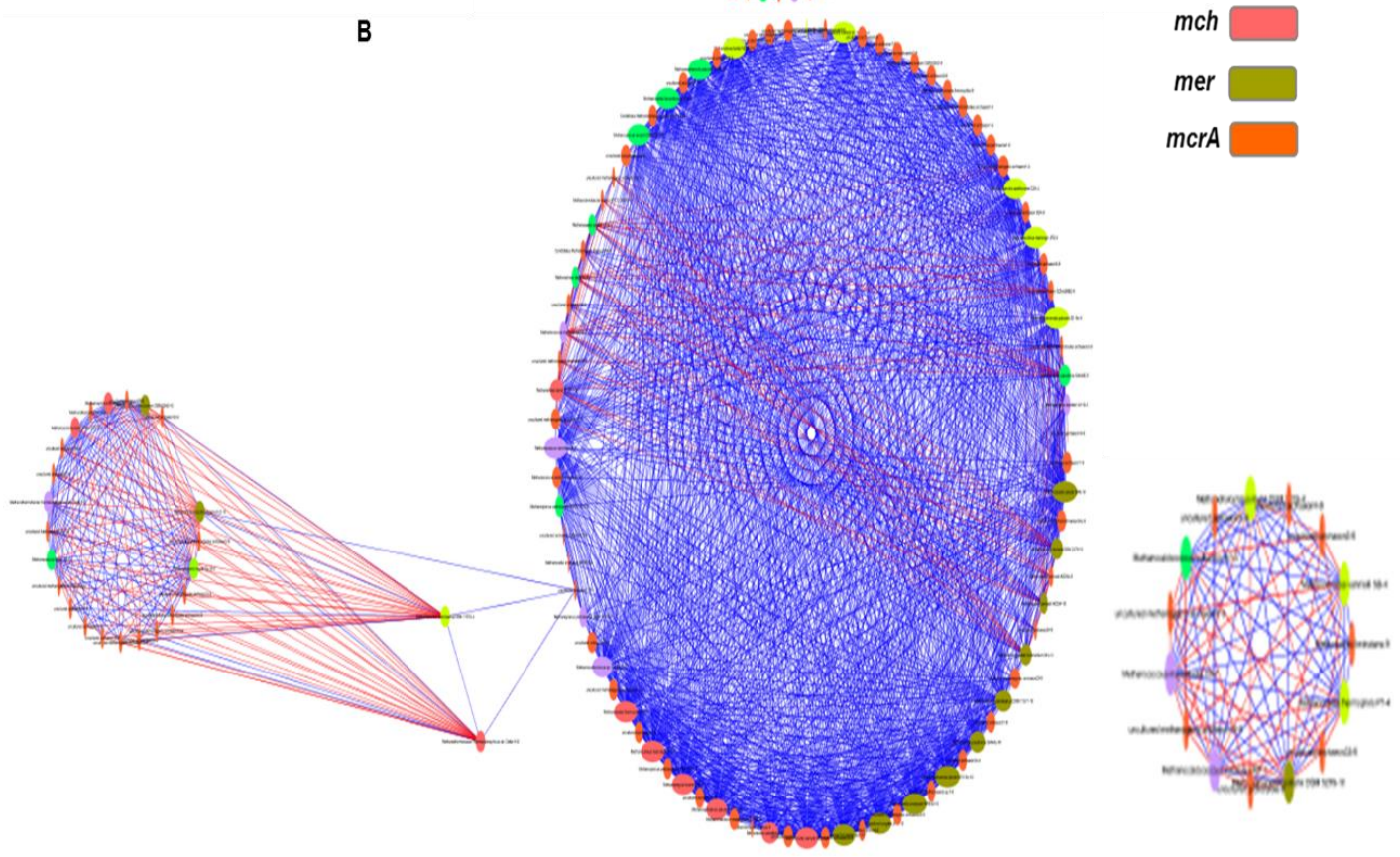

Figure S2: Correlation network interactions of HG pathway genes in a) MD and b) EG samples. The network represents the significant correlations of gene pairs $(\mathrm{p}<0.05)$. Blue edge represents a positive correlations whereas red depicts negative between nodes. The nodes that have few correlations with the nodes of the major cluster either extend into subnetworks originating from the main network and/or form independent network cluster (Figure S2-B). 
A

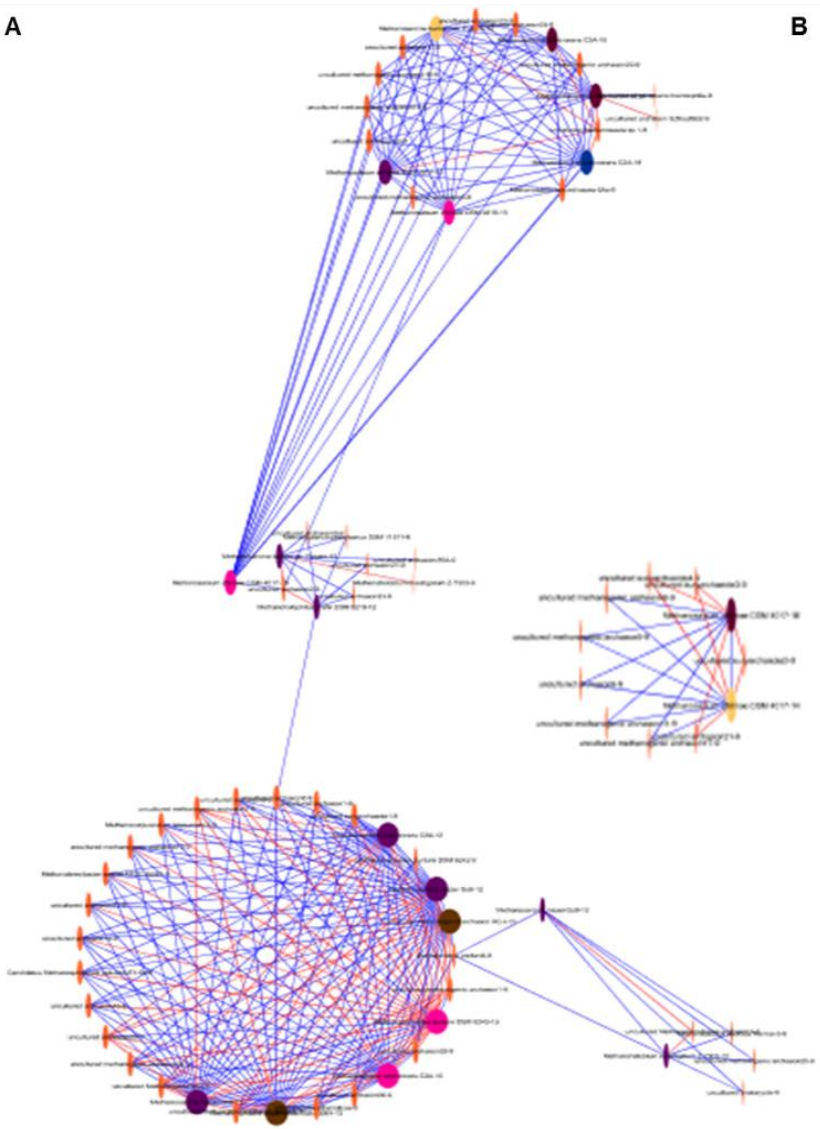

B

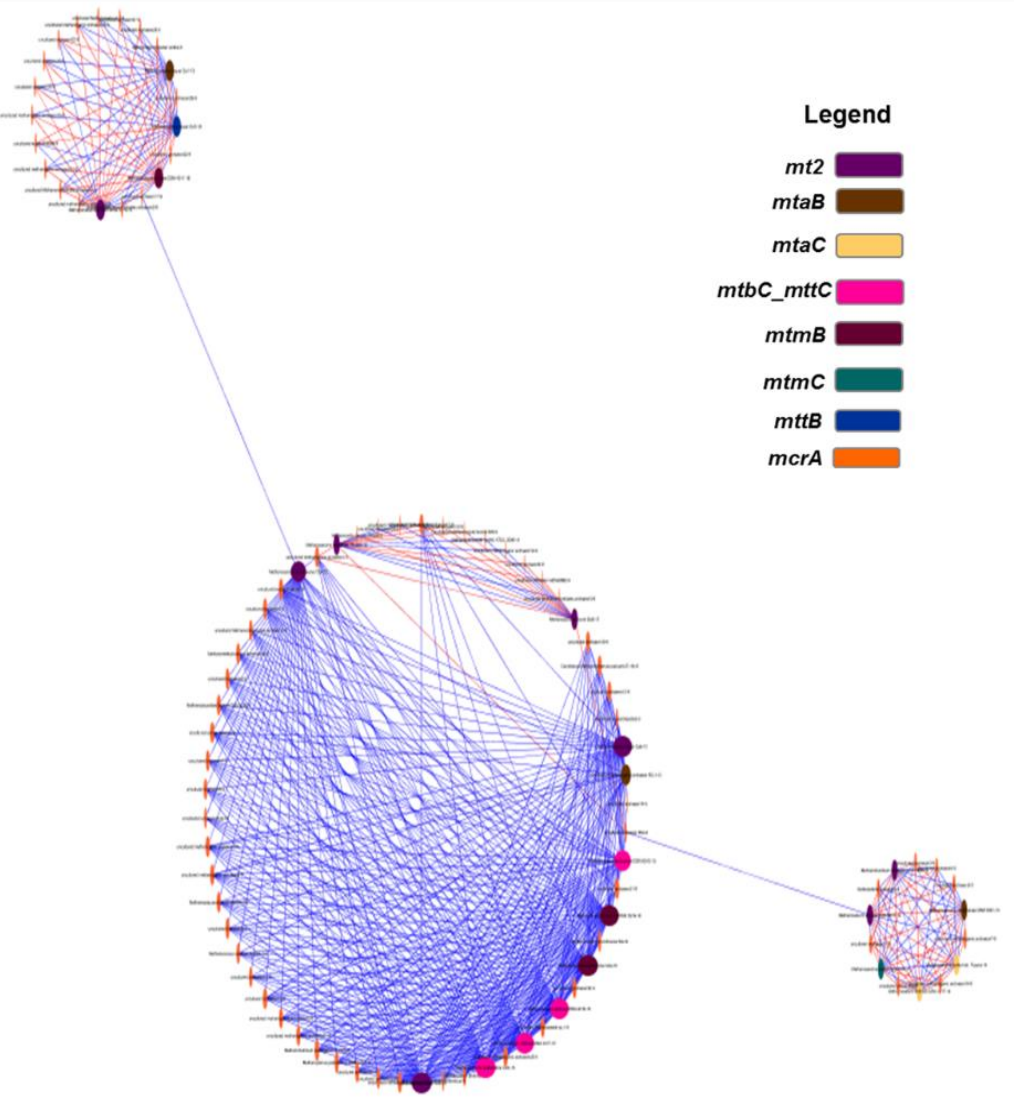

Figure S3: Correlation network interactions of MT pathway genes in a) MD and b) EG samples. The network illustrates the significant gene pair correlations $(\mathrm{p}<0.05)$. Blue edge represents a positive correlation and red edge shows negative interactions. Subnetworks originate from the main network (Figure S3-A-B) and/or form independent network cluster (Figure S3-A) if only few correlations are identified between nodes of the major cluster. 
VITA

PRIYANKA KUSHWAHA

EDUCATION

2011-2016 Ph.D. Biochemistry

Florida International University; Miami, Florida

2009-2011 Masters of Science, Forensic Science

Guru Gobind Singh Indraprastha University, New Delhi, India

2006-2009 Bachelor of Science (Honors), Biochemistry

University of Delhi, New Delhi, India

\section{PUBLICATIONS AND PRESENTATIONS}

Kushwaha, P., Zayas, J., Oliva, Y., Mendoza, M., Kallifatidis, B., and Mills, D. (2015). Methanogens within the Sawgrass Communities of the Everglades and Biscayne Bay Watersheds. Microbiology of the Everglades Ecosystem 375-385.

Damaso, N., Martin, L., Kushwaha, P., and Mills, D. (2014). F-108 polymer and capillary electrophoresis easily resolves complex environmental DNA mixtures and SNPs. Electrophoresis 35 (21-22):3208-3211.

Kushwaha, P., Damaso, N., Cheung, Y., and Mills, D. Influence of abiotic factors on the methanogenic mcrA gene across oxic and anoxic Miami-Dade County, FL soils. (In prep Microbial Research: Archaea).

Kushwaha, P., Damaso, N., Cheung, Y., and Mills, D. Biodiversity and distribution of cellulolytic microbial community in Miami-Dade County soils, FL. (In prep Microbial Ecology).

Kushwaha, P., Damaso, N., Servais, S., Kominoski, J., and Mills D. Network analyses to determine co-occurrence patterns of methanogenic-related guilds in soils. (In prep Soil Biology and Biogeochemistry).

Kushwaha, P., Damaso, N., Servais, S., Kominoski, J., and Mills D. (2016). Network analyses to determine co-occurrence patterns of methanogenic-related guilds in soils. Annual Meeting of Florida Branch of the American Society for Microbiology, Miami, Florida. 
Kushwaha, P., and Mills, D. (2016). The assessment of GeoChip ${ }^{\mathrm{TM}}$ functional gene microarray as an aid for soil provenance. American Academy of Forensic Science $68^{\text {th }}$ Annual Science Meeting, Las Veags, Nevada.

Kushwaha, P., Damaso, N., Cheung, Y., and Mills, D. (2015). Archaeal functional gene diversity related to carbon cycling in Miami-Dade County, FL soils. Annual Meeting of Florida Branch of the American Society for Microbiology, Cocoa Beach, Florida.

Kushwaha, P. and Mills, D. (2015). GeoChip as a tool to compare microbial diversity across Miami-Dade County Soils. Graduate Student Appreciation Week Scholarly Forum, FIU, Miami, Florida.

Kushwaha, P., Damaso, N., Cheung, Y., and Mills, D. (2015). GeoChip as a tool to compare microbial diversity across Miami-Dade County Soils. 79th Annual Meeting of the Florida Academy of Sciences, Saint Leo, Florida.

Kushwaha, P., Zayas, J., Oliva, Y., Mendoza, M., Kallifatidis, B., and Mills, D. (2015). Biodiversity of functional genes across Miami-Dade County Soils. Greater Everglades Ecosystem Restoration 2015: Science in support of Everglades restoration, Coral Springs, Florida.

Kushwaha, P., Zayas, J., Oliva, Y., Mendoza, M., Kallifatidis, B., and Mills, D. (2015). Biodiversity of functional genes: an aid in soil provenance. American Academy of Forensic Science 67th Annual Science Meeting, Orlando, Florida.

Kushwaha, P., Zayas, J., Oliva, Y., Mendoza, M., Kallifatidis, B., and Mills, D. (2015). Biodiversity of functional genes: an aid in soil provenance. Seventeenth Annual Biology Research Symposium, FIU, Miami, Florida.

Kushwaha, P., Zayas, J., Oliva, Y., Mendoza, M., Kallifatidis, B., and Mills, D. (2014). Biodiversity of cel48 gene across Miami-Dade County soils. Third Annual Forensic Science Symposium, FlU, Miami, Florida.

Kushwaha, P. and Mills, D. (2014). Analysis of Biolog microplates to profile microbial community across Black band samples. Graduate Student Appreciation Week Scholarly Forum, FIU, Miami, Florida. 